\title{
Effect of diesel exhaust particles on allergic reactions and airway responsiveness in ovalbumin-sensitized brown Norway rats
}

\author{
Caroline Dong \\ West Virginia University
}

Follow this and additional works at: https://researchrepository.wvu.edu/etd

\section{Recommended Citation}

Dong, Caroline, "Effect of diesel exhaust particles on allergic reactions and airway responsiveness in ovalbumin-sensitized brown Norway rats" (2007). Graduate Theses, Dissertations, and Problem Reports. 4297.

https://researchrepository.wvu.edu/etd/4297

This Dissertation is protected by copyright and/or related rights. It has been brought to you by the The Research Repository @ WVU with permission from the rights-holder(s). You are free to use this Dissertation in any way that is permitted by the copyright and related rights legislation that applies to your use. For other uses you must obtain permission from the rights-holder(s) directly, unless additional rights are indicated by a Creative Commons license in the record and/ or on the work itself. This Dissertation has been accepted for inclusion in WVU Graduate Theses, Dissertations, and Problem Reports collection by an authorized administrator of The Research Repository @ WVU.

For more information, please contact researchrepository@mail.wvu.edu. 


\title{
EFFECT OF DIESEL EXHAUST PARTICLES \\ ON ALLERGIC REACTIONS AND AIRWAY RESPONSIVENESS IN OVALBUMIN- SENSITIZED BROWN NORWAY RATS
}

\author{
Caroline Dong \\ Dissertation submitted to the \\ School of Pharmacy at West Virginia University \\ In partial fulfillment of the requirements for the degree of
}

\section{Doctor of Philosophy \\ In}

Pharmaceutical Sciences

\author{
Joseph K. H. Ma, Ph.D., Chair \\ Patrick S. Callery, Ph.D. \\ Vincent Castranova, Ph.D. \\ Yon Rojanasakul, Ph.D. \\ Val Vallyathan, Ph.D.
}

Department of Basic Pharmaceutical Sciences

\author{
Morgantown, West Virginia \\ 2007
}

Key Words: Diesel Exhaust Particles, Airway Inflammation, Airway Hyperresponsiveness, Alveolar Macrophages, Glutathione, Reactive Oxygen Species, Nitric Oxide, Cytokines 


\section{ABSTRACT \\ West Virginia University, School of Pharmacy \\ Doctoral Dissertation \\ Caroline Dong}

Diesel exhaust particles (DEP) are the major constituent of ambient particulate matter in urban environments and occupational settings. Exposure to DEP in combination with an allergen has been demonstrated to enhance allergen-related airway inflammation, immunoglobulin (Ig) E production, and airway responsiveness (AR) in human and in animal models. However, the mechanisms behind these effects of DEP are not yet fully understood. In this study, we compared the effects of short-term DEP exposure on ovalbumin (OVA)-mediated airway responses under two exposure protocols using an OVA-allergic rat model. Male Brown Norway rats were sensitized to aerosolized OVA $\left(40.5 \pm 6.3 \mathrm{mg} / \mathrm{m}^{3}\right)$ on days 1,8 , and 15 , and challenged with OVA on day 29 . The rats were exposed to DEP $\left(20 \mathrm{mg} / \mathrm{m}^{3}\right)$ for $4 \mathrm{~h} /$ day for 5 consecutive days either before sensitization (protocol A) or before OVA challenge on days 24-28 (protocol B). Control animals received filtered air and aerosolized saline instead of DEP and OVA, respectively. The results showed that DEP exposure 1) elicited an adjuvant effect on OVA-specific IgE and IgG production in serum under both protocols; 2) significantly reduced OVA-induced airway inflammation and lung injury in protocol A, but increased these markers in protocol B; 3) markedly lowered OVA-induced production of nitric oxide, reactive oxygen species, and interleukin (IL)-10 and IL-12 by alveolar macrophages (AM) in protocol A, but increased these parameters in protocol B; 4) 
significantly lowered the numbers of $\mathrm{T}$ cells and their $\mathrm{CD} 4^{+}$and $\mathrm{CD} 8^{+}$subsets in lungdraining lymph nodes in protocol A, but increased these cell counts in protocol B; 5) reduced intracellular glutathione in AM and lymphocytes in both protocols; and 6) enhanced AR of the OVA-sensitized rats to methacholine challenge in protocol B. These results suggest that the effects of DEP on the immune system, including aggravation or exacerbation of asthma, may be greatly influenced by allergic immune status and time of antigen exposure. 


\section{ACKNOWLEGEMENTS}

Though only my name appears on the cover of this dissertation, a great many people have contributed to its production. I owe my gratitude to all those people who have made this dissertation possible and because of whom my graduate experience has been one that I will cherish forever.

I would like to express my deepest gratitude to my advisor, Dr. Joseph. K.H. Ma, for his support, guidance and encouragement throughout my graduate studies. His advice was invaluable for the completion of my dissertation. He has taught me innumerable lessons and insights on the workings of academic research.

I will also give special thanks to Dr. Jane Y.C. Ma and Mr. Mark Barger for providing many valuable comments and help while I was doing my research work at NIOSH.

My thanks also to the members of my dissertation committee members, Dr. Yon Rojanasakul for giving me valuable suggestions that improved my presentation; Dr.

Patrick S. Callery for providing generous help and guidance on my career development; Dr. Vincent Castranova for his generous support and encouragement in my research work at NIOSH; Dr. Val Vallyathan for his valuable guidance and advice on how to improve my writing skills.

I am also grateful to the graduate students in the Basic Pharmaceutical Sciences, especially Weiyan Zhang, for her kindness, help and good advice. I am also thankful to 
Drs. Jenny Roberts and Xingdong Zhang for their generous help and support in my research work.

I would like to thank my husband, Dr. John Yin, for his understanding and love during the past few years. His support and encouragement was in the end what made this dissertation possible. My husband also gave me generous help in my research work, he was always giving me invaluable suggestions and advices, and I learned so much from him.

Finally, I would like to share my achievement with my family, especially my husband, John, my two lovely sons, Kevin and Max, and my sister-in-law, Xiuli. None of this would have been possible without the love and patience of them. 


\section{TABLE OF CONTENTS}

Page

EFFECT OF DIESEL EXHAUST PARTICLES ON ALLERGIC

REACTIONS AND AIRWAY RESPONSIVENESS IN

OVALBUMIN-SENSITIZED BROWN NORWAY RATS ........................ i

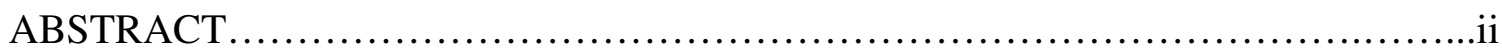

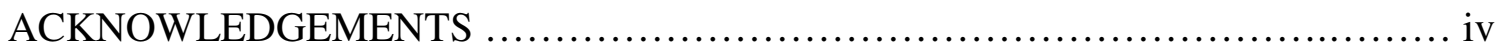

TABLE OF CONTENTS .................................................. vi

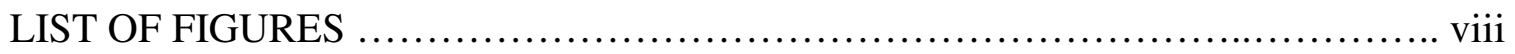

LIST OF ABBREAVIATIONS .................................................

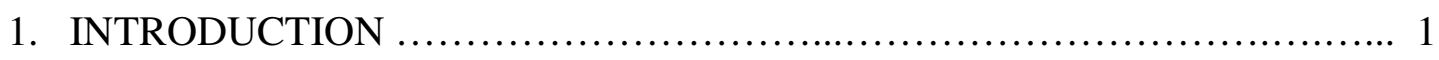

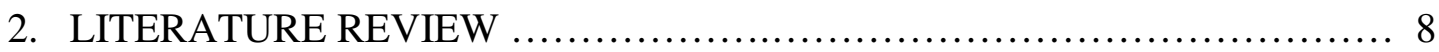

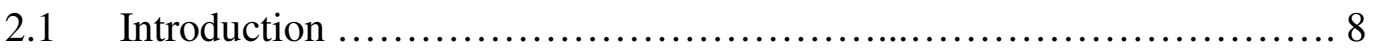

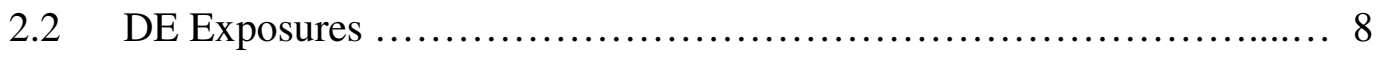

2.3 Health Effects of DEP: Epidemiological Studies ...................... 10

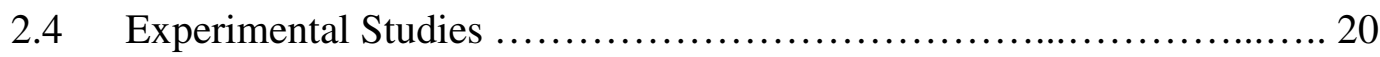

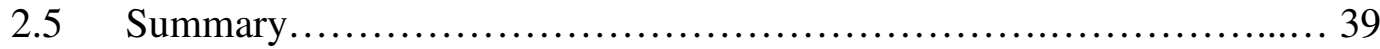

3. MATERIALS AND METHODS ........................................ 41

3.1 Animals and Exposure Schedule .................................... 41

3.2 Bronchoalveolar Lavage (BAL) and Determination of

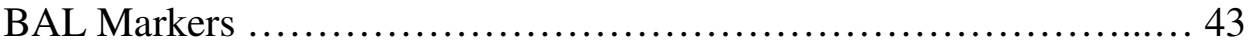

3.3 Analysis of Lymphocytes from Lung-Draining Lymph 


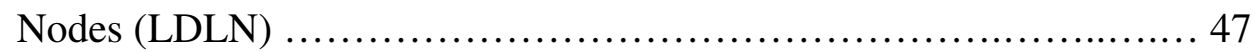

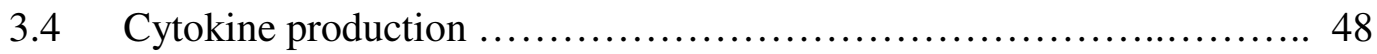

3.5 Determination of Intracellular GSH .............................. 49

3.6 Determination of OVA-Specific $\operatorname{IgE}$ and $\operatorname{IgG} \ldots \ldots \ldots \ldots \ldots \ldots \ldots \ldots \ldots$

3.7 Analysis of Alveolar Type II (ATII) Cells ......................... 51

3.8 Measurement of Airway Responsiveness ........................... 52

3.9 Analysis of B Lymphocytes from Spleens ...................... 52

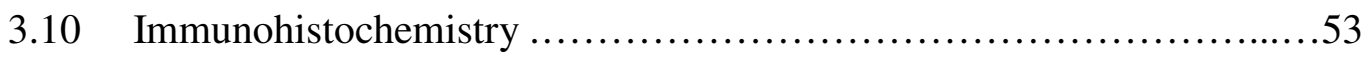

3.11 Statistical Analysis ..........................................54

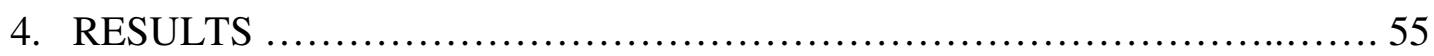

4.1 Results for Protocol A ............................................. 55

4.2 Results for Protocol B ..................................... 58

4.3 Results of Effects of DEP on B Lymphocytes .................... 62

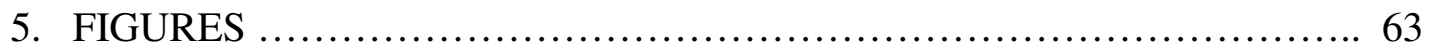

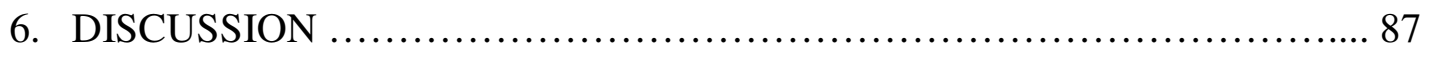

7. REFERENCES .................................................. 98 


\section{LIST OF FIGURES}

Figure 1. Yield of (A) LDH activity and (B) albumin content

63

Figure 2. Total numbers and differentials of BAL cells recovered

$$
\text { post-DEP exposure }
$$

Figure 3. Concentrations of NO in BAL fluid ................................65

Figure 4. Concentrations of NO in AM-conditioned media ...................... 66

Figure 5. Production of (A) IL-10 and (B) IL-12 by AM ......................... 67

Figure 6. Lymphocyte differentiation in LDLN of rats post-DEP exposure 68

Figure 7. Concentrations of intracellular GSH in (A) AM and

(B) lymphocyte 69

Figure 8. Relative concentrations of OVA-specific (A) IgE and

(B) IgG in serum 70

Figure 9. LDH activity (A) and albumin content (B) .71

Figure 10. Differentials of BAL cells recovered from rats 72

Figure 11. Numbers and differentials of lymphocytes 73

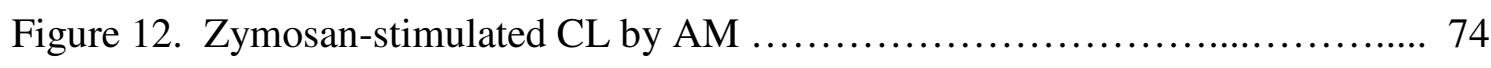

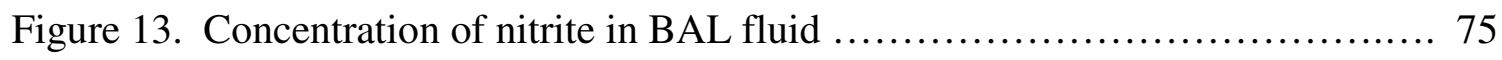

Figure 14. Concentration of nitrite in AM-conditioned media.................. 76

Figure 15. Flow cytometric analysis of intracellular generation of NO by ATII cells 77 
Figure 16. Flow cytometric analysis of intracellular generation of superoxide by ATII cells

Figure 17. Concentration of intracellular GSH in AM (A) and

lymphocytes (B)

Figure 18. Relative concentrations of OVA-specific $\operatorname{IgE}(\mathrm{A})$ and

$\operatorname{IgG}(\mathrm{B})$ in serum 80

Figure 19. Airway hyperresponsiveness in rats $24 \mathrm{~h}$ after OVA challenge. 81

Figure 20. Western blot analysis of iNOS expression in AM (A) and A TII cells $(\mathrm{B})$ 82

Figure 21 Relative concentrations of OVA-specific IgE in B cells isolated from spleens of the rats 83

Figure 22. Production of IL-1 $\beta$ in serum in different exposure groups ............... 84

Figure 23. Production of IL-10 in serum in different exposure groups ............. 85

Figure 24. Production of IL-6 in serum in different exposure groups ................ 86 


\section{LIST OF ABBREVIATIONS}

\begin{tabular}{|c|c|}
\hline AM: & Alveolar macrophage \\
\hline DEP: & Diesel exhaust particles \\
\hline PAH: & Polyaromatic hydrocarbon \\
\hline ESO: & Eosinophil \\
\hline LYM: & Lymphocyte \\
\hline PMN: & Polymorphonuclear neutrophil \\
\hline GSH: & Glutathione \\
\hline GSSG: & Glutathione disulfide \\
\hline NO: & Nitric oxide \\
\hline ROS: & Reactive oxygen species \\
\hline IgE: & Immunoglobulin E \\
\hline Th: & T helper \\
\hline iNOS: & Inducible nitric oxide synthase \\
\hline IL: & Interleukin \\
\hline OVA: & Ovalbumin \\
\hline CB: & Carbon black \\
\hline BAL: & Bronchoalveolar lavage \\
\hline GM-CSF: & Granulocyte-macrophage colony-stimulating factor \\
\hline TNF- $\alpha$ : & Tumor necrosis factor- $\alpha$ \\
\hline LPS: & Lipopolysaccharide \\
\hline
\end{tabular}


LDLN: $\quad$ Lung-draining lymph nodes

COPD: Chronic obstructive pulmonary disease

PM: $\quad$ Particulate matter

IFN- $\gamma: \quad$ Interferon- $\gamma$

CYP1A1: Cytochrome P450 1A1

NF- $\kappa B: \quad$ Nuclear factor $-\kappa B$

HO-1: $\quad$ Heme oxygenase-1 


\section{Introduction}

Asthma is an airway inflammatory disease characterized by a variable degree of airflow obstruction, bronchial hyperresponsiveness, and airway inflammation. The most prevalent form of asthma is allergic asthma. Elevation of allergen-specific immunoglobulin $(\mathrm{Ig}) \mathrm{E}$ is one of the hallmarks of allergic diseases. $\mathrm{IgG}$, on the other hand, has been reported to be related to late-phase asthmatic reactions and mast cell activation (Durham et al., 1984). An increase in activated CD4 ${ }^{+} \mathrm{T}$ helper 2 (Th2) cells in asthmatic airways after allergen challenge has been recognized for many years (Azzawi et al., 1990; Robinson et al., 1993), reinforcing an immunological basis for this disease. An allergic immune response to an allergen is characterized by the production of interleukin (IL)-4, IL-5, and IL-13 by the Th2 subset of allergen-specific $\mathrm{CD} 4^{+} \mathrm{T}$ lymphocytes (Ricci et al., 1994; Foster et al., 1997). IL-4 is the cytokine required for IgE production, while IL-5 plays a unique role in eosinophil development and activation. In addition, induction of inducible nitric oxide synthase (iNOS) is also closely associated with allergic asthma (Trifilieff et al., 2000; Iijima et al., 2001). Allergen-induced nitric oxide (NO) down-regulates Th1 cytokines but up-regulates Th2 cytokine production (Trifilieff et al., 2000), and there were close relationships among IL-5, NO, and eosinophils in ovalbumin (OVA)-challenged mice, where the rise in eosinophils was accompanied by an increase in iNOS expression and protein nitration on epithelial surface and peribronchial inflammatory cells (Iijima et al., 2001).

There has been a dramatic increase in the incidence of asthma in many developed countries during the last decades. Although the causes for this increase are not well 
known, a considerable amount of epidemiological evidence suggests that certain components of air pollution such as ozone, oxides of nitrogen and particulate matter as well as a variety of allergens may play important roles (Koren, 1995; Graham, 2004). Fine particles with widely different composition, such as carbon black (CB), titanium dioxide $\left(\mathrm{TiO}_{2}\right)$, polystyrene, polytetrafluoroethylene, residual oil fly ash (ROFA), house dust, and urban ambient particles, have been reported to exhibit adjuvant effects on the production of $\operatorname{IgE}$ in response to concurrently administered allergens (Ormstad et al., 1998; Lambert et al., 1999; van Zijverden and Granum, 2000; Hamada et al., 2000; Granum et al., 2001; Dybing et al., 2004). An important advance in this area is the discovery that diesel exhaust particles (DEP), a major component of environmental particulate pollutants in most industrialized urban areas, are implicated in the development of asthma and aggravation of pre-existing asthma (Lovik et al., 1997; Takano et al., 1997; Diaz-Sanchez et al., 1994, 1997). DEP, which consist of fine particulate and about $30 \%$ by weight organic materials adsorbed onto the carbonaceous core, have been shown to exert adjuvant effects on the response of humans and mice to inhaled or instilled allergens including increased allergen-specific IgE production, skewing of the immune response to Th2 cytokine production, increased eosinophils in the bronchoalveolar lavage (BAL) fluid, and increased airway hyperreactivity (Diaz-Sanchez et al., 1997, 1999; Miyabara et al., 1998; Ohta et al., 1999).

The underlying mechanisms by which DEP exert the adjuvant effects are not yet fully understood. Most of the studies have been focused on the role of reactive oxygen species (ROS) produced on exposure to DEP and the subsequent generation of oxidative stress within the exposed cells. At high concentrations, ROS is responsible for protein 
oxidation, lipid peroxidation, and DNA damage leading cellular damage in target cells such as macrophages and epithelial cells (Nel et al., 1998; Martin et al., 1997, Becker et al., 1996). At low oxidative stress levels, as defined by no or minimal changes in the cellular reduced glutathione (GSH)/glutathione disulfide (GSSG) ratios, the cells mount antioxidant and cytoprotective responses, e.g., heme-oxygenase 1 (HO-1) and superoxide dismutase expression ( $\mathrm{Li}$ et al., 2001). Glutathione is a tripeptide that is found in all mammalian tissues and is highly concentrated in the liver. Glutathione exists in the reduced GSH and oxidized GSSG forms (DeLeve and Kaplowitz, 1990). GSH is the predominant form, existing in millimolar concentrations in most cells whereas the GSSG content is less than $1 \%$ of GSH (Akerboom et al., 1982). GSH has several vital functions including detoxifying eletrophiles, scavenging free radicals, maintaining the essential thiol status of proteins by preventing oxidation of -SH groups, providing a pool for cysteine, and modulating critical cellular processes such as DNA synthesis and immune function (Diaz-Sanchez et al., 1997)

Studies have shown that DEP may augment both IL-4 and IL-5- dependent allergic responses (Diaz-Sanchez et al., 1997; Al-Humadi et al., 2002b; Takano et al., 1997), but the mechanism remains unclear. Evidence indicated that alveolar macrophages (AM), which are central to the inflammatory process, may play a role in the modulation of $\mathrm{T}$ cell-mediated immunity in an intracellular GSH level-dependent manner. The AM with high GSH content have shown to transform the naïve Th0 cells to Th1 cells, whereas AM with low GSH content may transform the naïve Th0 cells to Th2 cells when cultured with OVA-specific TCR-transgenic mouse spleen cells ( Murata et al., 2002). The macrophage-mediated Th1/Th2 balance is of significance, since OVA exposure resulted 
in a dose-dependent depletion of GSH in AM that is related to increased antigen-specific IgE and IgG production in rats (Al-Humadi et al., 2002a). Studies have shown that pulmonary type II cells may also play a role in modulating $\mathrm{T}$ cell activity and promoting eosinophile-dependent airway inflammation through the secretion of IL-8 and granulocyte-macrophage colony-stimulating factor (GM-CSF). Evidence showed that the release of IL-8 and GM-CSF by human bronchial epithelial cells was induced by recombinant IgE-dependent histamine-releasing factor (HRF-p23), an eosinophile chemoattractant that is inducible by hydrogen peroxide and is found in increasing levels in BAL fluid of asthmatic patients (Yoneda et al., 2004).

The adjuvant effect of DEP on allergen-induced airway inflammation has been demonstrated primarily in various mice models (Ichinose et al., 1997, 2002; Miyabara et al., 1998; Takano et al., 1997, 1998). Several studies have pointed out that strain differences in the modulation of allergic airway inflammation and antigen-specific IgE and/or IgG response by DEP existed, and apparently contradictory effects of DEP were observed among different mouse models (Ichinose et al., 1997; 2002). Steerenberg and colleagues $(1999,2003)$ also reported the use of Brown Norway $(B N)$ rats in elucidating the adjuvant effect of DEP on timothy grass pollen allergy after intranasal or intratracheal instillation of DEP in combination with the pollen allergen. In addition, an allergic asthma model of $\mathrm{BN}$ rats has been also established in our laboratory by sensitizing the animals with aerosolized OVA once a week over a month-long period that produced significant levels of OVA-specific IgE and IgG (Al-Humadi et al., 2002c). Exposure of rats to DEP $(5 \mathrm{mg} / \mathrm{kg})$ through intratracheal instillation prior to the OVA-sensitization enhanced production of antigen-specific antibodies at the end of allergen sensitization, 
and this enhancement correlated with an increase in IL-4 mRNA expression in lung tissue. Up to the present, the adjuvant effect of DEP was demonstrated mainly from studies where DEP were administered in combination with an allergen during the sensitization process, or already-sensitized human/animal models were employed. In practical settings, however, subjects may be sensitized or non-sensitized to allergen(s), and may encounter DEP and allergen exposure at the same or different times. Different exposure protocols for the timing of DEP and allergen exposures therefore should be pursued in order to gain insight into the complex effects of DEP on the pulmonary immune system. One of the important concerns raised is whether DEP, when given separately from an allergen, can have the adjuvant effect, i.e., augmentation of specific IgE or IgG response to an allergen encountered before or after DEP exposure.

Another important question regarding the involvement of DEP in allergic asthma is whether DEP may contribute to the chronic airway inflammation that has been recognized as an essential feature of the disease. A number of studies pointed out that fine and ultrafine particles, such as DEP, CB, ROFA, and metal particles, have the potential to trigger inflammatory mechanisms by modulating intracellular calcium concentrations, activation of transcription factors, and production of inflammatory cytokines through an oxidant-mediated mechanism (Sagai et al., 1996; Dick et al., 2003; Brown et al., 2004). These particles have also been shown to aggravate the antigeninduced inflammation when given together with an antigen (Lovik et al., 1997; Takano et al., 1997; Ichinose et al., 2002). DEP are carbon-based particles containing approximately $30 \%$ by weight various organic compounds, including PAHs, nitroaromatic compounds, quinones, aldehydes, and heterocyclic compounds, adsorbed onto the carbonaceous core 
(Schuetzle, 1983; Draper, 1986). Due to the complexity of their chemical properties, DEP may be different from the other particles in their modulating effect on inflammatory response and pulmonary immunity. Indeed, a study by Melgert et al. (2004) showed that short term exposure of mice to cigarette smoking, a complex mixture containing fine carbonaceous particles and various organic compounds, inhibited OVA-induced airway inflammatory responses. Studies from our laboratory have previously shown that DEP or their organic extracts, but not the carbonaceous core, CB or silica, suppress the production of lipopolysaccharide (LPS)-stimulated pro-inflammatory cytokines tumor necrosis factor (TNF)- $\alpha$ and IL-12, but increase the production of anti-inflammatory IL10 by rat AM (Yang et al., 1999; Yin et al., 2004a, b). Previous results have shown that DEP aggravate OVA-induced airway inflammation when given together with the antigen (Takano et al., 1997, 1998; Miyabara et al., 1998; Ichinose et al., 2002). However, shortterm exposure to DEP prior to sensitization may exert an anti-inflammatory effect which potentially attenuates the allergen-induced airway inflammation.

The objectives of this study were to develop rat models in which animals were exposed to DEP before or after sensitization, and use these models to examine the effects of short-term DEP exposure on allergen-induced $\operatorname{IgE}$ and $\mathrm{IgG}$ production and allergic airway inflammation. We hypothesize that DEP exposure prior to OVA sensitization (protocol A) augments the sensitization process but inhibits airway inflammation though AM orchestrated anti-inflammatory effect, while DEP exposure after the sensitization (protocol B) augments allergic responses and airway hyperreactivity through, in part, by activation of epithelial type II cells. To investigate the underlying mechanism of these effects, we measured alterations in intracellular GSH levels, production of NO and 
cytokines by AM and lymphocytes from lung-draining lymph nodes (LDLN), expression of iNOS in lung tissue, and alterations of $\mathrm{CD}^{+}$and $\mathrm{CD} 8^{+} \mathrm{T}$ cell subsets in LDLN. 


\section{Literature Review}

\subsection{Introduction}

The health effects of diesel exhaust (DE) have received increasing attention over the

past decades. Since early 1980's, considerable epidemiological evidence has accumulated to indicate that DE may exert significant adverse effects on humans. Exposure to DE may induce a variety of conditions including increased morbidity and mortality of lung cancer, allergic asthma, chronic obstructive pulmonary disease (COPD), and cardiovascular disorders. Experimental studies, both in vivo and in vitro, have been performed in order to understand the relevance of associations found in the epidemiological studies and the molecular and cellular mechanisms of actions. For the risk assessment of DE exposure, researches on the potential biomarkers of exposure, effects, and susceptibility have been also conducted. The aim of this review is to provide a summary of the current state of knowledge regarding environmental and occupational exposures to DE, epidemiological and experimental evidence for the adverse effects of DE exposure on human health, biomarkers for risk assessment, and the mechanisms by which DE exposure exerts its adverse health effects on humans.

\subsection{DE Exposures}

Air pollution caused by motor vehicle exhaust has been a significant environmental and occupational health concern and the focus of many studies for the last decades. Among the motor vehicle generated air pollutants, DE, emitted by heavy-duty diesel engines, is a major health concern. The heavy-duty diesel engines, which are being 
increasingly utilized for their high fuel efficiency and low levels of carbon dioxide emission, produce 30-100 times more particulate matter (PM) than the gasoline engines, making diesel exhaust particles (DEP) one of the major components of airborne PM in most urban and industrialized areas (Ma and Ma, 2002). DEP are carbon-based particles containing over several hundred different organic and inorganic components, including polycyclic aromatic hydrocarbons (PAHs), quinones, aldehydes, nitroaromatic and heterocyclic compounds, and traces of heavy metals such as iron, copper, chromium, and nickel, adsorbed onto the carbonaceous core (Schuetzle, 1983; Vouk et al., 1983). With a mass median diameter of approximately $0.2 \mu \mathrm{m}$ and over $80 \%$ of particles being in the size range around $0.1 \mu \mathrm{m}, \mathrm{DEP}$ can remain airborne for long periods of time and deposit in great numbers deeply in the lungs (Sydbom et al., 2001). Although data are not available on long-term retention of DEP in human lungs, it has been estimated from animal studies that about one-fourth of the particles mass inhaled by people is deposited in the deeper pulmonary regions, and some of which is retained with a half-life of several hundred days or more (McClellan, 1987). In addition to DEP, DE contains a complex mixture of toxic gases such as nitrogen oxides (NOx), sulphur dioxide $\left(\mathrm{SO}_{2}\right)$, carbon monoxide (CO), hydrocarbons, and formaldehyde (Scheepers and Bos, 1992).

Ambient concentrations of DEP vary markedly from different areas. While the ambient concentrations of DEP nationwide are relatively low, levels of DEP in certain urban areas can be considerable higher. In the Los Angeles Basin, for example, one estimate has placed the rate of DEP intake by humans at $0.3 \mathrm{mg}$ every 1-3 days (DiazSanchez, 1997). According to a report prepared by EPA (U.S. EPA, 2002), the seasonal and annual average DEP concentrations in nonurban areas before 1990 ranged from 2-5 
$\mu \mathrm{g} / \mathrm{m}^{3}$. DEP concentrations for urban areas in the same timeframe ranged from 4.4-13 $\mu \mathrm{g} / \mathrm{m}^{3}$, with concentrations on individual days ranging up to $22 \mu \mathrm{g} / \mathrm{m}^{3}$. Ambient measurements taken in 1990 or later suggest that seasonal or annual average DEP levels ranged from $0.2-2.6 \mu \mathrm{g} / \mathrm{m}^{3}$, with maximum reported values ranging up to $3.4 \mu \mathrm{g} / \mathrm{m}^{3}$ in suburban/nonurban locations. DEP concentrations in urban areas measured in the same timeframe ranged from $1.7-3.6 \mu \mathrm{g} / \mathrm{m}^{3}$, with maximum concentrations up to $7.3 \mu \mathrm{g} / \mathrm{m}^{3}$. The highest DEP concentrations reported were those in the vicinity of a bus stop in midtown Manhattan, which ranged from 13.2-46.7 $\mu \mathrm{g} / \mathrm{m}^{3}$. Information regarding DEP in occupational settings suggests a considerably higher exposure, raising an important health concern for exposure of truckers, railroad and construction workers, engine mechanics, and especially, underground miners. A report from the Department of Labor showed that the worst-case mean exposures to DEP in underground metal and nonmetal mines are about $2000 \mu \mathrm{g} / \mathrm{m}^{3}$, with maximum measurements as high as $3650 \mu \mathrm{g} / \mathrm{m}^{3}$ (U.S. Department of Labor, Mine Safety, and Health Administration, 1998). As reported by EPA (U.S. EPA, 2002), DEP exposure ranges up to approximately $1,280 \mu \mathrm{g} / \mathrm{m}^{3}$ for miners, with lower exposure measured for railroad workers $\left(39-191 \mu \mathrm{g} / \mathrm{m}^{3}\right)$, firefighters (4-748 $\left.\mu \mathrm{g} / \mathrm{m}^{3}\right)$, public transit personnel who work with diesel equipment $\left(7-98 \mu \mathrm{g} / \mathrm{m}^{3}\right)$, mechanics and dockworkers $\left(5-65 \mu \mathrm{g} / \mathrm{m}^{3}\right)$, truck drivers $\left(2-7 \mu \mathrm{g} / \mathrm{m}^{3}\right)$, and bus drivers $(1-3$ $\mu \mathrm{g} / \mathrm{m}^{3}$ ). The estimated 70 -year lifetime exposures equivalent to those for the occupational groups discussed above range from $0.4-2 \mu \mathrm{g} / \mathrm{m}^{3}$ ) on the low end to $2-269 \mu \mathrm{g} / \mathrm{m}^{3}$ ) on the high end (U.S. EPA, 2002).

\subsection{Health Effects of DEP: Epidemiological Studies}




\section{General Pulmonary Symptoms and Lung Function}

Epidemiologic evidences showed that both chronic exposure to lower concentrations of $\mathrm{DE}$ and acute exposure to high level of $\mathrm{DE}$ are associated with some respiratory symptoms. Brunekreef et al. (1997) studied children in six areas located near major motorways and assessed their exposure to traffic-related air pollution using separate traffic counts for automobiles and trucks in the Netherlands. The results showed that children living on busy streets were more likely to develop chronic respiratory symptoms than those living on streets with less traffic, with the association becoming stronger in children living closest $(<300 \mathrm{~m})$ to the motorways. Lung function was associated with truck traffic density but had a lesser association with automobile traffic density. The lung function was also associated with the concentration of black smoke measured inside the schools. These results indicated that exposure to traffic-related DE may lead to reduced lung function in children living near major motorways.

Occupational DE exposure occurs within working environments and usually at relatively high concentrations, making it possible for researchers to examine DEassociated health effects. The results are mixed. In a study of coal miners exposed or unexposed to DE, Reger et al. (1982) showed that persistent cough and phlegm were significantly higher in DE exposed workers, but the opposite was found for dyspnea. Compared with nondiesel-exposed workers, DE-exposed workers had significant decrease in forced vital capacity (FVC), forced expiratory volume in 1 sec (FEV1), and forced expiratory flow (FEF) rates. Yet, in a study of diesel bus garage workers, Gamble et al. (1987a) showed that diesel bus garage workers had elevated prevalence of cough, 
phlegm, and wheezing compared to "blue-collar" workers, but there was no association with tenure. When $\mathrm{NO}_{2}$ and respirable particles were determined with personal samplers and used as a surrogate measure of $\mathrm{DE}$, both $\mathrm{NO}_{2}$ and respirable particle exposures were associated with increased postwork shift symptoms of cough, difficult or labored breathing, chest tightness, and wheeze but not with lung function (Gamble et al., 1987b). The same research group also studied the effects of DE exposure on salt miners (Gamble and Jones, 1983a, 1983b). There was a nonsignificant increased trend for cough and dyspnea and a significant trend for phlegm by years of tenure in DE-exposed jobs, but no association with lung function (Gamble and Jones, 1983a; Gamble et al., 1983b). Other studies examining the health effects of DE exposure in underground potash or coal mines also found that measured lung function and symptoms were not associated with the cumulative $\mathrm{NO}_{2}$ exposure (Attfield et al., 1982; Robertson et al., 1984). The health effects of DE exposure have also been evaluated in farmers exposed to DE while working. The results showed that driving diesel tractors was associated with a duration dependent increase in odds ratio $(\mathrm{OR})$ of wheeze $(\mathrm{OR}=1.31,95 \%$ confidential interval [CI] 1.13-1.52) comparing to driving gasoline tractors $(\mathrm{OR}=1.11,95 \% \mathrm{CI} 1.02-1.21)$.

\section{Chronic Obstructive Phulmonary Disease (COPD)}

COPD is a progressive syndrome of expiratory airflow limitation caused by chronic inflammation of the airways and lung parenchyma. Increasing in incidence, COPD is the fourth leading cause of death in the United States and also a leading cause of morbidity and mortality worldwide. Occupational exposure to respiratory silica and other inorganic dusts, has been associated with COPD (Hnizdo and Vallyathan, 2003; Bergdahl et al., 
2004). Studies have also shown that exposure to vehicle motor exhaust may also contribute to the risk for morbidity and mortality of this disease. In a consecutive cross sectional study conducted during 1985-1994 in the Rhine-Ruhr Basin of Germany,

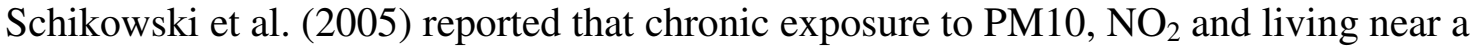
major road might increase the risk of developing COPD and can have a detrimental effect on lung function in women. Women living less than $100 \mathrm{~m}$ from a busy road had an increased risk for COPD (1.79 times, 95\% CI 1.06-3.02) and a significantly decreased lung function compared with those living farther away. In another cross sectional investigation, Ulvestad et al. (2000) studied the risk of COPD in 212 tunnel workers and a reference group of 205 other heavy construction workers in Norway. Compared with the reference subjects the tunnel workers had a significant decrease in FVC \% predicted and FEV1 \% predicted when related to years of exposure. Adjusted FEV1 decreased by $17 \mathrm{ml}$ for each year of tunnel work exposure compared with $0.5 \mathrm{ml}$ in outdoor heavy construction workers. The tunnel workers also reported significantly higher occurrence of respiratory symptoms. The prevalence of COPD was $14 \%$ in the tunnel workers compared with $8 \%$ in the reference subjects. Other studies showed that occupational exposure to motor vehicle pollution or among construction workers only had a marginally increased prevalence or mortality of COPD (Fleming and Charlton, 2001; Bergdahl et al., 2004). Recently Hart et al. (2006) recently reported a case-control study of railroad worker deaths between 1981 and 1982 which consisted of 536 cases with COPD and 1,525 controls with causes of death not related to DE or fine particle exposure. After adjustment for age, race, smoking, U.S. Census region of death, vitamin use, and total years off work, engineers and conductors with DE exposure from operating trains were 
found to have an increased risk of COPD mortality. The odds of COPD mortality increased with years of work in these jobs, and those who had worked 16 years or longer as an engineer or conductor after 1959 had an OR of 1.61 (95\% CI, 1.12-2.30). These results suggest that DE exposure contributed to COPD mortality in these workers.

\section{Asthma}

There has been a rapid increase in the prevalence of allergic diseases such as allergic asthma in the last decades. Asthma is a chronic respiratory disease manifested by bronchial hyperresponsiveness, reversible bronchial constriction, airway inflammation, and respiratory symptoms such as wheezing, dyspnea, coughing, and chest tightness (Busse et al., 2001). The increase in asthma and other allergic diseases has been a global phenomenon in industrial countries, which can not be attributed to genetic changes, but is assumed to be related to changes in environmental factors, including airborne PM, NOx, $\mathrm{SO}_{2}$, and ozone (Liccardi et al., 1998). DE, in addition to DEP, contains a complex mixture of gases such as $\mathrm{CO}, \mathrm{NOx}, \mathrm{SO}_{2}$, which may all contribute to the increased prevalence of asthma. Considering the health effects, recent focus has been on DEP, one of the major components of airborne PM in most urban and industrialized areas.

An early cross-sectional study has shown that the prevalence of cedar pollen allergy was higher near busy highways despite equivalent local exposure to cedar pollen in lessbusy areas (Ishizaki et al., 1987). This is among the earliest studies providing evidence on the relation between motor vehicle exhaust exposure and allergy. Since then, numerous epidemiological studies have shown associations between traffic density and prevalence 
or morbidity of asthma. Observations have shown that children raised in more polluted regions of a country are more likely to develop respiratory diseases and allergies compared with children raised in "cleaner" regions (Heinrich et al., 1999). In Japan, studies have suggested that children living close to roads with heavy traffic are more likely to develop allergies (D'Amato et al., 1998). A Germany study showed that more than 3,700 adolescent students who were living on streets with "constant" truck traffic were $71 \%$ more likely to report symptoms of allergic rhinitis and more than twice were likely to report wheezing symptom (Duhme et al., 1996). Brauer et al. (2002) examined the relationship between traffic-related air pollution and the development of asthmatic/allergic symptoms and respiratory infections in a birth cohort (approximately 4,000) study in The Netherlands. The results showed that the adjusted ORs for wheezing, physician-diagnosed asthma, ear/nose/throat infections, and flu/serious colds positively associated with concentrations of air pollutants $\left(\mathrm{NO}_{2}, \mathrm{PM} 2.5\right.$, and soot). These data, however, could not distinguish the specific role of DE exposure in asthma morbidity from that of the other forms of exhausts. A few studies have been performed with consideration of the DE effects under urban exposure. A European panel study of 61 children, of whom $77 \%$ were taking asthma medication, showed stronger associations for black smoke than for PM10 and ozone in relation to peak expiratory flow (PEF), respiratory symptoms, and bronchodilator use (Gielen et al., 1997). The authors hypothesized that black smoke may be a better surrogate for fine particles emitted by diesel engines or for the other chemicals that may be the causal components in DE. Oliver et al. (2001) reported that laborers, tunnel workers, and operating engineers who were exposed to DE in heavy and highway and tunnel construction were at increased risk 
for asthma, of which tunnel workers also appeared to be at increased risk for chronic bronchitis. In a cross-sectional study of 76 DE-exposed dockers and 63 reference subjects, Mastrangelo et al. (2003) found that long-standing exposure of non-atopic dockers to DE at concentrations similar to those in heavily polluted cities increased serum IgE levels $(\mathrm{OR}=11.4 ; 95 \%$ CI 1.44-526), but not the incidence of rhinitis or asthma. Moreover, none of the OR was significant among atopic individuals. However, Wade and Newman (1993) have described in a case report that three railroad workers who traveled in locomotive units right behind the diesel powered locomotive engine eventually developed asthma, which persisted 1-3 years. One individual's PEF rates fell in a work-related pattern when riding immediately behind the lead diesel engine. In two cases, physiologic abnormalities suggesting reversible restriction were observed. None had a previous history of asthma or other respiratory disease and none were smokers. This is the only report clearly implicating DE exposure as a cause of reactive airways disease, which was named "diesel asthma" by the authors.

\section{Lung Cancer}

DE contains high concentrations of respirable carbonaceous particles with absorbed organic and inorganic chemicals. Recognition that some of these compounds are mutagenic and carcinogenic agents has raised concern for the cancer-causing potential of DE exposure. DEP is known to cause lung cancer at least in rats (Mauderly et al., 1987) through chronic inhalation exposure. The combination of chemical data, genotoxicity, and experimental carcinogenicity has led the conclusion by National Institute for Occupational Safety and Health (NIOSH) that a potential carcinogenic hazard exist 
amongst those exposed to DE (NOISH, 1988). The International Agency for Research on Cancer (IARC) to classify DE as a probable human carcinogen (IARC, 1989). Since then, extensive epidemiologic studies, mainly on lung cancers, among exposed workers have been conducted, and provided evidence that occupational exposure to diesel motor emissions may be associated with an increased risk in developing lung cancer.

There have been no fewer than a dozen of epidemilolgical reports demonstrated the risk of DEP-induced cancer in various workers (Garshick et al. 1987, 1988, 2004, 2006; Laden et al., 2006; Bunn et al., 2002, U.S. EPA, 2002; Saverin et al., 1999; California EPA, 1997; Steenland et al., 1998; Stayner et al., 1998). Boffetta and colleagues (Boffetta et al., 1988) showed that in U.S., railroad workers, heavy equipment operators, miners, and truck drivers had a higher mortality both for all causes and for lung cancer when compared with subjects with other occupations and no exposure to DE. Truck drivers exposed to DE were not at excess risk of lung cancer when compared with truck drivers unexposed to DE, but showed a trend of increasing risk with duration of exposure. Similar results have been also obtained in an investigation on the risk of lung cancer among male and female workers exposed to DE in a large record-linkage study. In Sweden studies by Boffetta et al., (2001) showed that men exposed to DE in the 1960 census experienced an increased risk of lung cancer with the RR of 0.95 (95\% CI 0.91.0), 1.1 (95\% CI 1.1-1.2), and 1.3 (95\% CI 1.3-1.4) for low, medium, and high intensity of exposure, respectively. The risk was higher for squamous cell carcinoma of the lung than for other histological types. In a 1979-1985 population-based case-control study conducted in Montreal, Canada, Parent et al. (2006) demonstrated that an increased risk 
in lung cancer was associated with exposure to DE, after adjustments for potential confounders, but not with exposure to gasoline exhaust.

In total, these studies have established a relationship between DE exposure and lung cancer with various workers, including miners, railroad workers and professional drivers (e.g., trucks, buses, and taxies and found correlation between increased risk in cancer and duration of DE exposure.

\section{Cardiovascular Effects}

Air pollution not only exerts respiratory effects, but also increases cardiovascular morbidity and mortality (Peters et al., 1999). Epidemiological studies have associated increased mortality in cardiovascular diseases with heavy air pollution (Dockery and Pope, 1994, Schwartz, 1994). Some recent studies have shown that exposure to particulate air pollution may increase the susceptibility to ischemic heart diseases (IHD) and the occurrence of myocardial infarction (Pekkanen et al., 2002; Peters et al., 2001; Zanobetti and Schwartz, 2005).

Several studies have linked the exposure to vehicle exhaust with various cardiovascular responses. In a cohort study by Hoek et al. (2002), the risk of death from cardiopulmonary causes in persons living close to a major road or highway was two times higher than those living farther from a major road or highway, after adjustment for risk factors such as age, sex, and smoking status (Hoek et al., 2002). Le Tertre et al. (2002) examined the association between airborne particles and hospital admissions for cardiac causes in eight European cities. The pooled percentage increases associated with a 10 
$\mu \mathrm{g} / \mathrm{m}^{3}$ increase in PM10 and black smoke were $0.5 \%$ (95\% CI $\left.0.2-0.8\right)$ and $1.1 \%$ (95\% CI: 0.4 to 1.8 ) for cardiac admissions of all ages, $0.7 \%$ (95\% CI 0.4-1.0) and 1.3\% (95\% CI 0.4-2.2) for cardiac admissions over 65 years, and, $0.8 \%$ (95\% CI 0.3-1.2) and $1.1 \%$ (95\% CI 0.7-1.5) for IHD over 65 years. Analysis of the effects of particulate air pollution on cardiac admissions suggested the primary effect was likely to be mainly attributable to DE. In a retrospective cohort mortality study, Finkelstein et al. (2004) compared the risk of IHD mortality among heavy equipment operators to that of members of other construction unions. Two hundred fifty nine of 1,009 deaths among the heavy equipment operators were attributed to IHD, with a proportional mortality ratio of 1.09 (95\% CI 0.96-1.2). The mortality for IHD mortality, comparing the heavy equipment operators to all other workers combined was 1.47 (95\% CI 1.17-1.84) for ages 25-64, 1.20 (95\% CI 0.96-1.50) for ages 65 or more, and 1.32 (95\% CI 1.13-1.55) for all ages combined. In a case control study by Gustavsson et al. (2001), the risk of myocardial infarction from occupational exposure to motor exhaust, other combustion products, organic solvents, lead, and dynamite was investigated. The RR of myocardial infarction was 2.11 (95\% CI 1.23-3.60) among those who were highly exposed and 1.42 (95\% CI 1.05-1.92) among those who were intermediately exposed to combustion products from organic material. The other exposures were not consistently associated with myocardial infarction, while a possible association between exposure to dynamite and organic solvents with an increased risk was observed. A later case control study by the same group indicated that occupational exposure of professional drivers might contribute to their risk for myocardial infarction (Bigert et al., 2003). The crude ORs for myocardial infarction were 2.14 (95\% CI 1.34-3.41), 1.88 (95\% CI 1.19-2.98), and 1.66 
(95\% CI 1.22-2.26), among bus, taxi, and truck drivers. Adjustment for potential confounders gave lower but still increased ORs of 1.49 (95\% CI 0.90-2.45), 1.34 (95\% CI 0.82-2.19) and 1.10 (95\% CI 0.79-1.53), respectively. The authors concluded that the work environment of these professional drivers might contribute to their increased risk for myocardial infarction. These studies indicated that environmental and occupational exposure to DE had adverse effects upon the cardiovascular system that increase risk of morbidity and mortality of cardiovascular diseases such as IHD and/or myocardial infarction.

\subsection{Experimental Studies}

\section{Human Studies on DE Exposure and Asthma}

Experimental studies using human subjects have shown that DEP induce airway inflammation, thus playing a role in the increase prevalence of allergic diseases. In a study by Salvi et al. (1999), fifteen healthy volunteers were exposed to a high

concentration of DEP $\left(300 \mu \mathrm{g} / \mathrm{m}^{3}\right)$ in a chamber for $1 \mathrm{~h}$. At $6 \mathrm{~h}$ after exposure there was a significant increase in the number of neutrophils, mast cells, $\mathrm{CD} 4^{+}$and $\mathrm{CD} 8^{+}$ lymphocytes in the airway mucosa, suggesting DEP may enhance inflammatory cell infiltration from blood vessel to the airway. Furthermore, an elevated concentration of methyl-histamine was detected in the bronchoalveolar lavage (BAL) fluid, indicating an increased degranulation of mast cells. However, lung function was unaffected by DEP exposure in contrast to the increased inflammatory cell infiltration detected in the airways, suggesting that lung function measurements alone cannot be used to exclude adverse effect of DEP. Other similar studies using healthy nonsmoker volunteers exposed 
to DEP (200-300 $\mu \mathrm{g} / \mathrm{m}^{3}$ ) for 1-2 $\mathrm{h}$ also showed an inflammatory responses in the airways (Nordenhall, 2000; Nightingale et al., 2000).

Individuals with asthma have inflamed airways and are clinically more sensitive to air pollutants than control subjects. PM pollution adversely affects the airways, with asthmatic subjects thought to be especially sensitive. Several studies have been conducted to examine whether motor vehicle-derived air pollution or DE would promote asthmatic reactions in mild allergic asthma. In a study by Svartengren et al. (2000), volunteers with mild allergic asthma were exposed to air for $30 \mathrm{~min}$ in a city road tunnel or in a suburban area with much lower pollution levels. Although subjective symptoms during tunnel exposure were not pronounced, subjects exposed to tunnel $\mathrm{NO}_{2}$ levels at or higher than $300 \mu \mathrm{g} / \mathrm{m}^{3}$ had a significantly greater early reaction following a low dose of allergen inhalation as well as lower lung function (FEV1) and more asthma symptoms during the late phase compared to controls. Also, subjects with PM2.5 exposure at or higher than $100 \mu \mathrm{g} / \mathrm{m}^{3}$ had a slightly increased early reaction compared to controls. These data suggested that exposure to motor vehicle-derived air pollution may significantly enhance asthmatic reactions to subsequently inhaled allergens. In other studies on the effects of DE exposure on asthmatic reactions, Holgate and colleagues (Holgate et al., 2003; Stenfors et al., 2004) reported an increase in airway resistance of similar magnitude in both healthy and mild asthmatic subjects $2 \mathrm{~h}$ after exposed to ambient levels of DE. Healthy subjects, but not subjects with mild asthma, developed airway inflammation $6 \mathrm{~h}$ after DE exposure, with airways neutrophilia and lymphocytosis together with an increase in interleukin (IL)-8 protein in BAL fluid, bronchial mucosa and upregulation of the endothelial adhesion molecules, suggesting low level DE exposure did not induce a 
neutrophilic response or exacerbated their pre-existing eosinophilic airway inflammation (Holgate et al., 2003). When the asthmatic subjects were exposed to high concentration of DE, however, worsen lung function and asthmatic responses were noted by the same group (Nordenhall et al., 2001). In this study, fourteen atopic asthmatics with stable disease and on continuous treatment with inhaled corticosteroids were exposed to DE (300 $\left.\mu \mathrm{g} / \mathrm{m}^{3} \mathrm{PM} 10\right)$ for $1 \mathrm{~h}$. Exposure to DE was associated with a significant increase in airway resistance immediately after the exposure and the degree of hyperresponsiveness to methacholine at $24 \mathrm{~h}$ after exposure, compared to air control subjects. These studies indicated that short-term exposure to high levels of DE is associated with adverse effects in asthmatic airways, even in the presence of inhaled corticosteroid therapy.

DEP have been shown to potentiate IgE production in human respiratory mucosal membranes or even lead to primary sensitization of humans by driving a de novo mucosal IgE response. A human nasal challenge study was performed in which human subjects were exposed to various doses of DEP to investigate the effect of DEP on the production of localized immunoglobulins. Four days after challenge with $0.3 \mathrm{mg}$ DEP, increased production of IgE but not other immunoglobulins was detected (Diaz-Sanchez et al., 1994). Studies have also shown that DEP may have an adjuvant effect to allergens on human subjects. Ragweed-sensitive individuals were exposed to $0.3 \mathrm{mg}$ DEP and ragweed. Ragweed challenge alone enhanced the production of $\operatorname{IgE}, \operatorname{IgG} 4$, and also allergen-specific IgE in the BAL fluid. However, in DEP and ragweed combined exposed group, there was a 16-fold increase in ragweed-specific IgE. Although DEP alone enhanced total IgE, it was the combination of DEP and ragweed that led to an increased production of ragweed-specific IgE and an increased expression of T helper type 2 (Th2) 
cytokines (Diaz-Sanchez et al., 1994). Data from these human studies suggested that DEP may play a role in the increase prevalence of allergic diseases by enhancing Th2 responses and IgE production. In another study, Diaz-Sanchez et al. (1999) examined the ability of DEP exposure to lead to primary sensitization of humans. Atopic subjects were immunized with a neoantigen keyhole limpet hemocyanin (KLH) and DEP were administered $24 \mathrm{~h}$ before each KLH exposure. Exposure to KLH alone led to the generation of an anti-KLH IgG and IgA humoral response, which was detected in nasal fluid samples. In contrast, when challenged with KLH preceded by DEP, 9 of the 15 subjects produced anti-KLH-specific IgE. KLH-specific IgG and IgA at levels similar to that seen with KLH alone could also be detected. Subjects who received DEP and KLH had significantly increased IL-4, but not interferon (IFN)- $\gamma$, in nasal lavage fluid, whereas these cytokines were unchanged in subjects receiving KLH alone. These studies demonstrated that DEP can not only potentiate IgE production in human respiratory mucosal membranes, but also act as mucosal adjuvant to a de novo $\operatorname{IgE}$ response and may increase allergic sensitization.

\section{Human Studies on DE Exposure and Cardiovascular Diseases}

Human studies suggested that PM has the potential to affect important cardiovascular parameters. It has been shown that acute exposure to air pollution resulted in increased plasma viscosity (Peters et al., 1997) and increased infiltration of inflammatory cells in the blood (Salvi et al., 1999). Ultra-fine particles were shown to provoke alveolar inflammation with release of mediators capable of causing exacerbations of lung disease and of increasing blood coagulability in susceptible individuals, thus explaining the 
observed increases in cardiovascular deaths associated with urban pollution episodes (Seaton et al., 1995). Another report showed that exposure to PM led to changes in haemoglobin concentration, haematocrit and red blood cell counts and decreased platelet number and fibrinogen levels (Seaton et al., 1999). Peters et al. (2004) conducted a casecrossover study to assess whether exposure to traffic can trigger myocardial infarction. An association was found between exposure to traffic and the onset of a myocardial infarction within one hour afterward $(\mathrm{OR}=2.92 ; 95 \% \mathrm{CI} 2.22-3.83)$. The time the subjects spent in cars, on public transportation, motorcycles, or bicycles was consistently linked with an increase in the risk of myocardial infarction. The subject's use of a car was considered to be the most common source of exposure to traffic, while the time spent on public transportation was associated with the onset of a myocardial infarction one hour later. These results showed that transient exposure to traffic might increase the risk of myocardial infarction in susceptible persons. A recent human study further showed that compared to air controls, short-term inhalation exposure of healthy men to DE, at levels encountered in an urban environment, impairs the regulation of vascular tone and endogenous fibrinolysis, two important and complementary aspects of vascular function in humans (Mills et al., 2005). These important findings provide a potential mechanism that links DE to the pathogenesis of atherothrombosis and acute myocardial infarction.

\section{Modulation of the Pulmonary Immune Responses}

In recent years, ambient air pollution has been associated with hospitalizations and deaths due to exacerbations of cardiovascular and respiratory diseases (Samet, 2000). Increasing evidence shows that DEP may exert a strong modulating effect on the 
pulmonary immune system. Particularly, DEP and other particulate air pollution have been linked to asthma (Norris et al., 1999; Lipsett et al., 1997; D'Amato, 1999). DEP can act as nonspecific airway irritants at relatively high levels. At lower levels, DEP promote release of specific cytokines, chemokines, immunoglobulins, and reactive oxygen species (ROS), which are central chemical messengers in the inflammatory processes of asthma. Release of these mediators of the allergic and inflammatory response initiates a cascade that can culminate in airway inflammation, mucus secretion, serum leakage into the airways, and bronchial smooth muscle contraction (Pandya et al., 2002). In addition, modulation of the pulmonary immune responses by DEP is also directly associated with their adverse effect on pulmonary infections (Yang et al, 2001; Yin et al., 2002, 2003, 2004a, 2004b, 2005, 2006).

The cytotoxicity and immune-modulating effects of DEP have been examined in a number of studies using human bronchial and nasal epithelial cells. DEP exposure led to cell membrane damage in a dose- and time-dependent manner. Transmission electron microscopy study showed that DEP underwent endocytosis and translocated into epithelial cells (Boland et al., 1999). When the nasal or bronchial epithelial cells were exposed to DEP, their synthesis and release of proinflammatory cytokines such as IL-1, IL-6, IL-8, adhesion molecules, and granulolcyte-macrophage colony-stimulating factor (GM-CSF), were significantly increased (Devalia et al., 1997; Boland et al., 1999). Study found that carbon black (CB) particles, which resembled the carbonaceous core of DEP, had no effect on cytokine release, suggesting the cytokine effect appeared to be attributed to the adsorbed organic compounds (Boland et al., 1999). Furthermore, DEP were shown to induce the degranulation of eosinophils and enhance their adhesiveness to epithelial 
cells without changing the eosinophils survival rate, suggesting that DEP are likely to play an important role in promoting nasal hypersensitivity induced by increased eosinophil infiltration and degranulation (Terada et al., 1997). In a recent study, Mamessier et al. (2006) assessed the effect of DEP on the activation of T-cells, the main cells orchestrating asthma inflammation. The study showed that DEP could activate Tcells in asthmatics only, with a higher effect occurring during exacerbations.

IL-8, a member of CXC chemokine family mainly produced by macrophages, is one of the key mediators in attracting neutrophils to the airways (Lezcano-Meza et al., 1999). Since neutrophils are the most important inflammatory leukocytes in airway secretions of patients with acute severe asthma (Ordonez et al., 2000), the effect of DEP on the secretion of IL-8 is significant. In a study by Bayram et al. (1998a), DEP exposure attenuated the ciliary beat frequency of human bronchial epithelial cells and increased their release of IL-8, GM-CSF, and soluble intercellular adhesion molecule (ICAM)-1. Increased production of IL-8 was also observed in bronchial washings and bronchial tissues of healthy human volunteers after exposure to DEP (Salvi et al., 2000). In another study, the effects of DEP on the production of IL- 8 by cultured human bronchial cells were compared between healthy volunteers and atopic patients with mild asthma. There was a significant increase in the levels of IL-8 in the bronchial cells from asthmatic patients when they were treated by $10 \mu \mathrm{g} / \mathrm{ml}$ DEP. In the cells from nonasthmatics, only higher concentrations of DEP (50 and $100 \mu \mathrm{g} / \mathrm{ml}$ ) caused an increase in the release of IL8. The results indicated that the bronchial cells from asthmatic patients were more 
sensitive to DEP than those from nonasthmatics and that the DEP-mediated IL-8 production may play a role in asthmatic responses (Bayram et al., 1998b).

DEP may also promote expression of the Th2 immune response phenotype that has been associated with asthma and allergic disease. Many kinds of cytokines stimulate B cells and $\mathrm{T}$ cell switching to the Th2 subtype, attract and prolong the infiltration and survival of eosinophils, and increase local IgE production, resulting in allergic or asthmatic response. IL-4, for example, is a Th2 cytokine which induces isotype switching of $\mathrm{B}$ cells in antibody production from $\operatorname{IgM}$ to IgE. IL-5, on the other hand, is important for the proliferation and activation of eosinophils after exposure to some types of allergens such as pollen and OVA (Miyabara et al., 1998). In a study by Diaz-Sanchez et al. (1996), healthy, nonsmoking human volunteers were exposed to DEP and mRNA expression for cytokines in nasal lavage was examined. Before challenge, most individuals had detectable mRNA levels of only a few cytokines (IFN- $\gamma$, IL-2 and IL-13). However, after challenge with $0.3 \mathrm{mg}$ DEP, these three cytokines and a number of additional kinds (IL-4, IL-5, IL-6 and IL-10) were measured in increasing levels (DiazSanchez et al., 1996). Furthermore, DEP have been shown to enhance Th2 cytokine production more efficiently when combined with an allergen than exposure to an allergen or DEP alone. Exposure of mice to DEP with OVA markedly increased local IL-4 and IL-5 levels compared with either antigen or DEP alone (Takano et al., 1997). In a human study, Diaz-Sanchez et al. (1997) also showed that healthy human individuals exposed to DEP together with ragweed antigen had higher levels of IL-5 production in nasal lavage fluid than those exposed to DEP alone. 
One of the important effects of DEP on modulation of the immune responses is thought to increase IgE synthesis, thus facilitating allergic sensitization in atopic subjects and the subsequent development of clinical respiratory symptoms. $\operatorname{IgE}$ is produced by activated $\mathrm{B}$ cells in response to a specific allergen. Once produced $\operatorname{IgE}$ attaches to mast cells and, when cross-linked by allergen, induces mast cells to release histamine and leukotrienes. The chemicals released from mast cells cause constriction of bronchial smooth muscle, mucus secretion, and serum leakage into the airways and result in acute asthma symptoms (Busse, 2001). The mast cell is often considered the central cell type in the acute asthmatic response, and $\operatorname{IgE}$ is the critical immunoglobulin driving the mast cell response. Extensive studies have been conducted to demonstrate that DEP, the organic compounds of DEP, as well as other physical particles may enhance IgE production, either alone or acting as an adjuvant to allergens (Takafuji et al., 1987; Takenaka et al., 1995, Diaz-Sanchez et al., 1996; Takano et al., 1997; Dong et al., 2005a, 2005b). It has been suggested that DEP may enhance IgE production by activating B cells through inducing Th2 cytokines. One study showed that when human B cell was stimulated by IL-4, the IgE production was significantly increased after exposure to phenanthrene, a major polyaromatic hydrocarbon and one of the most important DEP components (Tsien et al., 1997).

While DEP enhance the Th2 responses to allergic sensitization, the same particles have been also shown to suppress the host defense mechanism against bacterial infection, which may contribute to the etiology of air pollution-associated pulmonary diseases such as infections of the upper and lower respiratory tract. Animal studies conducted in our 
laboratory consistently demonstrate that DEP exposure suppresses both the innate, orchestrated by alveolar macrophages (AM), and T-cell mediated immune responses, resulting in an increased susceptibility of the lung to bacterial infection (Yang et al, 2001; Yin et al., 2002, 2003, 2004a, 2004b, 2005). DEP were shown to inhibit $L$. monocytogenes-induced AM production of IL-1 $\beta$ and tumor necrosis factor (TNF)- $\alpha$, which are responsible for the innate immunity, and IL-12, which initiates the development of Th1 responses, but enhance L. monocytogenes-induced AM production of IL-10, which prolongs survival of the bacteria in these phagocytes. On the other hand, DEP exposure also suppressed the development of bacteria-specific lymphocytes from lung-draining lymph nodes, as indicated by the decreased numbers of $\mathrm{T}$ lymphocytes and their $\mathrm{CD} 4^{+}$and $\mathrm{CD} 8^{+}$subsets. Cytokine production by lymphocytes from DEP-exposed and L. monocytogenes-infected rats showed a marked decrease in the production of IL-2 and IFN- $\gamma$ compared to bacterial infection alone, suggesting that either DEP inhibit the production of cytokines by lymphocytes or these lymphocytes contained $\mathrm{T}$ cell subsets that are different from those of bacterial infection alone and less effective in mediating Th1 immune responses (Yin et al., 2003, 2004a, 2005). In vitro studies further showed that DEP or organic extracts of DEP, but not washed DEP or CB, dose-dependently suppressed L. monocytogenes-induced secretion of TNF- $\alpha$, IL-1 $\beta$, IL-12 by AM and IL-2 and IFN- $\gamma$ by lymphocytes obtained from L. monocytogenes-infected rats, but augmented the AM secretion of IL-10. Parallel to the alterations in cytokine secretion, DEP or organic extracts of DEP, but not washed DEP or $\mathrm{CB}$, significantly decreased the phagocytotic and bacterial killing activities of rat AM (Yin et al., 2006). These results provide direct evidence that DEP, through the actions of organic components, suppresses 
AM immune functions against bacterial infection. Inhibition of AM phagocytic function and alterations of AM and lymphocyte cytokine secretion by DEP and DEP organic compounds may be implicated in the diminished AM bactericidal activity and the lymphatic arm of the host immune system, thus resulting in an suppressed pulmonary clearance of pathogens and increased susceptibility of the lung to infection.

\section{Biomarker Studies}

In recent years, studies have been carried out that have led to the discovery of biological and biochemical markers, which are increasingly valuable for predicting and preventing diseases with environmental etiology, including biomarkers of exposure, effect, and susceptibility for DE. In most of the human biomarkers studies, DNA from peripheral blood/leukocytes or other cells/tissues are used to evaluate the genotoxicity of DE exposure. Pohjola et al. (2003) have examined diesel-derived PAH binding to DNA and compared the differences in DNA adduct forming capacity of diesel- and gasolinederived PAH in human bronchial epithelial cells. The levels of DNA adducts were in good accord with the 10 DNA adduct-forming PAH concentrations analyzed in the extracts of particulates form both exhausts. SRM 1650, a standard material for DEP, dose-dependently formed DNA adducts in the cells, which was about 11- and 31-fold more than gasoline engine exhaust, when PAH-DNA adduct levels were calculated on an emission basis (adducts/mg PM/km) (Pohjola et al., 2003). Studies have also shown an increased formation of 8-hydroxy-2'-deoxyguanosine (8-OHdG) in peripheral blood lymphocytes and altered antioxidant capacities in serum and red blood cells of coal miners (Schins et al., 1995, 1999). Kuusimaki et al. (2004) have assessed and evaluated 
the biomarkers of exposure to DE in bus-garage and waste-collection workers. In the seven measured urinary PAH metabolites including 2-naphthol, 1-hydroxyphenanthrene, 2-hydroxyphenanthrene, 3-hydroxyphenanthrene, 4-hydroxyphenanthrene, 9hydroxyphenanthrene and 1-hydroxypyrene (1-OH-P), the concentrations of 1-OH-P and 2-naphthol and the sum of seven urinary PAH metabolites were higher in the exposed group than in the control group. In addition, increased $\mathrm{O}(6)$-alkylguanine DNA adducts were detected in the white blood cells of underground workers, suggesting higher exposure to nitroso-compounds (Scheepers et al., 2002).

Xenobiotic metabolizing enzymes, especially cytochrome P450 (CYP) 1A1 and GSTM1, are involved in the activation and conjugation of PAHs and are controlled by polymorphic genes. In the biomarker of susceptibility studies, Adonis et al. (2003) therefore connected DE exposure with CYP1A1 and GSTM1 and studied the contribution of CYP1A1 and GSTM1 polymorphisms on 1-OH-P urinary levels used as the PAH exposure biomarker. They studied 59 diesel exposed (38 diesel revision workers and 21 subjects working in an urban area as established street vendors) and 44 non-exposed subjects living in a rural area. When 1-OH-P levels were related with genotypes, an association was observed for the CYP1A1 2A genotype, so that the diesel-exposed workers carrying the CYP1A1 2A allele showed significantly higher 1-OH-P levels than the subjects from the rural area with the same genotype. On the other hand, there was no significant correlation between urinary 1-OH-P levels and GSTM1 null genotype, although higher levels of the urinary metabolite were found in individuals carrying the combined CYP1A1 2A and GSTM1 null genotype. These results suggested an association between levels of the exposure biomarker 1-OH-P and presence of the 
CYP1A1 2A genotype, a potential genetic susceptibility biomarker which might be useful in identifying individuals at higher risk among people exposed to high PAH levels in DE.

Since benzene, a component of DE, causes alterations in porphyrin metabolism, and some of these may lead to the formation of tumors, heme synthesis is proposed as a biomarker of early health effects of DE. Muzyka et al. (2002) have investigated the levels of 5-aminolevulinic acid (ALA) and protoporphyrin (PP), activities of ALA synthase and ferrochelatase, as well as levels of PP associated with DNA (PP/DNA) in lymphocytes from workers exposed to DE at a marine diesel fuel terminal. Levels of ALA, PP, and ALA-synthase activity were significantly increased in marine terminal workers. At the same time ferrochelatase activity was decreased compared to unexposed controls. In an investigation carried out at a coal mine and at an oil-shale mine, Muzyka et al. (2003, 2004) reported that the values of PP and PP/DNA in lymphocytes appeared to be significantly increased only in miners in the oil-shale mine. There was no difference in the levels of PP and PP/DNA and ferrochelatase activity between surface workers and miners at the coal mine. The level of heme in lymphocytes of coal mine miners was significantly higher than in miners of the oil-shale mine. The activity of ferrochelatase was significantly lower in underground workers compared to surface workers at this mine. These studies suggested that alterations of porphyrin and heme metabolism in peripheral lymphocytes might serve as biomarker in assessment of exposure to DE effects. In addition, Knudsen et al. (2005) have shown that DNA damage in frozen blood samples was significantly higher in underground workers driving diesel-powered excavation machines than surface workers. 


\section{Mechanisms of DEP-Induced Pulmonary Responses}

Although extensive studies have been conducted, the mechanisms by which DE exerts its adverse health effects have not yet been fully understood. This may be at least partially due to the complex physical and chemical features of DE composition. However, emerging data suggest a key role for DEP-induced oxidative stress in their health effects. DEP or the organic DEP components have been shown to induce production of ROS in a variety of cell types, which have been involved in the pathogenesis and development of many different health conditions and are likely to be responsible for the adverse effects of DEP on the cardiopulmonary system, including lung cancer, asthma, COPD, and cardiovascular diseases. This review, rather than attempting to review all available data on mechanistic studies, highlights those that aid our understanding of the role of ROS in DE-induced adverse effects.

Studies have shown that the particulate component of DEP elicits respiratory burst activity of inflammatory cells, such as AM and neutrophils in the production of ROS and proinflammatory cytokines. The organic components of DEP, such as PAHs and quinones, on the other hand, have been shown to produce intracellular ROS in AM through interaction with metabolizing enzymes such as CYP1A1 (Ma and Ma, 2002; Baulig et al., 2003; Yin et al., 2004b). PAHs are converted to quinones via biotransformation involving CYP1A1, expoxide hydrolase, and dihydrodiol dehydrogenase (Penning et al., 1999). Quinones act as catalysts to produce ROS and may be key compounds in PM toxicity along with transition metals (Penning et al., 1999; Monks et al., 1992). Redox cycling of quinones undergoes one-electron reductions by 
NADPH cytochrome P450 reductase to form semiquinones (Monks et al., 1992), which can be recycled to the original quinones, leading to the formation of superoxide. Transition metals, such as $\mathrm{Fe}, \mathrm{Ni}, \mathrm{Cu}, \mathrm{Co}$ and $\mathrm{Cr}$ are also important in $\mathrm{ROS}$ generation through the Fenton and Haber-Weiss reactions (Kehrer et al., 2000). It is possible that transition metals may synergize with organic PM components in ROS generation (Stearns et al., 2002).

An imbalance between the production of ROS and antioxidant capacity leads to a state of oxidative stress that contributes to the pathogenesis of a number of human diseases including those of the lung by damaging lipids, protein, and DNA. The genotoxicity of DEP may be mediated by ROS, although it may be caused by direct (primary) actions of PAHs, which are known to be genotoxic in vivo and capable of forming DNA adducts (Tsurudome et al., 1999; Arlt et al., 2001). Indeed, ROS has been shown to be genotoxic and proliferating substances that lead to tumor formation (Oberdorster, 1995; Oberdorster, 1997; Borm et al., 1996; Morrow et al, 1996). ROS are able to induce oxidation of DNA bases, DNA strand breaks, or lipid peroxidationmediated DNA adducts (Kasai et al, 1986; Schraufstatter et al., 1988; Aruoma et al., 1989; Trush et al., 1991). In vivo studies have shown that the 8-hydroxyguanine levels in rat lung DNA increased markedly at an early phase after DEP exposure, by the generation of ROS and the inhibition of 8-hydroxyguanine repair activity (Tsurudome et al., 1999). These studies indicated that the ROS produced after DEP exposure may play an important role in the genotoxicity and carcinogenicity of DEP. 
An important mechanism of DEP mediated pulmonary responses involves the generation of ROS and depletion of the antioxidant capacity in lung cells. Li et al. (2002) demonstrated that the organic DEP extract induces a stratified oxidative stress response, leading to heme oxygenase 1 (HO-1) expression at normal reduced glutathione/glutathione disulfide (GSH/GSSG) ratios and that the activation of Jun kinase and IL-8 production at intermediary oxidative stress levels culminated in cellular apoptosis in parallel with a sharp decline in GSH/GSSG ratios. Whitekus et al. (2002) also showed that DEP induced an oxidative stress as indicated by a decrease in intracellular GSH/GSSG ratios and protein and lipid oxidation in vitro, which could be blocked by the thiol antioxidants, bucillamine (BUC) and N-acetylcysteine (NAC). They further demonstrated that NAC and BUC effectively inhibited the generation of lipid peroxidation and protein oxidation in the lungs and the adjuvant effects of DEP in the induction of OVA-specific IgE and IgG1 production in OVA- plus DEP-exposed animals. These results showed that DEP may alter allergic responses, which are at least partially, attributed to the DEP-induced oxidative stress in AM and epithelial lung cells.

In fact, ROS has been implicated in the etiology and pathogenesis of allergic asthma. ROS can reproduce many of the athophysiological features of asthma including enhanced arachidonic acid release, airway smooth muscle contraction, increased airway reactivity and secretions, increased vascular permeability, and increased synthesis of chemoattractants Owen et al., 1991; Sadeghi-Hashjin et al., 1996). ROS-mediated injury to the epithelium produces hyperresponsiveness of human peripheral airways, suggesting that ROS may play a role in the pathogenesis of asthma (Hulsmann et al., 1994). Neutrophils isolated from peripheral blood of asthmatic patients can generate greater 
amounts of superoxide and $\mathrm{H}_{2} \mathrm{O}_{2}$, and their ability to produce superoxide correlates with the degree of airway hyperresponsiveness to inhaled methacholine (Seltzer et al., 1986; Hiltermann et al., 1998). Inflammatory cells obtained from asthmatic patients, particularly eosinophils, which produce more superoxide than neutrophils or macrophages, release ROS at baseline and after stimulation ex vivo (Sedgwick et al., 1990; Sanders et al., 1995). This suggests that the biochemical milieu in asthma contains factors which may prime ROS generation in vivo. Eosinophils play a critical role in asthma because their increased presence in BAL fluid and blood is closely linked with bronchial hyperresponsiveness (Foreman et al., 1999; Wood et al., 2000). BAL fluid eosinophils, AM, and neutrophils from asthmatic patients produce more ROS than do those from normal subjects (Teramoto et al., 1996; Schauer et al., 1991). ROS directly contract airway smooth muscle preparations and this effect is enhanced when the epithelium is injured or removed. This observation might provide a mechanistic link between epithelial injury arising from a variety of causes and airway hyperresponsiveness (Hulsmann et al., 1994). ROS also appear to directly stimulate histamine release from mast cells and mucus secretion from airway epithelial cells (Krishna et al., 1998). In addition, there is also increasing evidence showing that oxidative stress has been proposed in the pathogenesis of many other conditions such as pulmonary infection, COPD and cardiovascular diseases (Yin et al., 2004b; Langen et al., 2003; Rahman, 2005; Tao et al., 2003; Hirano et al., 2003). For example, Yin et al. (2004b) have shown the role of ROS in modulation of the AM-mediated immune responses to $L$. monocytogenes by DEP. Exposure of L. monocytogenes-infected AM to DEP or their organic extracts resulted in an increased expression of intracellular ROS and HO-1, 
followed by an increased secretion of IL-10 but decreased secretion of TNF- $\alpha$ and IL-12 from the cells. Interestingly, direct stimulation of the AM with pyrogallol, a superoxide donor, up-regulated HO-1 and IL-10 but decreased secretion of IL-12. This study provides direct evidence that DEP mediated ROS response exerts a modulating effect on immune responses against bacterial infection, causing a switch of immune response from Th1 to Th2, thereby enhances both respiratory infection and allergic asthma.

At least two well-known classes of transcription factors, the nuclear factor- $\mathrm{kB}$ (NF$\mathrm{\kappa B})$ and the activator protein-1 (AP-1) families, are regulated by the intracellular redox state (Pinkus et al., 1996). Expression of cytokine genes is controlled by transcription factors, which interact with specific sequence motifs in the promoter region of the gene. Particularly, NF- $\mathrm{KB}$ plays a key role in regulation of the expression of various genes involved in the inflammatory and immune response (Jany et al., 1995). NF-אB activation

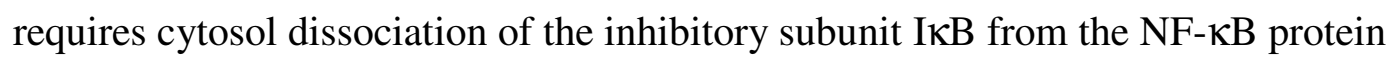
complex, allowing its nuclear translocation and binding to DNA consensus sites. A

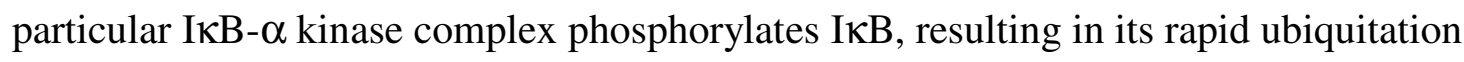
and subsequent degradation by the proteasome (Zandi et al., 1997).

Studies have shown that DEP activate several signaling pathways, such as mitogenactivated protein kinases (MAPK) and transcription factors, in particular NF- $\mathrm{KB}$ in human bronchial epithelial cells (Hashimoto et al., 1999; Marano et al., 2002; Takizawa et al., 2003). Electronphoresis mobility assays have shown that DEP exposure may enhance the binding of NF- $\mathrm{kB}$ to DNA in airway epithelial cells (Baeza-Squiban, 1999; 
Takizawa et al., 1999). Furthermore, transient transfection experiments with a construct containing NF- $\mathrm{KB}$ binding DNA consensus sites concluded that DEP might induce the activation of NF-kB-dependent gene transcription (Takizawa et al., 1999). Although no data exist for the activation of AP-1 by DEP, evidence showed that $\beta$-naphthoflavone ( $\beta$ $\mathrm{NAF}$ ), a prototype of $\mathrm{PAH}$, and a derivative tert-butylhydroxyquinone (tBHQ), a prototype quinone, might induce AP-1 electrophoretic mobility shift complexes in macrophage cell lines (Ng et al., 1998). Ng et al. reported that $\beta-\mathrm{NAF}$ and tBHQ induced the activity of the N-terminal jun kinase (JNK) MAPK cascade. This cascade, which is involved in the transcriptional activation and expression of c-Jun and serves to regulate different aspects of AP-1 transcriptional activity, can be induced by various kinds of injurious chemicals and cellular stress inducers, including genotoxic chemicals, inflammatory cytokines, and $\mathrm{H}_{2} \mathrm{O}_{2}$ (Kyriakis et al., 1994). These data indicated that DEP and DEP-derived PAHs and their quinone derivatives could induce the activation of MAPK cascades as well as transcription factors NF- $\mathrm{KB}$ and AP-1. These effects were also dependent on the role of ROS. Studies have shown that the release of DEP-induced cytokines and the activation of MAPK and NF-kB were significantly inhibited by antioxidants (such as NAC), indicating that ROS was strongly incriminated in these DEP effects (Hashimoto et al., 2000; Marano et al., 2002; Baulig et al., 2003; Takizawa et al., 2003).

In addition to the adjuvant effect, DEP can also induce IgE production by acting directly on B cells. Takenaka et al. (1995) demonstrated that the organic DEP extract of PAHs enhanced human IgE production from purified B cells. Additionally, the pattern of 
mRNAs coding for distinct isoforms of the $\varepsilon$ chain was altered by PAH-DEP, and B-cell expression of the low-affinity IgE receptor was upregulated by PAH-DEP. Studies by other investigators have also indicated that the organic extract of DEP (PAH-DEP) and particularly, phenanthrene, a major component of DEP, consistently enhanced IgE production by 2C4/F3, a human Epstein-Barr virus transformed isotype switched, IgE producing B cell line (Tsien et al., 1997). Enhanced IgE production in the human airway, resulting from exposure to $\mathrm{PAH}-\mathrm{DEP}$, may be an important factor in the increase in airway allergic disease.

\subsection{Summary}

Ample studies have indicated that DE, at levels occurring in both ambient and occupational settings, exerts adverse health effects on humans. There is a general agreement in the scientific community that exposure to relatively high levels of DE are likely to cause lung cancer in humans, although contradiction exists which challenge the notion that DE is a probable human carcinogen (Bunn et al., 2002, 2004; Hesterberg et al., 2005). DEP exposure is also associated with a number of non-specific lung diseases including pulmonary bacterial infection and allergic asthma.

Epidemiology data further linked DE exposure with excess risk for respiratory symptoms, reduced lung function, COPD, and cardiovascular diseases in humans. Both the organic and particulate components of DEP have been shown to play a role in modulating the immune inflammatory responses and the induction of genotoxicity. Allergic asthma is a complex disease which involves B cell production of allergen- 
specific antibodies that leads to eosinophil infiltration and airway inflammation resulting in obstructive airway disease through enhanced Th2 immunity.

The production of ROS by lung cells (including AM and type II cells) which result in oxidative stress is considered a key factor responsible for the adverse DEP effects. The literature suggests that DEP may alter pulmonary immune responses through multiple pathways that include enhanced Th2 immunity, induction of airway inflammation through direct effect on epithelial cells, and systemic effect on B cell responses. Because of the multiple pathways, it is likely that the relative timing of DEP exposure and allergen sensitization may play a role in DEP-mediated allergic asthma. 


\section{MATERIALS AND METHODS}

\subsection{Animals and Exposure Schedule}

Male Brown Norway rats [BN/CrlBR] weighing 200-225 g were obtained from Charles River Laboratories (Wilmington, MA). The animals were housed in a clean-air and virus-free room with restricted access, given a conventional laboratory diet and tap water ad libitum, and allowed to acclimate for 1 week before use in an animal facility approved by the Association for Assessment and Accreditation of Laboratory Animal Care.

\section{OVA Immunization.}

A solution of OVA (Grade V, Sigma Chemical Co., St. Louis, MO) in endotoxin-free saline (1\%) was aerosolized using a DeVilbiss-646 nebulizer (DeVilbiss, Somerset, PA). To achieve the desired concentration, filtered air was passed through the nebulizer and used as a diluent for the aerosolized OVA. The concentration of OVA in the chamber was determined by collecting samples onto $0.4 \mu \mathrm{m}$ filters (Polycarbonate Membrane, Poretics Corporation, Livermore, CA) from a chamber side port at a rate of 1 1/min. Filters were washed with $10 \mathrm{ml}$ of endotoxin-free saline and analyzed for protein using the Coomassie blue dye reagent (Bio-Rad Laboratories, Hercules, CA). Rats were sensitized to OVA at an average chamber concentration of $42.3 \pm 5.7 \mathrm{mg} / \mathrm{m}^{3}$ for $30 \mathrm{~min}$ on days 1,8 , and 15 , and challenged with OVA on day 29 (protocol A). The animals were subjected to wholebody plethysmography on day 30,24 h after the last OVA dose, and they were sacrificed

on day 31 for biochemical and cellular measurements (protocol B). Nonsensitized 
animals were exposed to aerosolized endotoxin-free saline following the same exposure schedule.

\section{DEP Exposure.}

\section{a. Protocol A and B.}

A standardized DEP sample (standard reference material 2975), representing heavyduty diesel engine with a mass median aerodynamic diameter of $0.5 \mu \mathrm{m}$, was purchased from the National Institute of Standards and Technology (Gaithersburg, MD). Diesel exhaust particles were suspended in endotoxin-free sterile saline (Baxter Healthcare Corporation, Deerfield, IL), followed by sonication for $2 \mathrm{~min}$ in an ultrasonic processor with a micro tip (Heat System-Ultrasonics, Plainview, NY) prior to use. The DEP inhalation exposure system used in this study has been described and characterized elsewhere (Yin et al., 2002, 2004a). Rats were exposed to either filtered air or DEP (22.7

$\left.\pm 2.5 \mathrm{mg} / \mathrm{m}^{3}\right), 4 \mathrm{~h}$ /day for 5 consecutive days either prior to the sensitization from day -4 to day 0 (protocol A) or on days 24-28 of the sensitization process (protocol B), $24 \mathrm{~h}$ prior to the last (challenge) dose of OVA using a nose-only directed flow exposure unit (CH Technologies, Inc., Westwood, NJ). The DEP concentration in the exposure unit was monitored by both gravimetric sampling of dust collected on a polycarbonate membrane filter (37 mm, $0.45 \mu \mathrm{m}$, Poretics Corporation, Livermore, CA) at a sampling rate of 1 1/min, and with a Grimm Model 1.108 portable dust monitor (GRIMM Technologies, Inc., Douglasville, GA), which allows continuous measurement of the particle concentration in the exposure unit in real time. The estimated mean lung deposition of 
DEP for the above-described inhalation exposure, calculated based on the method of Leong et al. (1998), was $402 \pm 58 \mu \mathrm{g} / \mathrm{rat}$.

The exposure groups (5 rats/group) for the present study were: nonsensitized/ airexposed/saline challenged (saline + air); non-sensitized/DEP exposed/ saline challenged (saline + DEP); OVA-sensitized/air-exposed/OVA challenged (OVA + air); and OVAsensitized/DEP-exposed/OVA challenged (OVA + DEP). All parameters were measured after saline/OVA challenge (the last dose) with and without DEP exposure.

b. DEP by Intratracheally Instillation (i.t.)

Rats were anesthetized with sodium methohexital (35mg/kg intraperitoneally) and placed on an inclined restraint board. A 0.3-ml suspension of DEP at a dose of $35 \mathrm{mg} / \mathrm{Kg}$ body weight, or equivalent amount of saline (control) was intratracheally instilled. Rats were sacrificed 3 days postexposure.

\section{LPS Treatment.}

A solution of lipopolysaccharide (LPS) (Sigma Chemical Co., St. Louis, MO) in sterile water $(0.5 \mathrm{mg} / \mathrm{Kg})$ was intraperitoneally injected to the rats. The rats were sacrificed 2 hours after LPS treatment.

\subsection{Bronchoalveolar Lavage (BAL) and Determination of BAL Markers}

\section{$B A L$.}


Rats were deeply anesthetized with an overdose of sodium pentobarbital $(200 \mathrm{mg} / \mathrm{kg}$, ip; Butler, Columbus, $\mathrm{OH}$ ) and euthanized by exsanguination via the vena cava. After clamping off the right apical lobe, the trachea was cannulated and the remaining lung lobes were first lavaged with $6 \mathrm{ml} \mathrm{Ca}{ }^{2+/} \mathrm{Mg}^{2+}$-free phosphate buffered solution (PBS, 145 $\mathrm{mM} \mathrm{NaCl}, 5 \mathrm{mM} \mathrm{KCl}, 1.9 \mathrm{mM} \mathrm{NaH} \mathrm{PO}_{4}, 9.35 \mathrm{mM} \mathrm{Na}_{2} \mathrm{HPO}_{4}$, and $5.5 \mathrm{mM}$ glucose; $\mathrm{pH}$ 7.4). The first BAL fluid sample was centrifuged at $500 \times \mathrm{g}$ for $10 \mathrm{~min}$ at $4^{\circ} \mathrm{C}$, and the resultant cell-free supernatant $(\sim 4 \mathrm{ml} / \mathrm{rat})$ was analyzed for various biochemical parameters. The lungs were further lavaged with $6 \mathrm{ml}$ aliquots of PBS until $80 \mathrm{ml}$ of BAL fluid was collected. These samples were also centrifuged for $10 \mathrm{~min}$ at $500 \times \mathrm{g}$, and the cell-free BAL fluid discarded. The cell pellets from all washes for each rat were combined, washed, and resuspended in PBS and evaluated as described below.

\section{BAL Cell Differentiation.}

The BAL cells were numerated couted using a CoulterMultisizer II and AccuComp software (Coulter Electronics, Hialeah, FL). Cell suspensions $\left(5 \times 10^{4}\right.$ cells) were centrifuged for $5 \mathrm{~min}$ at $800 \mathrm{rpm}$ and pelleted onto a slide using a Cytospin centrifuge (Shandon Life Sciences International, Cheshire, England). Three hundred cells per rat were identified and differentiated after labeling with Leukostat stain (Fisher Scientific, Pittsburgh, PA). The absolute numbers of cells differentiated were calculated by multiplying the total number of cells by the percentage of the total within each cell type.

\section{Albumin and LDH.}


The albumin content, which indicates injury to the bronchoalveolar-capillary barrier, and LDH activity, which indicates cytotoxicity, were determined in the first fraction of acellular BAL fluid, using a COBAS MIRA auto-analyzer (Roche Diagnostic Systems, Montclair, NJ). Albumin content was determined colorimetrically at $628 \mathrm{~nm}$ based on albumin binding to bromcresol green using an albumin BCG diagnostic kit (Sigma). Lactate dehydrogenase activity was determined by measuring the oxidation of lactate to pyruvate coupled with the formation of reduced form of nicotinamide adenine dinucleotide at $340 \mathrm{~nm}$ using the Roche Diagnostic reagents and procedures (Roche Diagnostic Systems, Indianapolis, IN).

\section{Chemiluminescence (CL).}

The light generation as CL by resting or stimulated AM as a result of ROS production was determined in a total volume of $0.5 \mathrm{ml}$ HEPES buffer. Resting CL was determined by incubating BAL cells containing $0.5 \times 10^{6} \mathrm{AM}$ at $37^{\circ} \mathrm{C}$ for $10 \mathrm{~min}$ in $0.008 \%(\mathrm{w} / \mathrm{v})$ luminol (Sigma) followed by the measurement of CL for 15 min. Luminol was used as an amplifier to enhance detection of the light and was first dissolved in a small amount of ethanol before being brought up to its final concentration in HEPES buffer. To determine zymosan-stimulated CL, unopsonized zymosan ( $2 \mathrm{mg} / \mathrm{ml}$, Sigma) was added immediately prior to the measurement of CL. Measurement of CL was performed with an automated Berthold Autolumat LB 953 luminometer (Wallace, Inc., Gaithersburg, MD) for 15 min, and the integral of counts versus time was calculated. Zymosan-stimulated CL was calculated as the total counts of stimulated cells minus the total counts of the 
corresponding resting cells. The zymosan-stimulated CL was attributed to AM only, as rat neutrophils do not respond to unopsonized zymosan in this system.

\section{NO Production.}

The production of NO by AM was determined as follows. Cells were suspended in Eagle's minimum essential medium (MEM, Biowhittaker, Walkersville, MD) supplemented with $1 \mathrm{mM}$ glutamine, $100 \mu \mathrm{g} / \mathrm{ml}$ streptomycin, 100 units/ml penicillin, and $10 \%$ heat-inactivated fetal bovine serum (FBS). Aliquots of $1 \mathrm{ml}$ cell suspension containing $2 \times 10^{6} \mathrm{AM}$ were incubated in a humidified incubator $\left(37^{\circ} \mathrm{C}\right.$ and $\left.5 \% \mathrm{CO}_{2}\right)$ for $2 \mathrm{~h}$ to allow cell attachment to the culture plate. The non-adherent BAL cells were removed by rinsing the monolayer three times with culture medium. The remaining AMenriched cells were incubated in $1 \mathrm{ml}$ medium for $24 \mathrm{~h}$ at $37^{\circ} \mathrm{C}$ and $5 \% \mathrm{CO}_{2}$. The level of nitrite produced from NO in the AM-conditioned media was measured colorimetrically with the Greiss reaction using sodium nitrite as a standard (Green et al., 1982). The levels of NO in the first fraction of acellular BAL fluids were also determined using the Greiss assay.

\section{Western Blot Analysis.}

The recovered AM-enriched cells were washed with PBS and then suspended in 100 $\mu \mathrm{l}$ of a lysis buffer (50 mM Tris-HCl, 1\% NP-40, 2 mM EDTA, $100 \mathrm{mM} \mathrm{NaCl,} 20 \mu \mathrm{g} / \mathrm{ml}$ aprotinin, $20 \mu \mathrm{g} / \mathrm{ml}$ leupeptin, $1 \mathrm{mM}$ phenylmethylsulfonyl fluoride; $\mathrm{pH} 7.5$ ) and left on ice for $10 \mathrm{~min}$. Cytoplasmic extracts were separated from the nuclei by centrifugation at $14,000 \mathrm{rpm}$ for $10 \mathrm{~min}$ at $4^{\circ} \mathrm{C}$, and protein content determined using a BCA Protein 
Assay Kit (Pierce, Rockford, IL). An equal amount of protein (30 $\mu \mathrm{g} /$ well) for each sample was boiled for 5 min, loaded, and run for electrophoresis in a 4-20\% Tris-Glycine gel (Invitrogen, Carlsbad, CA) at $125 \mathrm{~V}$. The gel was transferred electrophoretically (BioRad Laboratories, Hercules, CA) to a nitrocellulose membrane (Schleicher \& Schuell, Keene, NH), and the blots were blocked with 5\% milk in TBST buffer (20 mM Tris-HCl, $100 \mathrm{mM} \mathrm{NaCl}, 0.1 \%$ Tween 20; $\mathrm{pH}$ 7.5) for $1 \mathrm{~h}$ at room temperature. Membranes were then probed with a polyclonal rabbit antibody against inducible NO synthase (iNOS) and a horseradish peroxidase-conjugated anti-rabbit IgG (Santa Cruz Biotechnology, Santa Cruz, CA). Blots were developed using commercially developed enhanced chemiluminescence reagent (Amersham Biosciences, Piscataway, NJ). For quantification, bands in photographs were scanned by a densitometer linked to a computer system (Personal Densitometer SI, Amersham Biosciences, Piscataway, NJ).

\subsection{Analysis of Lymphocytes from Lung-Draining Lymph Nodes (LDLN)}

\section{Isolation of Lymphocytes.}

Lymphocytes were isolated from LDLN as described previously (Yin et al., 2003). Briefly, LDLN were excised from each rat after BAL, teased apart, and homogenized with a glass pestle in a screen cup (Sigma). Single cell suspensions were obtained by passing the cell clumps through a 22-gauge needle attached to a 10-ml syringe, and washed twice with PBS. Lymphocytes were isolated by Histopaque (density 1.083; Sigma) gradient centrifugation. Samples were centrifuged for $30 \mathrm{~min}$ at $2500 \mathrm{rpm}$, and lymphocytes were collected, washed, re-suspended in $1 \mathrm{ml}$ of PBS, and counted using a standard hemocytometer. The cell samples thus prepared showed predominance of 
lymphocytes and cell viability of greater than $98 \%$ as determined by the trypan blue exclusion technique.

\section{Flow Cytometric Analysis.}

The effects of OVA and/or DEP exposures on frequencies of T cell subsets in LDLN, i.e., the expression of CD3, CD4, and CD8 cell surface markers, were examined with a flow cytometric method described elsewhere (Yin et al., 2003). Lymphocytes $\left(10^{6}\right.$ cells) were stained with the addition of FITC-labeled conjugated antibodies against these cell surface markers (BD Pharmingen, San Diego, CA). The flow cytometric data were collected with a Becton-Dickinson FACScan using FACScan Research Software (Becton-Dickinson Immunocytometry System) and analyzed using the PC-LYSYS software (Becton-Dickinson).

\subsection{Cytokine Production.}

The BAL cells were suspended in Eagle's minimum essential medium (MEM, Biowhittaker, Walkersville, MD) supplemented with $1 \mathrm{mM}$ glutamine, $100 \mu \mathrm{g} / \mathrm{ml}$ streptomycin, 100 units/ml penicillin, and 10\% heat-inactivated fetal bovine serum. Aliquots of $1 \mathrm{ml}$ cell suspensions, adjusted to contain $2 \times 10^{6} \mathrm{AM}$, were added to each well of a 24 -well tissue culture plate and incubated in a humidified incubator $\left(37^{\circ} \mathrm{C}\right.$ and $5 \% \mathrm{CO}_{2}$ ) for $2 \mathrm{~h}$ to allow cell attachment to the culture plate. The nonadherent BAL cells were then removed by rinsing the monolayer three times with culture medium. The remaining AM-enriched cells or lymphocytes $\left(2 \times 10^{6}\right)$ isolated from LDLN were then incubated in $1 \mathrm{ml}$ medium at $37^{\circ} \mathrm{C}$ and $5 \% \mathrm{CO}_{2}$ for $24 \mathrm{~h}$. The AM- or lymphocyte- 
conditioned media were collected, centrifuged $(1200 \times \mathrm{g}$ for $4 \mathrm{~min})$, and aliquots of the supernatants were stored at $-70^{\circ} \mathrm{C}$ until assayed.

The production of IL-10 in AM-conditioned media under various exposure conditions was quantified by the enzyme-linked immunosorbent assay (ELISA) using the OptEIA ELISA Sets (BD PharMingen) as previously described (Yin et al., 2004a). The levels of IL-12 in the AM-conditioned media and IL-4 and interferon (IFN)- $\gamma$ in the lymphocyteconditioned media and serum were quantified by ELISA using commercial ELISA kits (BioSource International, Inc., Camarillo, CA). The range of detection was: 7.8-500 $\mathrm{pg} / \mathrm{ml}$ for IL-4 and IL-12, 15.6-1000 pg/ml for IL-10, and 31.3-2000 pg/ml for IFN- $\gamma$.

The levels of IL-10, IL-6, and IL-1 $\beta$ in blood samples from saline, DEP (by i.t) and LPS (by i.p) treated rats were measured by ELISA using commercial ELISA kits (BioSource International, Inc., Camarillo, CA).

\subsection{Determination of Intracellular GSH}

Alveolar macrophages or lymphocytes $\left(2 \times 10^{5}\right.$ cells $)$ were plated in $96-$ well microplates, washed twice with PBS, and lysed with $240 \mu$ of a cold lysing buffer $(0.1 \%$ triton $\mathrm{X}-100$ in $0.1 \mathrm{M}$ sodium phosphate buffer, $5 \mathrm{mM}$ EDTA, $\mathrm{pH}$ 7.5). The lysates were acidified with $0.1 \mathrm{~N} \mathrm{HCl}(12 \mu \mathrm{l})$ and protein precipitated with $50 \%$ sulfosalicyclic acid $(12 \mu \mathrm{l})$ followed by centrifugation at $4^{\circ} \mathrm{C}$. Samples of the supernatants were assayed for total GSH according to the method of Buchmuller-Rouiller et al. (1995). Briefly, $50 \mu \mathrm{l}$ of cell supernatants or GSH standards were distributed to each well of a 96-well microplate, followed by $50 \mu \mathrm{l}$ of $2.4 \mathrm{mM} 5,5^{\prime}$-dithio-bis(2-nitrobenzoic acid). After the mixture was 
incubated at room temperature for $10 \mathrm{~min}, 50 \mu \mathrm{l}$ each of NADPH $(0.667 \mathrm{mg} / \mathrm{ml})$ and glutathione reductase $(40 \mu \mathrm{g} / \mathrm{ml})$ were added. The results of the GSH-specific reaction were monitored by OD readings at $405 \mathrm{~nm}$ every minute for $8 \mathrm{~min}$ with a Spectramax 250 plate spectrophotometer using Softmax Pro 2.6 software (Molecular Devices Corp., Sunnyvale, CA). One of the OD readings obtained with the most satisfied standard curve was selected as the final result.

\subsection{Determination of OVA-Specific IgE and IgG from Blood Serum}

Blood samples were collected during exsanguination from the vena cava of rats at sacrifice. The sera dilutions with 5\% horse serum albumin (HOSA)/PBS of 1/50 were analyzed for OVA-specific IgE and IgG. Diluted sera (100 $\mu \mathrm{l})$ were added to a 96-well plate (ICN Biomedicals, Horsham, PA) that had been previously coated with $200 \mu \mathrm{l}$ of $1 \%$ OVA carbonate coating buffer and blocked with a 5\% HOSA/coating buffer according to the method of Voller and Bidwell (1986). The plates were incubated overnight at $4^{\circ} \mathrm{C}$ and subsequently incubated with sheep anti-rat $\operatorname{IgE}(100 \mu 1,1: 2500$ dilution in HOSA/PBS, ICN Biomedicals, Costa Mesa, CA) which, according to manufacturer provided information, is specific for IgE class and does not cross-react with the other Ig classes, including IgG. The plates were then incubated with horseradish peroxidase-bound donkey anti-sheep IgG (100 $\mu 1,1: 5000$ dilution in HOSA/ PBS, ICN Biomedicals) for $2 \mathrm{~h}$ each at room temperature. The plates were washed 3 times after each incubation, treated with tetramethylbenzidine (Sigma), and read at $630 \mathrm{~nm}$. Ovalbumin-specific IgG was determined using goat anti-rat IgG (1:500 dilution in HOSA/PBS, Sigma) and peroxidase-labeled rabbit anti-goat IgG (1:12,500 dilution in 
HOSA/PBS, Sigma) as detection antibodies, following the same protocol described above. The serum from one animal exposed to OVA was assigned a value of 100 and used as a reference to obtain relative concentrations for the OVA-specific IgE and IgG in serum samples from each group.

\subsection{Analysis of Alveolar Type II (ATII) Cells}

\section{Isolation of ATII Cells.}

Type II cells were isolated using a standard protocol (Dobbs et al., 1986). Briefly, after removal of AM and blood cells, elastase solution (MP Biomedicals, Inc., Irvine, CA) was instilled via the trachea to dissociate the cells from lung tissue. The lung tissue was then minced in the presence of DNase I (Sigma) and FBS, and the suspension was sequentially filtered through nylon mesh. The cell suspension was plated on bacteriological plastic dishes coated with rat $\operatorname{IgG}$ (Sigma). After $1 \mathrm{~h}$ at $37^{\circ} \mathrm{C}$, the nonadherent ATII cells were removed from the plate to which AM and other immune cells were adherent. Cells obtained by this method contained 90\% ATII cells and $>90 \%$ excluded trypan blue.

\section{Western Blot Analysis.}

Expression of iNOS in ATII cells was determined by Western blot analysis using the same procedures for AM as described above, using cytoplasmic protein (30 $\mu \mathrm{g} / \mathrm{well})$ extracted from the freshly isolated ATII cells.

Flow Cytometric Analysis for ROS 
Freshly isolated ATII cells $\left(5 \times 10^{5}\right.$ cells) were washed with a washing buffer (PBS with $2 \% \mathrm{FBS}$ and $0.02 \% \mathrm{NaN}_{3}, \mathrm{pH} 7.4$ ), and re-suspended in DMEM/F12 medium (Invitrogen, Carlsbad, CA) containing $10 \mu \mathrm{M}$ of 4,5 diaminofluorescein diacetate (DAF, Sigma) or $5 \mu \mathrm{M}$ dihydroethidium (DHE, Molecular Probes, Eugene, OR) at $37^{\circ} \mathrm{C}$ for 30 min. After washing, the flow cytometric data were immediately collected with a BectonDickinson FACScan using FACScan Research Software (Becton-Dickinson Immunocytometry System, San Jose, CA), and analyzed using the PC-LYSYS software (Becton-Dickinson).

\subsection{Measurement of Airway Responsiveness}

Airway responsiveness was assessed by inducing airflow obstruction with a methacholine (MCh) aerosol using a noninvasive method (Hamelmann et al., 1997). Minute volume, tidal volume, breathing frequency, and enhanced pause (Penh) were obtained from conscious rats placed in a whole-body plethysmograph (Buxco Electronics Inc., Troy, NY). In this system, rats were unrestrained and tolerated repetitive measurements. Measurements of MCh responsiveness were obtained by exposing rats for 3 min to aerosolized PBS and incremental doses $(6.25-25 \mathrm{mg} / \mathrm{ml})$ of aerosolized MCh (Sigma) in PBS, and monitoring the breathing pattern for 3 min after each MCh challenge. The Penh values measured during each 3-min sequence were averaged and expressed, for each MCh concentration, as a percentage of baseline Penh values observed after PBS exposure.

\subsection{Analysis of B Lymphocytes from Spleens.}




\section{Isolation of B Lymphocytes.}

B lymphocytes from rats that had been treated with DEP and saline by i.t. were isolated from the spleen according to the manufacturer's protocol as described in the commercial MagCellect rat B cell isolation kit (R \& D Systems, MN). Cells were cultured in 96 - well round-bottomed microtiter culture plates in PRMI 1640 supplemented with $10 \%$ fetal calf serum, $2 \mathrm{mmol} / \mathrm{L}$ glutamine, $50 \mathrm{U} / \mathrm{ml}$ penicillin, and 50 $\mu \mathrm{g} / \mathrm{ml}$ streptomycin. B cells were seeded at $2 \times 10^{5}$ cells in $0.2 \mathrm{ml}$ complete PRMI per well cocultured with OVA (10mg/ml), IL-4 (10ng/ml) and LPS (10 $\mu \mathrm{g} / \mathrm{ml})$. Cultures were maintained at $37^{\circ} \mathrm{C}$ in a $5 \%$ atmosphere for $7,14,21$ days, at each time point the supernatant was collected for IgE measurement.

\section{Determination of OVA- specific IgE.}

IgE production by B lymphocytes was measured by the same analysis using the same procedures as for blood which were described above.

\subsection{Immunohistochemistry}

Before BAL, the right apical lobe was clamped off to prevent entry of lavage fluid. Following BAL and excision of LDLN, the clamp was removed and all lobes were inflated intratracheally with $10 \%$ formalin. The right apical lobe was processed within 24 $\mathrm{h}$ and embedded in paraffin. Sections were cut at $5 \mu \mathrm{m}$, deparaffinized in xylene, rehydrated, and stained for iNOS expression (Porter et al., 2002). Briefly, microwave antigen retrieval with citrate buffer ( $\mathrm{pH}$ 6.0) of rehydrated tissue was performed, 
followed by peroxidase blocking with a 1:1 mixture of $3 \% \mathrm{H}_{2} \mathrm{O}_{2}$ and methanol. Slides were incubated overnight at $4{ }^{\circ} \mathrm{C}$ with iNOS monoclonal antibody (N32020, Transduction Laboratories, Lexington, KY, 1:50 dilution). Localization was achieved using a streptavidin-biotinperoxidase system for use on rat specimens (K0609, Dako, Carpinteria, CA), with diaminobenzidene (Zymed Laboratories, San Francisco, CA) as the chromogen. Tissues were counterstained with Mayer's hematoxylin, dehydrated and covered with a coverslip. Non-stained sections where the primary antibody was omitted were obtained as negative controls, and sections from rats that had been intratracheally instilled with lipopolysacchride (LPS, Sigma, 10mg/kg) $24 \mathrm{~h}$ prior to sacrifice were stained for positive controls.

\subsection{Statistical Analysis}

Results are expressed as means \pm standard error (SE). The significance of the interaction among different treatment groups for different parameters at each time point was assessed by analysis of variance (ANOVA). The significance of difference between individual groups was analyzed using the Tukey-Kramer's Honestly Significant Different Test. For all analyses, the criterion of significance was set at $\mathrm{p}<0.05$. 


\section{RESULTS}

\subsection{Results for Protocol A}

\section{Lung Inflammation/Injury}

The LDH activity and albumin content in the first acellular BAL fluids of rats from various exposure groups were determined as markers of lung injury and cytotoxicity (Figure 1), whereas the numbers of recovered AM, Polymorphonuclear neutrophils (PMNs), lymphocytes, and eosinophils in BAL fluids were counted as an index of airway inflammation (Figure 2). These data show that both the BAL proteins and inflammatory cell counts for DEP exposure alone, when measured at 9 and 30 days after exposure, were not different from those of the air-exposed control, suggesting that DEP exposure did not cause lung injury at 9 or 30 days post-exposure. Exposure of rats to OVA (administered weekly at a dose of $40.5 \pm 6.3 \mathrm{mg} / \mathrm{m}^{3}$ ) caused significant increases in neutrophils, lymphocytes, eosinophils, albumin, and LDH activity in the rat lung after two exposures (measured at day 9). These increases were further substantiated in rats receiving 5 OVA exposures (measured at day 30), with a clear increase in total BAL cells apparent when comparing to that of the air-exposed control. DEP exposure alone did not induce inflammation but had a strong effect on OVA-induced inflammatory responses. As shown in Figures 1 and 2, the combined DEP and OVA exposure resulted in a significant decrease in OVA-induced inflammatory cell infiltration at day 30 and LDH and albumin at days 9 and 30 of DEP exposure. 


\section{Alveolar Macrophage Function}

$\mathrm{NO}$, an important marker of allergic inflammatory responses, in the acellular BAL fluid (Figure 3) and in AM-conditioned media (Figure 4) from various exposure groups was determined. The OVA exposure resulted in an increase in NO levels in the acellular BAL fluid and AM-conditioned media. This increase, however, was significantly attenuated in rats already exposed to DEP. DEP exposure alone did not affect NO production in samples obtained at day 9, although the NO levels in the BAL fluid at day 30 showed a moderate decrease comparing to that of the air-exposed controls.

Figure 5 shows the production of IL-10 and IL-12 by AM. DEP exposure had no significant effect on the production of IL-10 (Figure 5A) or IL-12 (Figure 5B) by AM recovered from rats 9 and 30 days after exposure. In contrast, OVA sensitization markedly elevated both IL-10 and IL-12 secretion by AM at both time points. The production of these cytokines by AM from rats exposed to both DEP and OVA was significantly lower than cells from rats exposed to OVA alone.

\section{Lymphocyte Population and Cytokine Production}

Figure 6 shows the numbers of lymphocytes, T cells, and their CD4 ${ }^{+}$and $\mathrm{CD} 8^{+}$ subsets recovered from LDLN for each exposure group on day 9 (Figure 6A) and day 30 (Figure 6B). DEP exposure was found to increase the numbers of total lymphocytes, $\mathrm{T}$ cells, and their $\mathrm{CD}^{+}$and $\mathrm{CD}^{+}$subsets in the LDLN compared to the air-exposed control. Likewise, OVA exposure significantly increased these cell counts on day 9 as well as on day 30. In the combined DEP and OVA exposure, however, there was a 
significant reduction in total lymphocytes, $\mathrm{T}$ cells and $\mathrm{CD} 4^{+}$and $\mathrm{CD} 8^{+}$subsets in the rat lung on day 30 when compared to data for the OVA-only exposure groups.

Levels of IL-4 and IFN- $\gamma$ in lymphocyte-conditioned media were below the detection limit of the ELISA kits used. The effects of DEP and OVA exposure on these cytokines, therefore, could not be determined.

\section{Intracellular GSH Levels in AM and Lymphocytes}

The effect of DEP and OVA exposures on intracellular GSH levels was studied in AM (Figure 7A) and lymphocytes (Figure 7B) from various exposure groups. DEP exposure alone slightly decreased GSH levels in AM, but markedly reduced GSH concentration in lymphocytes on day 9 and day 30. Exposure to OVA significantly decreased intracellular GSH in both cell types. Under the combined DEP and OVA exposure, AM and lymphocytes exhibited a greater depletion of intracellular GSH at day 9 and at day 30 compared to either DEP or OVA exposure alone.

\section{OVA-Specific IgE and IgG Levels in Serum}

In all samples collected on day 9, both serum IgE and IgG levels were under the detection limits. On day 30, neither air- nor DEP-exposed rats exhibit measurable IgE levels in the serum (Figure 8A). The OVA exposure, however, resulted in elevated IgE level, and this antibody production was further enhanced in rats pre-exposed to DEP (Figure 8A). The IgE level for the combined DEP and OVA exposure was 2.2-times higher than that of the OVA exposure alone. Similarly, OVA sensitization also increased 
OVA-specific IgG production, and in combination with DEP exposure, resulted in an even greater production of IgG (Figure 8B). The IgG level for the combined DEP and OVA exposure was about 2-times higher than that of the OVA exposure alone. These results indicate that DEP have an adjuvant effect on the production of both $\operatorname{IgG}$ and $\operatorname{IgE}$.

\section{Effects of DEP and OVA on Lung iNOS Expression}

Immunohistochemical analysis of iNOS in lung tissues showed that AM from various exposure groups did not stain for iNOS. At day 9 after DEP exposure, one of the five rats in the combined DEP and OVA exposure showed slightly positive iNOS staining in the airway epithelium. On day 30, two of the 5 rats from the combined exposure and one of five rats from the OVA exposure alone showed positive airway staining. In comparison, both AM and airway epithelia from LPS-treated animals were highly positive in iNOS staining (data not shown).

\subsection{Results for Protocol B}

\section{Lung Inflammation/Injury}

The LDH activity and albumin content in the first fraction of acellular BAL fluid (Figure 9) and the numbers of AM, eosinophils, neutrophils, and lymphocytes recovered from BAL fluid (Figure 10) were determined as measurements of lung injury and airway inflammation. None of DEP, OVA, or the combined OVA and DEP exposure induced elevated levels of LDH activity and albumin content, indicating that the exposure protocols did not cause significant lung injury that may complicate the experimental 
results. DEP exposure alone induced a moderate but significant increase in the number of neutrophils recovered from BAL fluid. OVA exposure induced a greater infiltration of neutrophils than DEP, and also resulted in infiltration of eosinophils and lymphocytes. The OVA-induced eosinophil count was markedly increased by DEP, even though DEP exposure alone had no effect on this cell type. In comparison, the OVA-mediated infiltration of neutrophils and lymphocytes was not augmented by DEP in the combined OVA-DEP exposure. These results show that DEP, under the current dose and exposure protocol, did not cause substantial inflammation to the lung or augment OVA- induced neutrophil and lymphocyte infiltration, but strongly enhanced the infiltration of eosinophils that mediates airway inflammation and AHR.

\section{Lymphocyte Population}

The numbers of total lymphocytes, $\mathrm{T}$ cells, and their $\mathrm{CD} 4^{+}$and $\mathrm{CD} 8^{+}$subsets in LDLN from rats sensitized and challenged by OVA were significantly higher than those of the air-exposed, non-sensitized rats (Figure 11). While DEP exposure alone moderately increased these lymphocyte counts, the combined DEP and OVA exposure resulted in a substantial increase in the numbers of $\mathrm{CD}^{+}$and $\mathrm{CD}^{+} \mathrm{T}$ cells compared to cell counts measured for OVA exposure alone.

\section{ROS and NO Production}

AM from various exposure groups were assessed for ROS production by measurement of CL in response to zymosan stimulation (Figure 12). Exposure to DEP or OVA alone had no effect on CL production by AM. However, a substantial elevation in 
CL was observed for the combined OVA and DEP exposure group. The production of $\mathrm{NO}$, a highly reactive nitrogen intermediate, was measured in the acellular BAL fluid (Figure 13) and in AM-conditioned media (Figure 14). Both OVA and DEP exposures resulted in increased presence of $\mathrm{NO}$ in the acellular BAL fluid and in AM-conditioned media, and these levels were further increased in samples from the combined OVA and DEP exposure.

The effect of DEP exposure on OVA-induced generation of nitrogen species and reactive oxygen was also studied in ATII cells isolated from the rats. The intracellular presence of NO (Figure 15) and superoxide (Figure 16) were determined by flow cytometry after the cells were stained with DAF-DA and DHE, the relative specific probes for intracellular generation of $\mathrm{NO}$ and superoxide, respectively. The ATII cells from OVA-exposed rats exhibited higher percentage of cells that produce NO and superoxide than those of the air-exposed, non-sensitized rats. While DEP exposure alone increased the percentage of ATII cells that produce superoxide but not NO, the combined DEP and OVA exposure resulted in significant increase in the percentage of the cells that produce NO (Figure 15) and superoxide (Figure 16) over the control.

\section{GSH Levels in AM and Lymphocytes}

The levels of GSH in AM and lymphocytes from DEP or OVA-exposed rats were not significantly changed compared to the controls (Figure 17). Under combined DEP and OVA exposure, however, the intracellular GSH levels were significantly reduced in both cell types compared to all other groups. 


\section{OVA-specific IgE and IgG Production}

In all the samples collected from non-sensitized rats, both IgE and IgG concentrations were under the detection limits. OVA sensitization resulted in a significant production of antigen-specific IgE, and its level was 2-times higher in rats that received the combined OVA and DEP exposure than in rats sensitized to OVA but exposed to air (Figure 18A). OVA sensitization also resulted in the production of OVA-specific IgG, whose level was likewise increased, 1.7 fold, by DEP exposure (Figure 18B). DEP exposure alone had no effect on IgG production. These results indicate that DEP exposure augments the immune responses of rats to OVA in the production of allergen-specific IgE and IgG.

\section{Airway Reactivity}

The effect of DEP exposure on OVA-induced AHR was evaluated from Penh values in rats from various treatment groups following MCh challenge (Figure 19). The baseline Penh values were not significantly affected by OVA or DEP. However, airway responsiveness to $\mathrm{MCh}$ was significantly increased in rats from the combined OVA and DEP, whereas it was not in rats from other exposure groups. Thus, DEP exposure had a synergistic effect with OVA on inducing AHR in rats.

\section{iNOS Expression}

Immunohistochemical analysis for iNOS expression in lung tissues showed no staining of AM in any exposure group. However, the airway epithelium was found positive in all five rats from the combined DEP and OVA exposure, 3 out of 5 rats from 
DEP or OVA exposure alone, and 2 out of 5 rats from the air-exposed, non-sensitized control (data not shown). The OVA exposure was also found to increase iNOS expression in AM and ATII cells isolated from the rats as detected by Western blot analysis (Figure 20). Although DEP exposure alone did not induce iNOS in AM and ATII cells, the combined DEP and OVA exposure resulted in a significantly higher iNOS expression in these cells than those from any other groups.

\subsection{Results of Effects of DEP on B Lymphocytes and Cytokine Production}

\section{OVA-specific IgE Production}

OVA-specific Ig E production by B lymphocytes isolated from saline, DEP, and LPS exposed rats showed no difference on day7, day14 and day21 (figure 21).

\section{Cytokine Production}

IL-1 $\beta$ and IL-10 production in blood serum showed no difference between different treatment groups (figure $22+23$ ). However, LPS exposure resulted in a great increase in the IL-6 production in blood samples compared with that from saline and DEP treated rats (figure 24). 

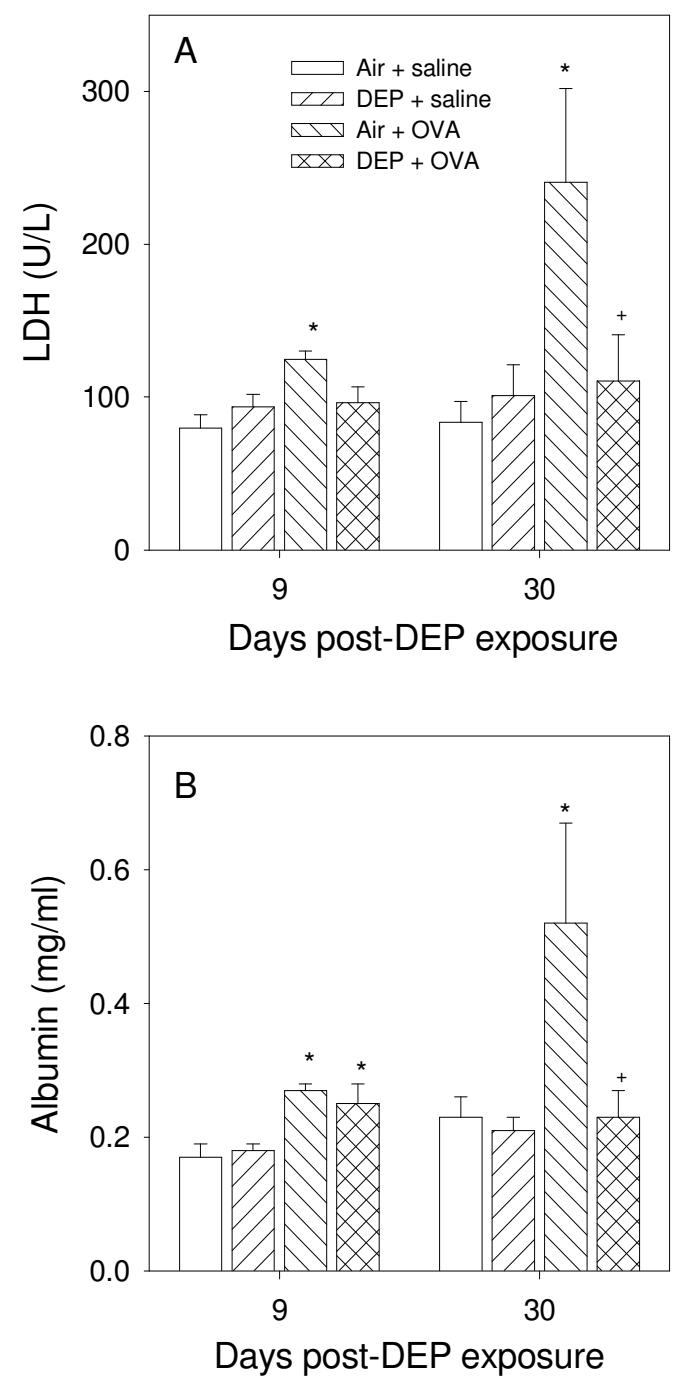

Figure 1. Yield of (A) LDH activity and (B) albumin content in bronchoalveolar lavage (BAL) fluid from rats $(n=5)$. * Significantly different from air + saline group, $p<0.05$; ${ }^{+}$Significantly different from air + OVA group, $p<0.05$. 

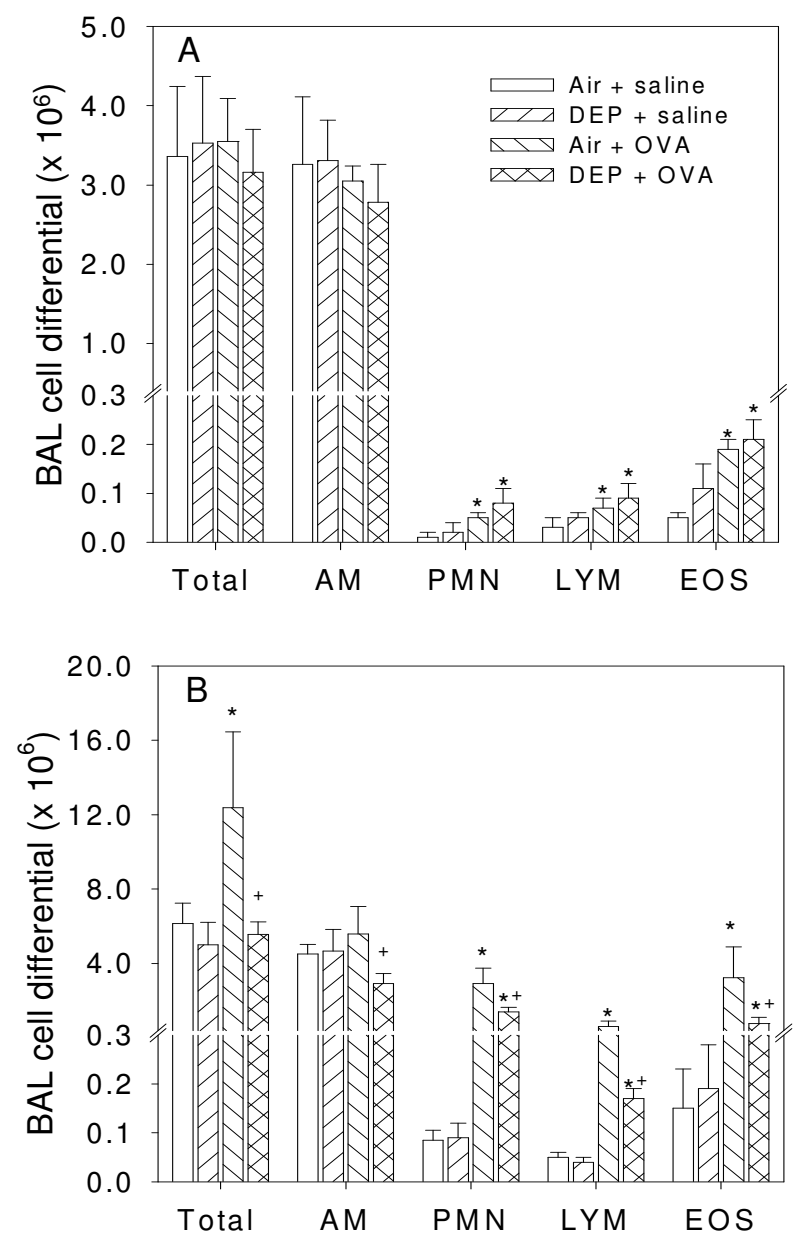

Figure 2. Total numbers and differentials of BAL cells recovered at (A) day 9 and (B) day 30 post-DEP exposure $(\mathrm{n}=5)$. "Significantly different from air + saline group, $p<$ $0.05 ;^{+}$Significantly different from air + OVA group, $p<0.05$. AM: alveolar macrophages, PMN: polymorphonuclear neutrophils, LYM: lymphocytes, EOS: eosinophils. 


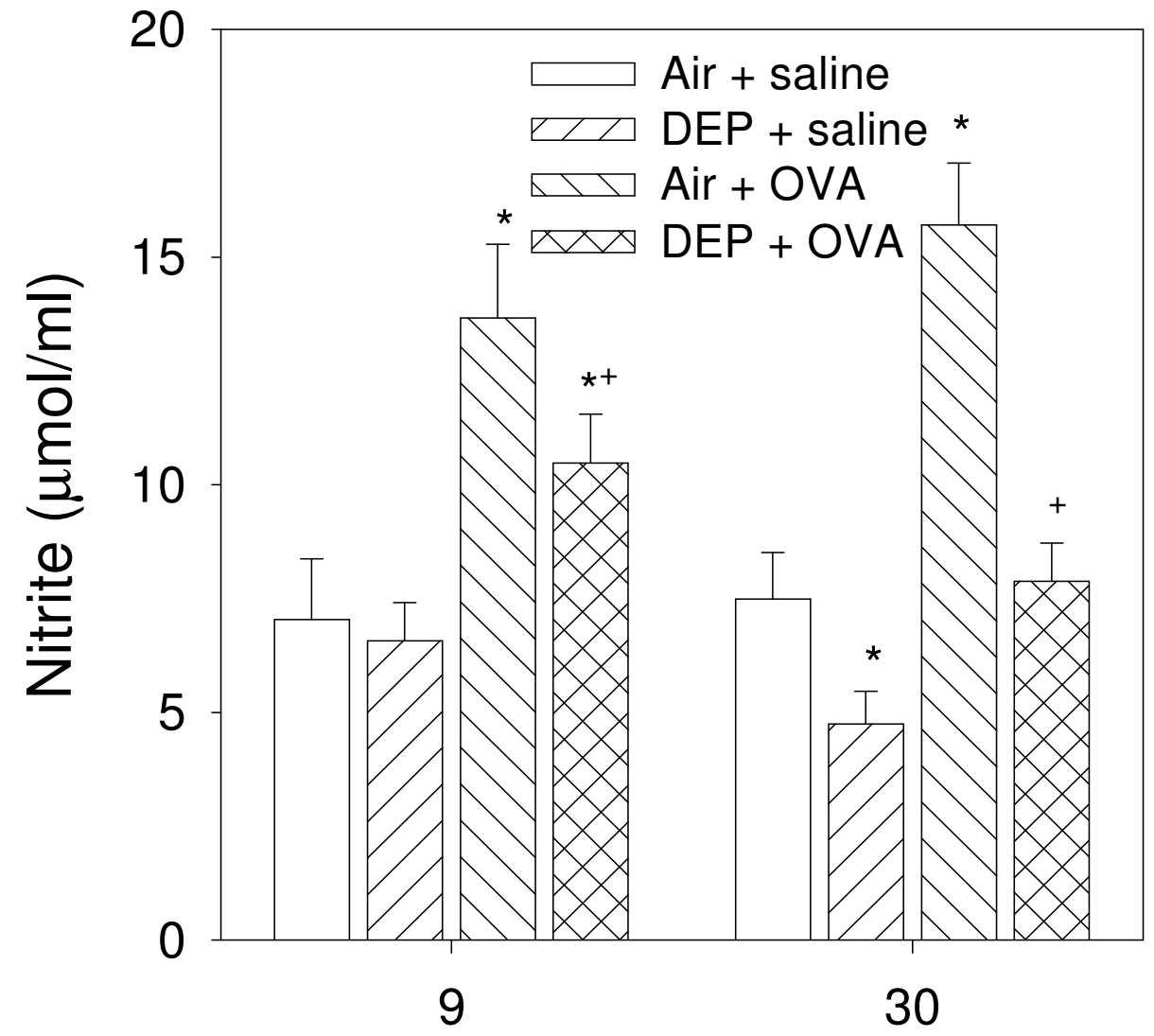

Figure 3. Concentrations of NO in BAL fluid. "Significantly different from air + saline group, $p<0.05{ }^{+}$Significantly different from air + OVA group, $p<0.05$. 


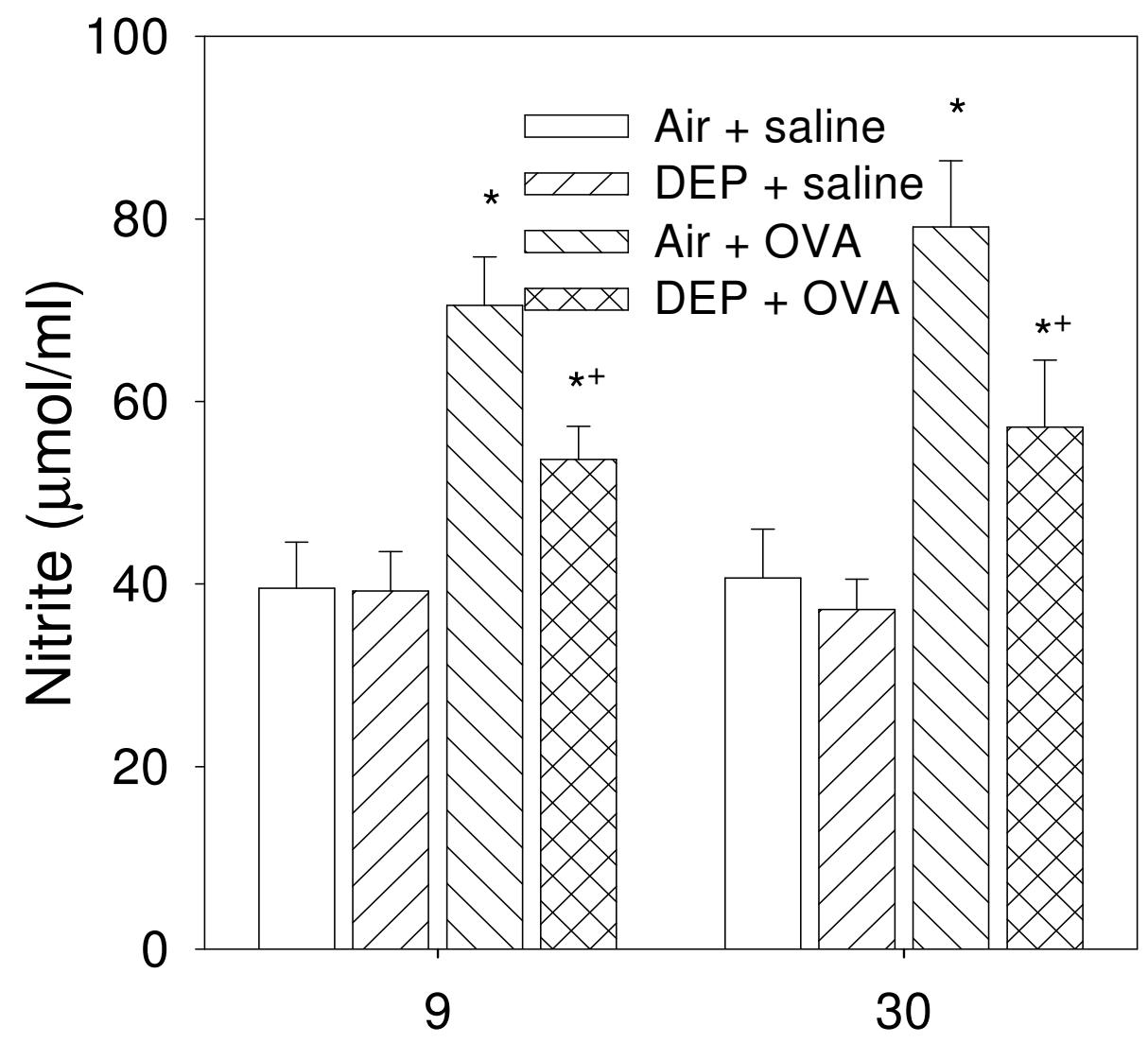

Figure 4. Concentrations of NO in AM-conditioned media $(\mathrm{n}=5)$. " Significantly different from air + saline group, $p<0.05 ;{ }^{+}$Significantly different from air + OVA group, $p<0.05$. 

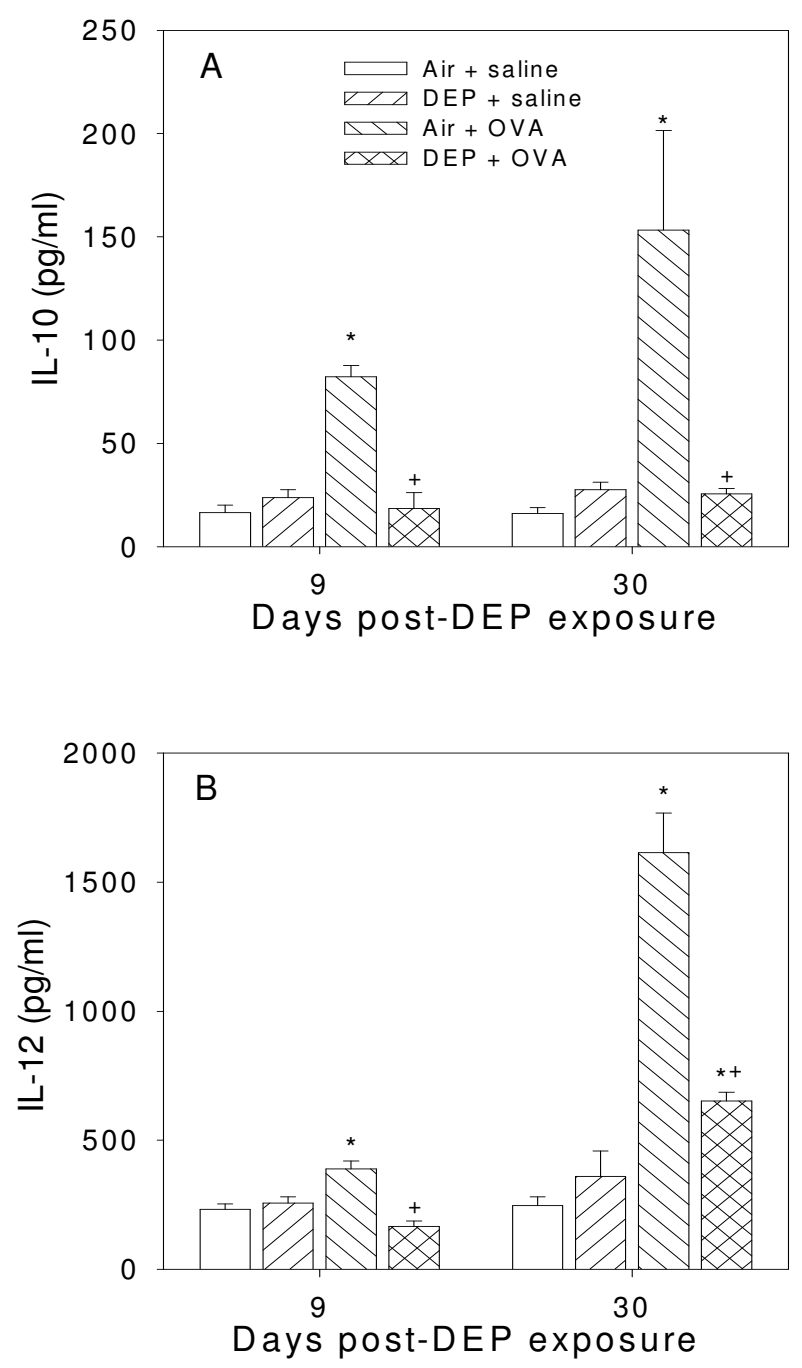

Figure 5. Production of (A) IL-10 and (B) IL-12 by AM. AM were incubated at $37^{\circ} \mathrm{C}$ and $5 \% \mathrm{CO}_{2}$ for $24 \mathrm{~h}$. Concentrations of the cytokines in the culture media were quantified $(\mathrm{n}=5)$. *Significantly different from air + saline group, $p<0.05$;

${ }^{+}$Significantly different from air + OVA group, $p<0.05$. 

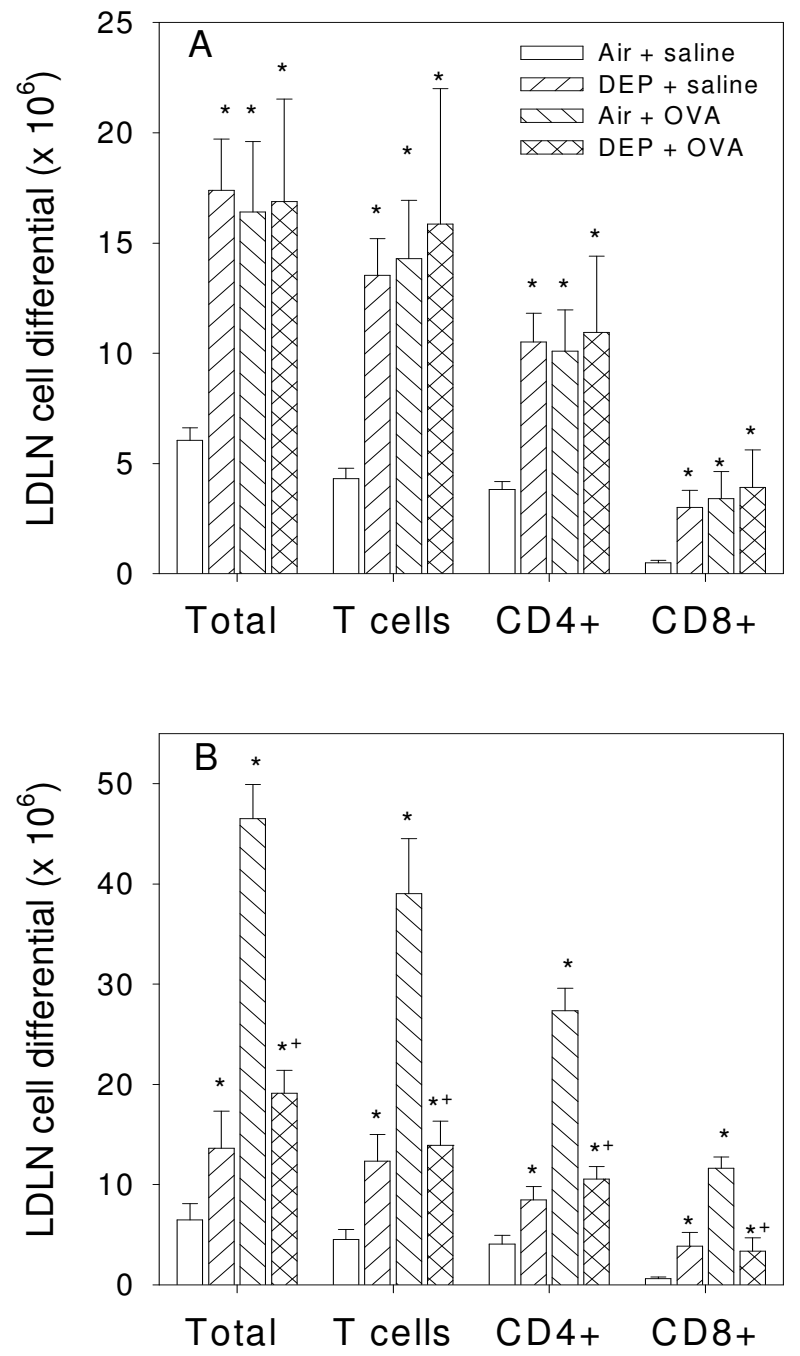

Figure 6. Lymphocyte differentiation in lung-draining lymph nodes (LDLN) of rats at (A) day 9 and (B) day 30 post-DEP exposure $(\mathrm{n}=5)$. "Significantly different from air + saline group, $p<0.05 ;{ }^{+}$Significantly different from air + OVA group, $p<0.05$. 

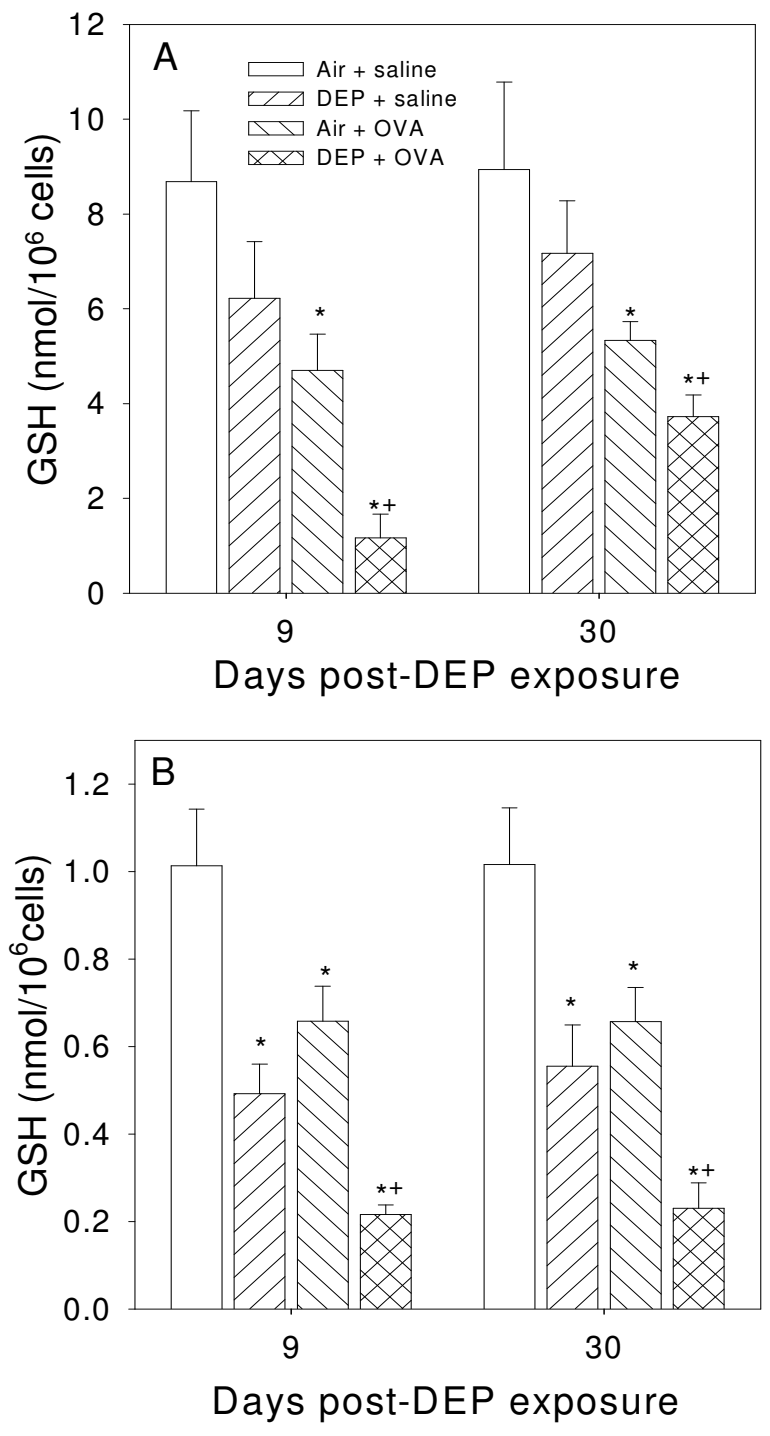

Figure 7. Concentrations of intracellular GSH in (A) AM and (B) lymphocytes isolated from lung-draining lymph nodes of rats at day 9 and day 30 post-DEP exposure $(\mathrm{n}=5)$. "Significantly different from air + saline group, $p<0.05$; ${ }^{+}$Significantly different from air + OVA group, $p<0.05$. 

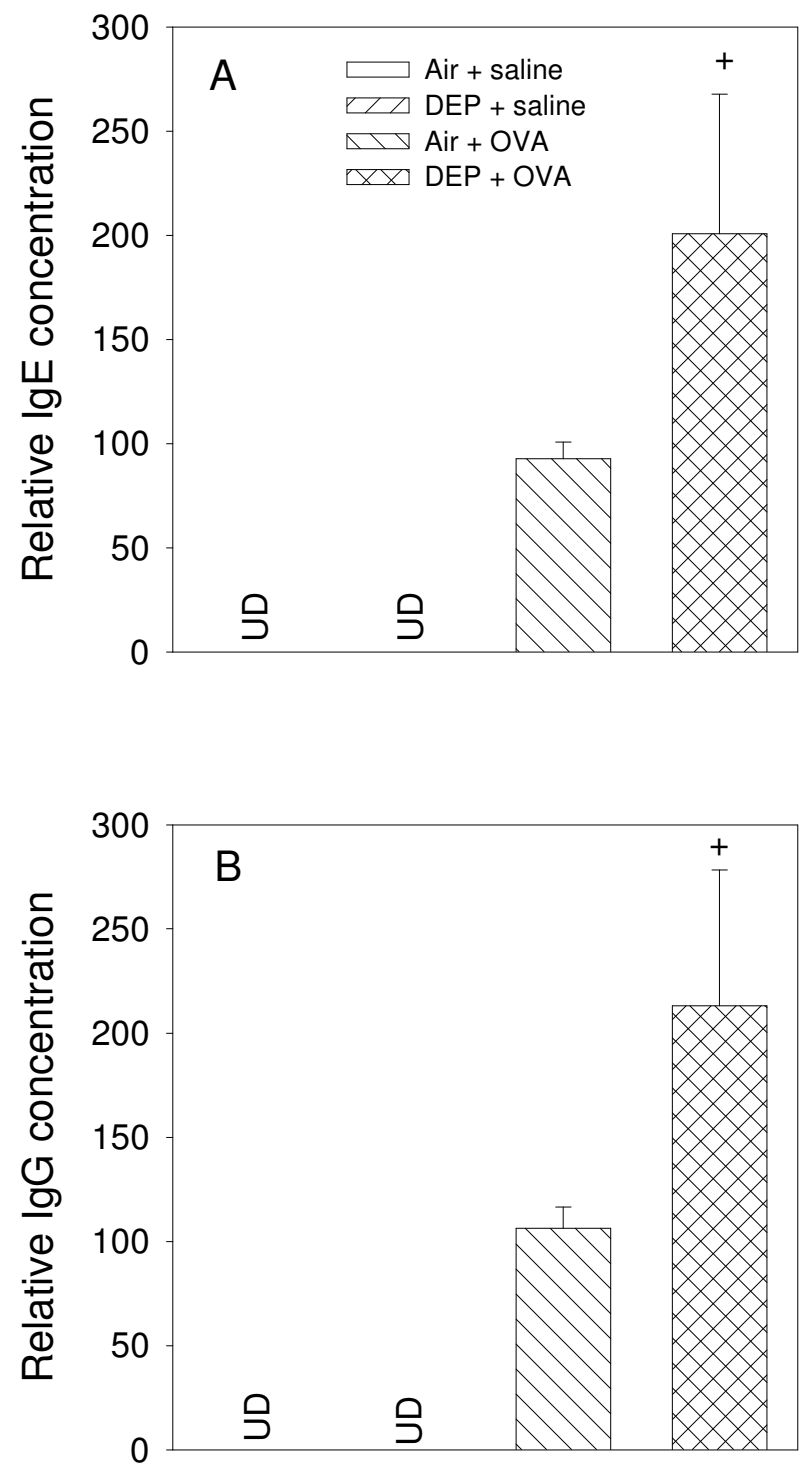

Figure 8. Relative concentrations of OVA-specific (A) $\operatorname{IgE}$ and (B) $\operatorname{IgG}$ in serum collected at day 30 post-DEP exposure $(\mathrm{n}=5)$. ${ }^{+}$Significantly different from air + OVA group, $p<0.05$. UD: Under detection limit. 

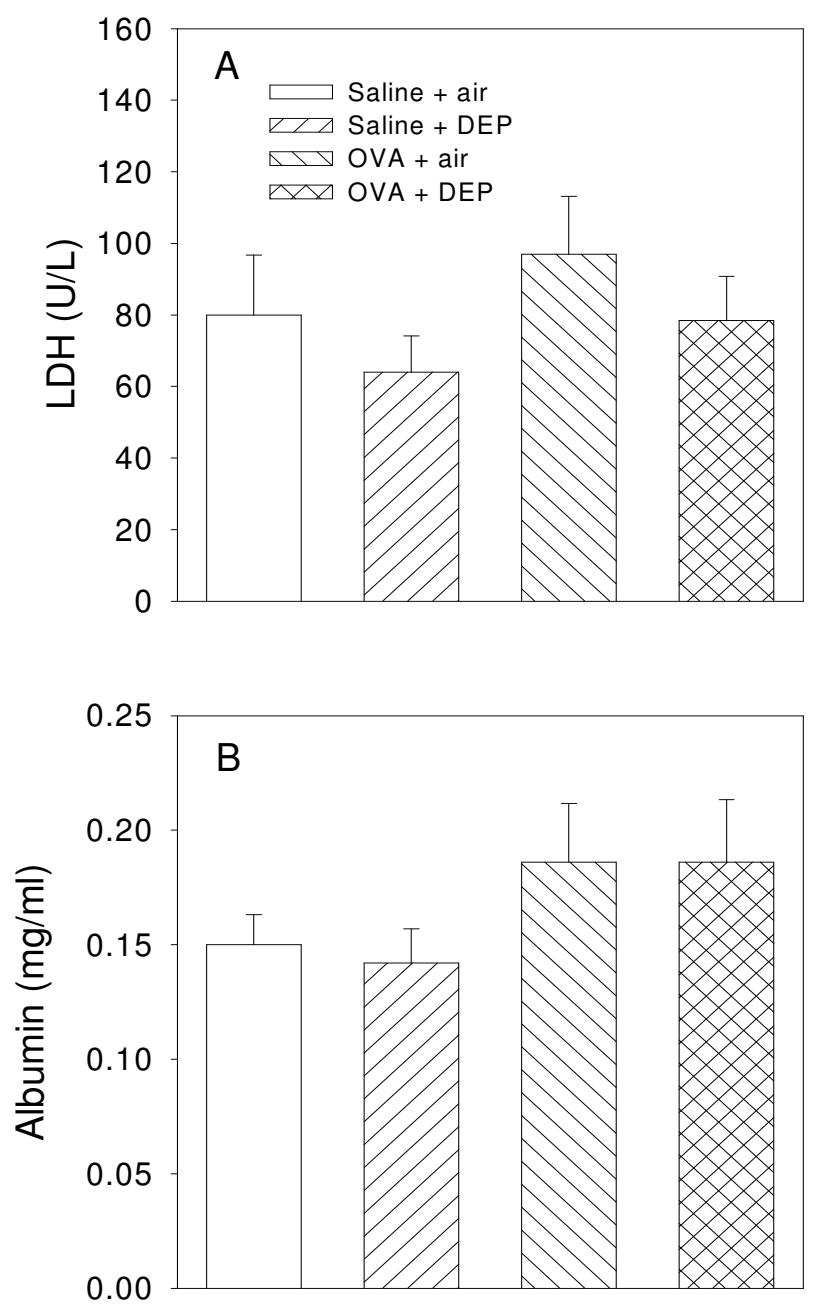

Figure 9. LDH activity (A) and albumin content (B) in the first fraction of BAL fluid collected from rats. Values are expressed as the means $\pm S E(n=5)$. No significant difference was found among any treatments for both measurements. 

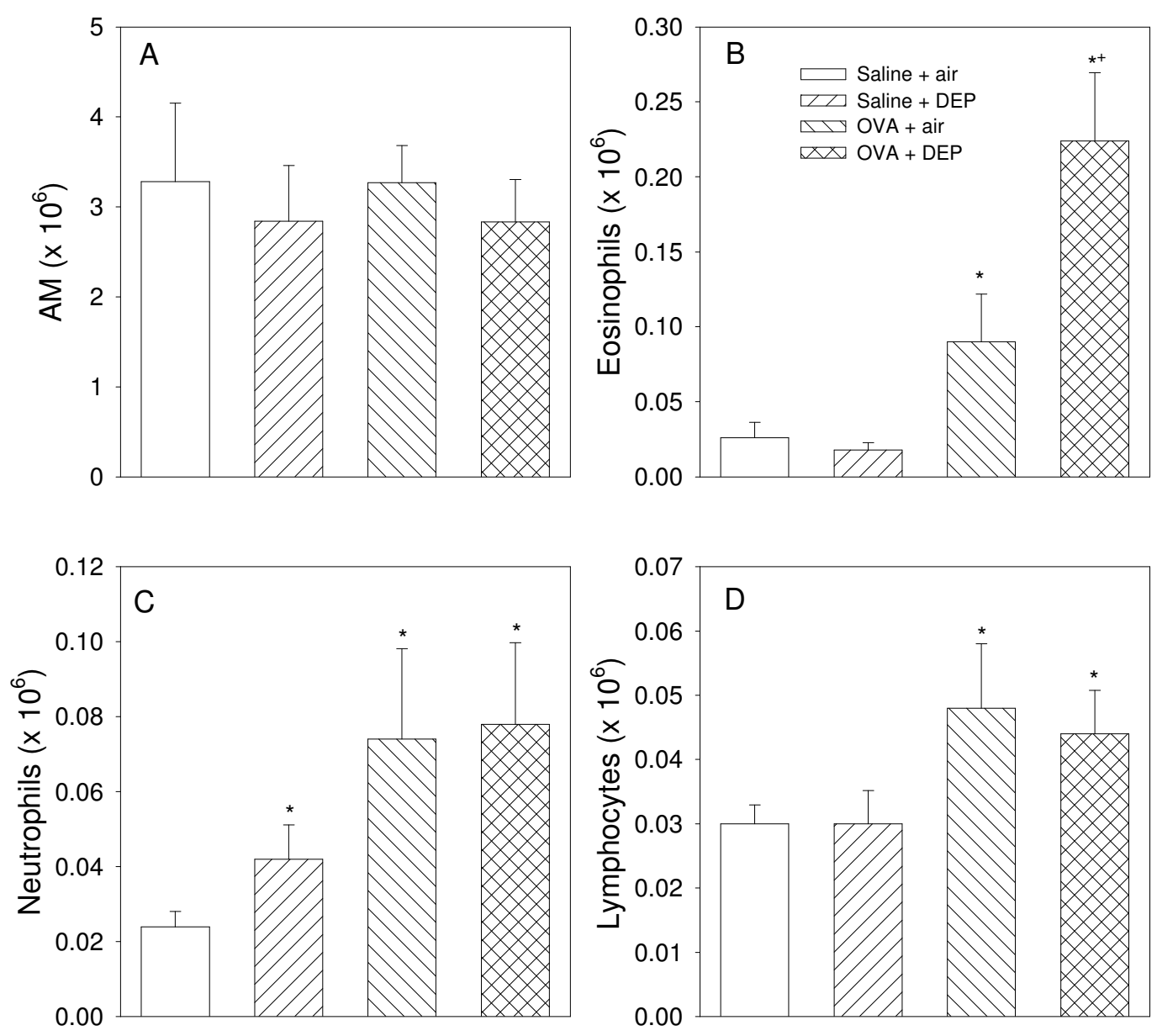

Figure 10. Differentials of BAL cells recovered from rats. Values are expressed as the means \pm SE $(n=5)$. *Significantly different from air + saline group, $p<0.05$

${ }^{+}$Significantly different from air + OVA group, $p<0.05$. 

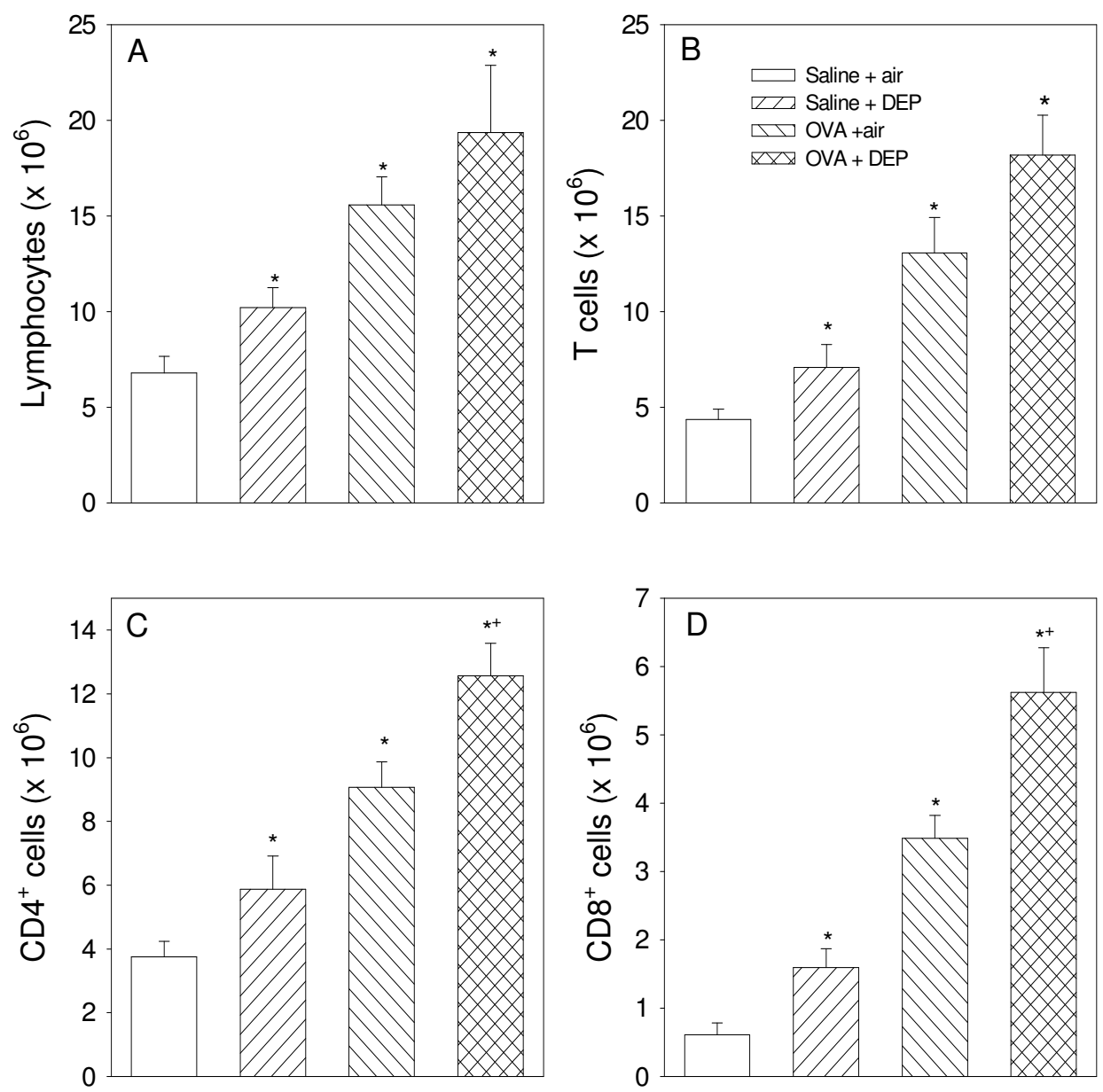

Figure 11. Numbers and differentials of lymphocytes isolated from lung-draining lymph nodes (LDLN) of rats. Values are expressed as the means \pm SE $(n=5)$. "Significantly different from air + saline group, $p<0.05 ;{ }^{+}$Significantly different from air + OVA group, $p<0.05$. 


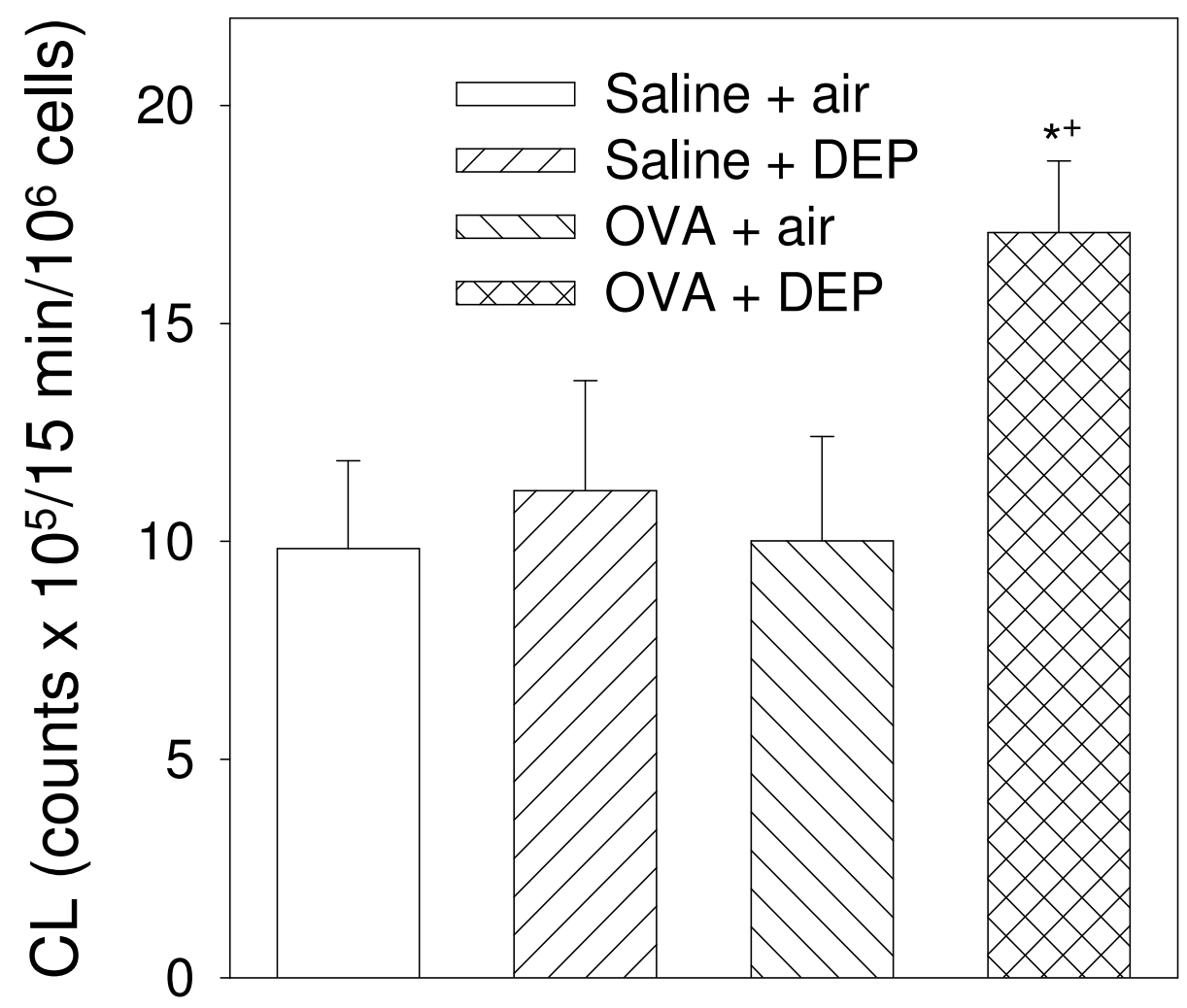

Figure 12. Zymosan-stimulated CL by AM. Values are expressed as the means \pm SE (n $=5$ ). ${ }^{*}$ Significantly different from air + saline group, $p<0.05 ;{ }^{+}$Significantly different from air + OVA group, $p<0.05$. 


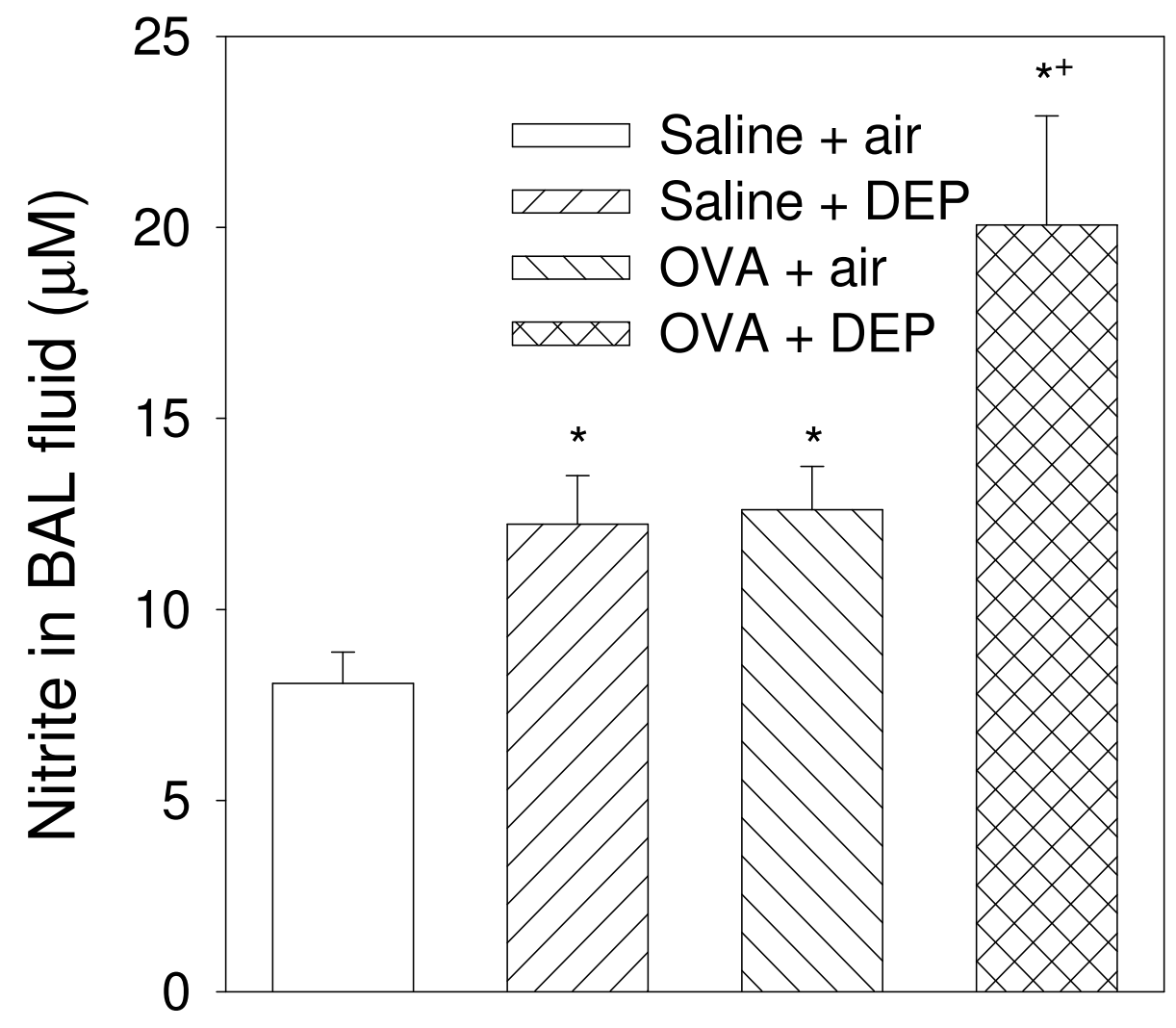

Figure 13. Nitrite in BAL fluid. Values are expressed as the means $\pm S E(n=5)$.

*Significantly different from air + saline group, $p<0.05 ;{ }^{+}$Significantly different from air + OVA group, $p<0.05$. 


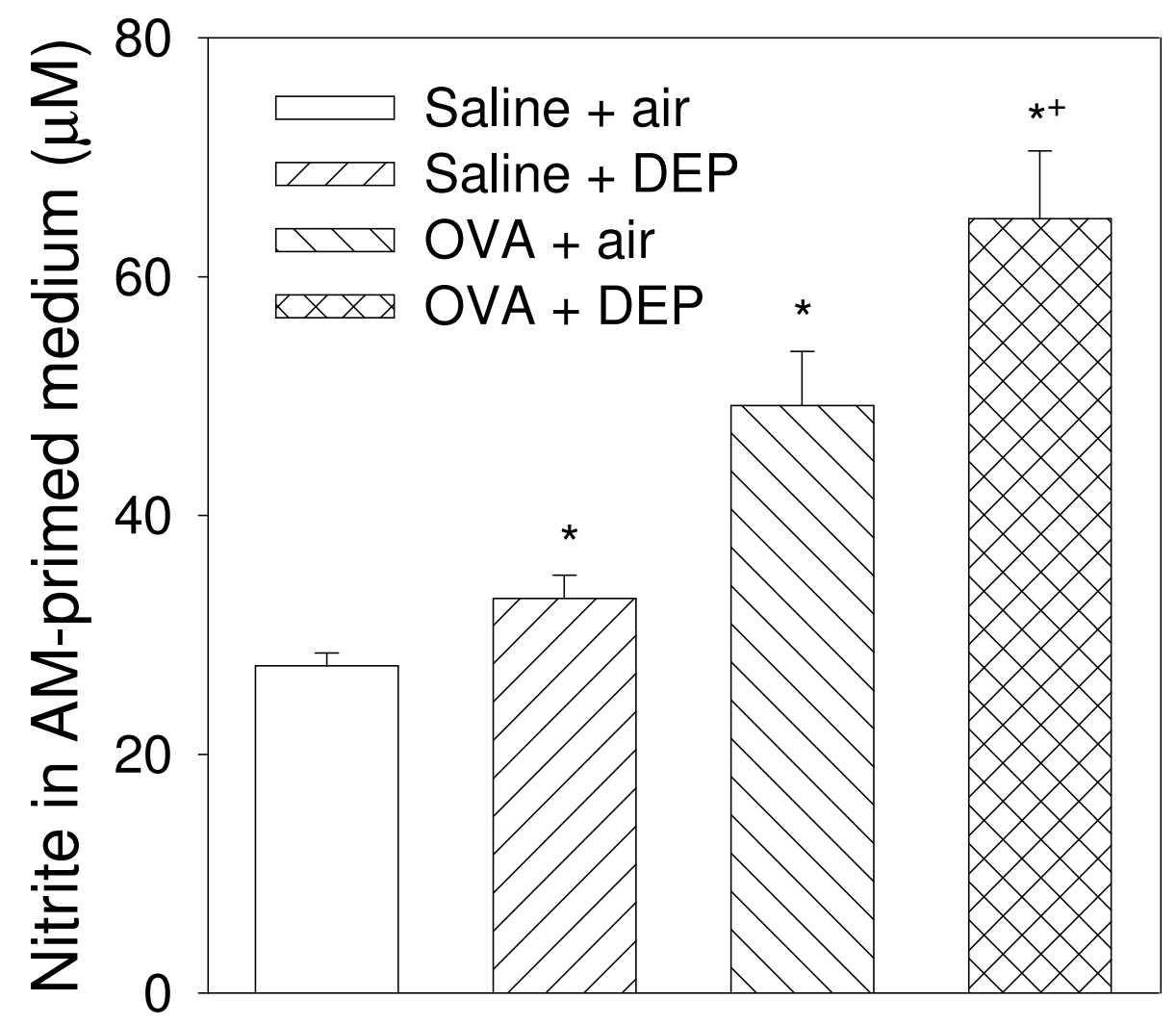

Figure 14. Nitrite in AM-conditioned media. Values are expressed as the means \pm SE (n $=5$ ). ${ }^{*}$ Significantly different from air + saline group, $p<0.05 ;{ }^{+}$Significantly different from air + OVA group, $p<0.05$. 


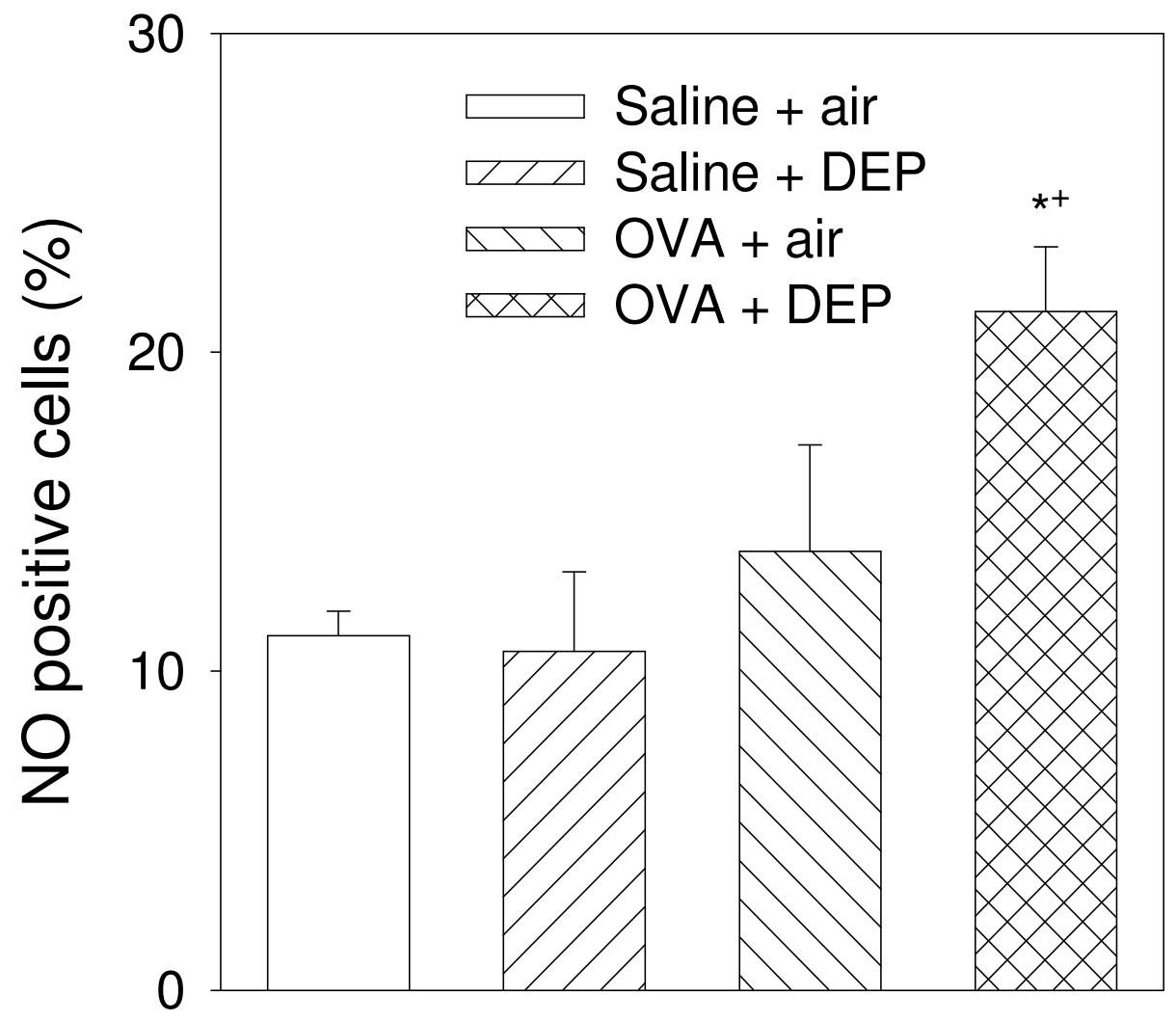

Figure 15. Flow cytometric analysis of intracellular generation of NO by ATII cells.

Values are expressed as the means \pm SE $(n=5)$. *Significantly different from air + saline group, $p<0.05 ;{ }^{+}$Significantly different from air + OVA group, $p<0.05$. 


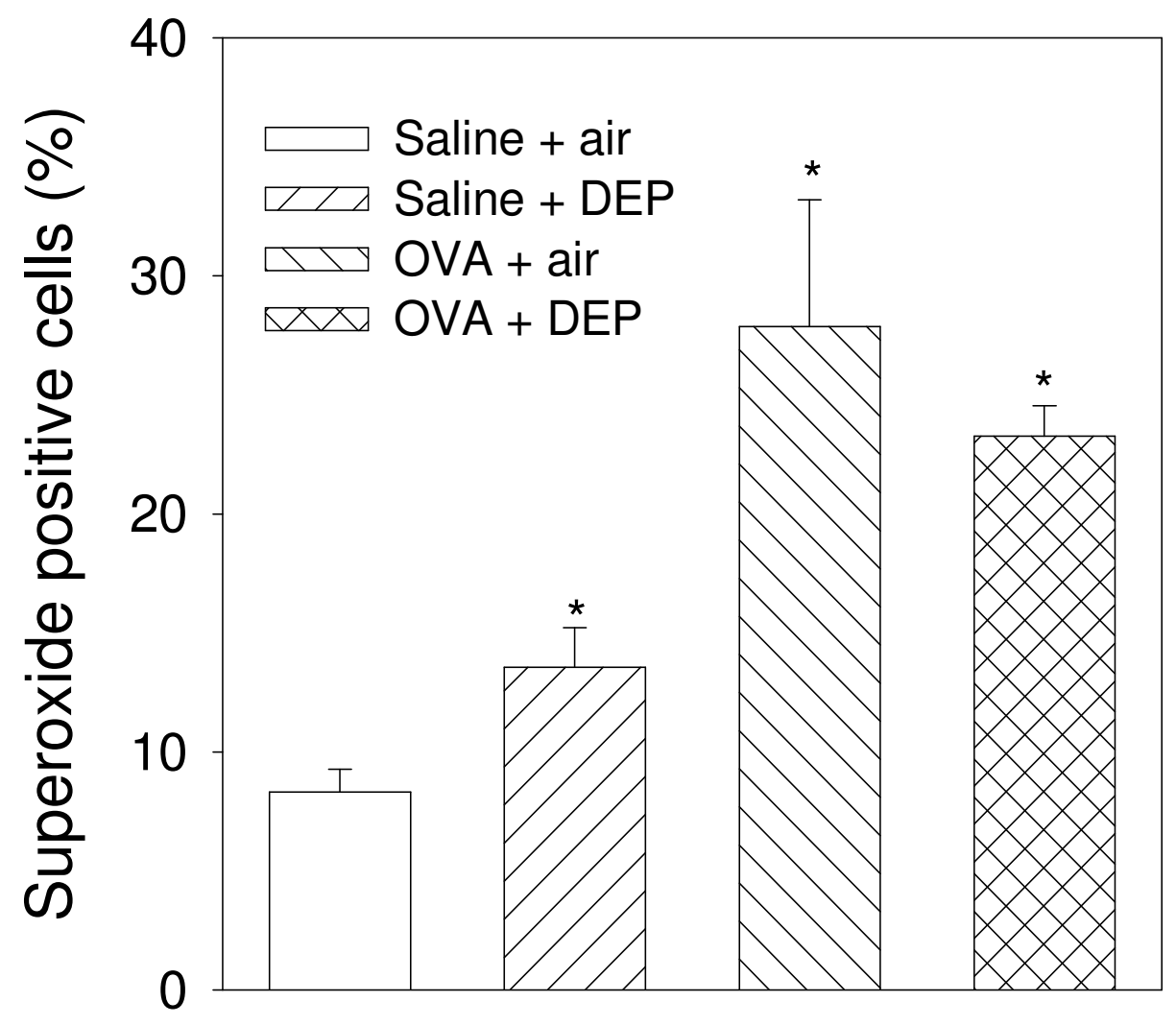

Figure 16. Flow cytometric analysis of intracellular generation of superoxide by ATII cells. Values are expressed as the means $\pm \mathrm{SE}(\mathrm{n}=5)$. "Significantly different from air + saline group, $p<0.05 ;{ }^{+}$Significantly different from air + OVA group, $p<0.05$. 

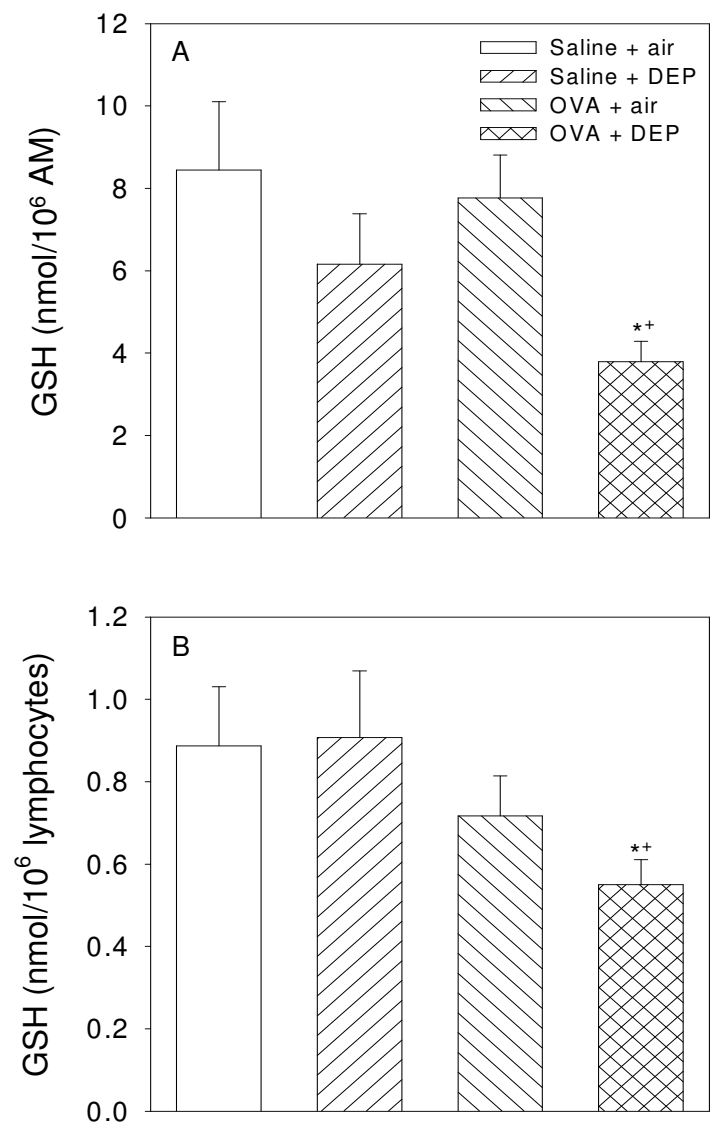

Figure 17. Concentration of intracellular GSH in AM (A) and lymphocytes (B) isolated from lung-draining lymph nodes of rats. Values are expressed as the means $\pm \operatorname{SE}(n=5)$. "Significantly different from air + saline group, $p<0.05$; ${ }^{+}$Significantly different from air + OVA group, $p<0.05$. 

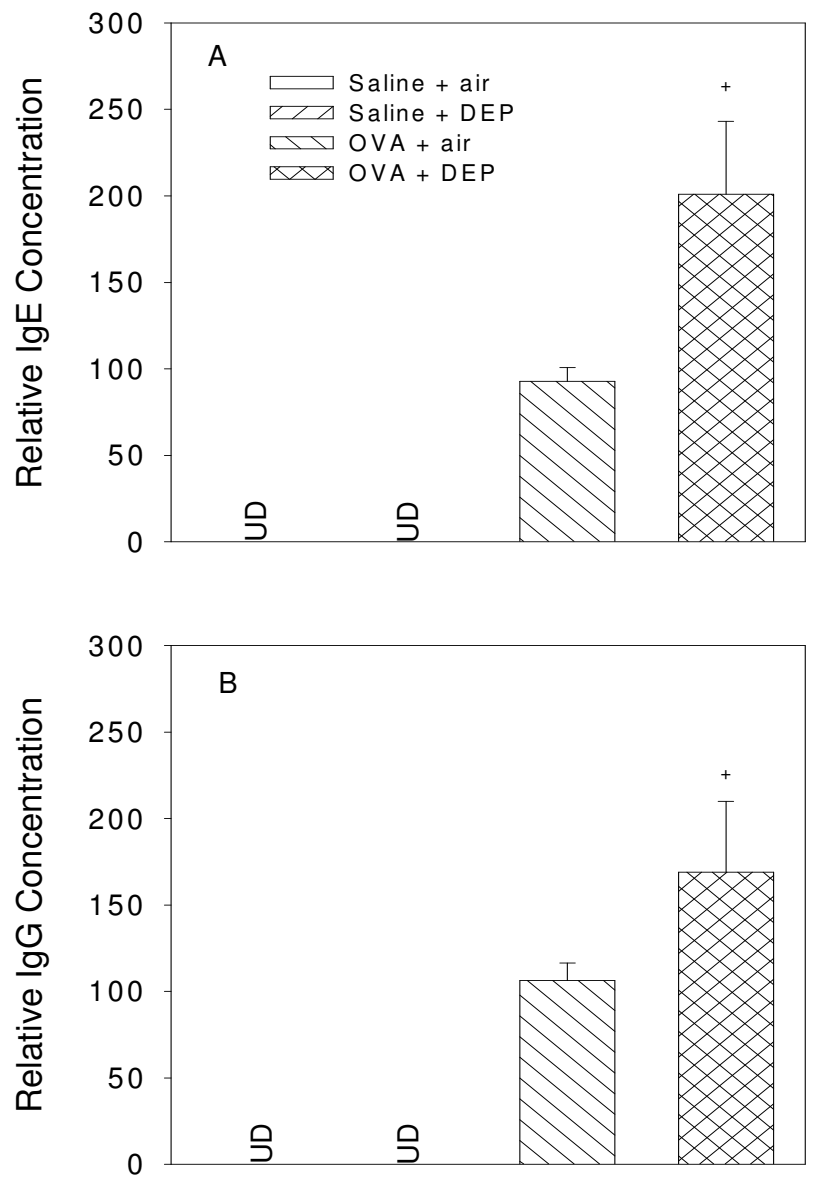

Figure 18. Relative concentrations of OVA-specific $\operatorname{IgE}(A)$ and $\operatorname{IgG}(\mathrm{B})$ in serum collected from rats. Values are expressed as the means \pm SE $(n=5) .{ }^{+}$Significantly different from air + OVA group, $p<0.05$. UD: under detection limit. 


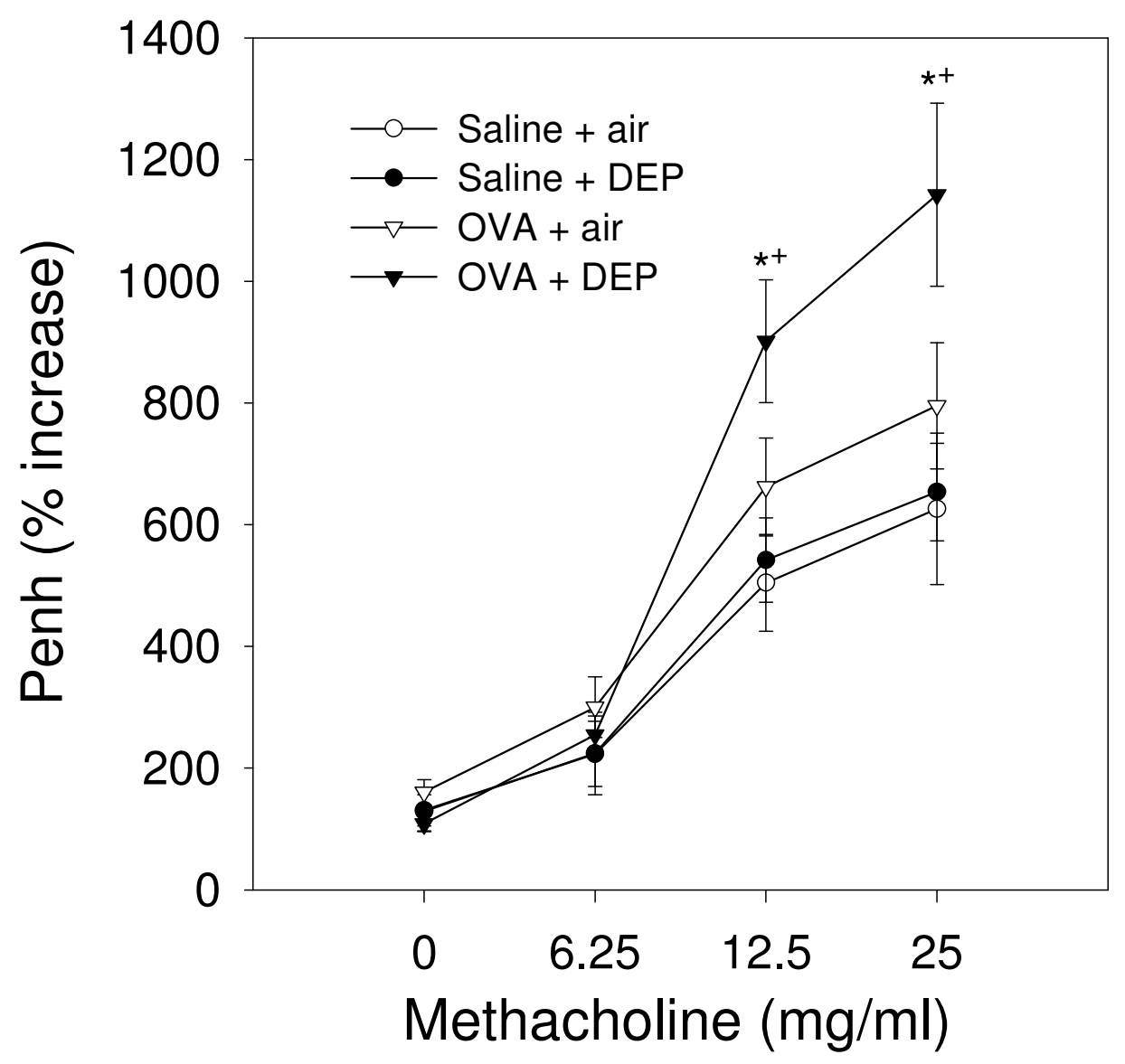

Figure 19. Airway hyperresponsiveness in rats $24 \mathrm{~h}$ after OVA challenge.

Responsiveness was assessed by measuring enhanced pause (Penh) values of rats in response to inhaled methacholine $(\mathrm{Mch})$ aerosolized from $\mathrm{MCh}$ solutions in PBS at various concentrations $(6.25-25 \mathrm{mg} / \mathrm{ml})$. Values are expressed as the means $\pm S E(n=5)$ of the percentage of baseline Penh values after PBS exposure. *Significantly different from air + saline group, $p<0.05$; ${ }^{+}$Significantly different from air + OVA group, $p<$ 0.05 . 


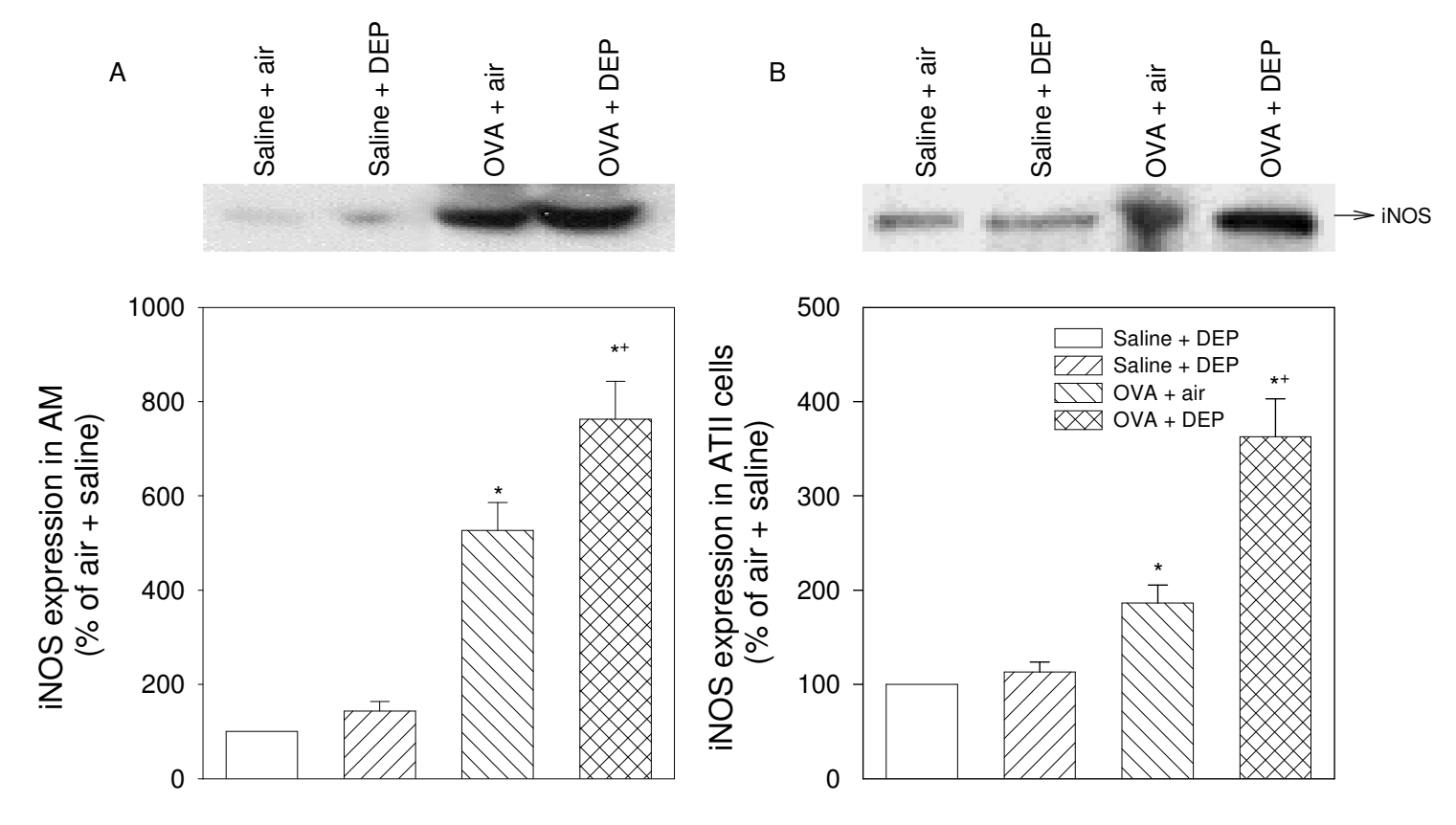

Figure 20. Western blot analysis of iNOS expression in AM (A) and ATII cells (B). The top panels show representive results of the Western blot analysis and the bottom panels show percentage increase in band density which represents the means $\pm S E(n=5)$. *Significantly different from air + saline group, $p<0.05 ;{ }^{*}$ Significantly different from air + OVA group, $p<0.05$. 


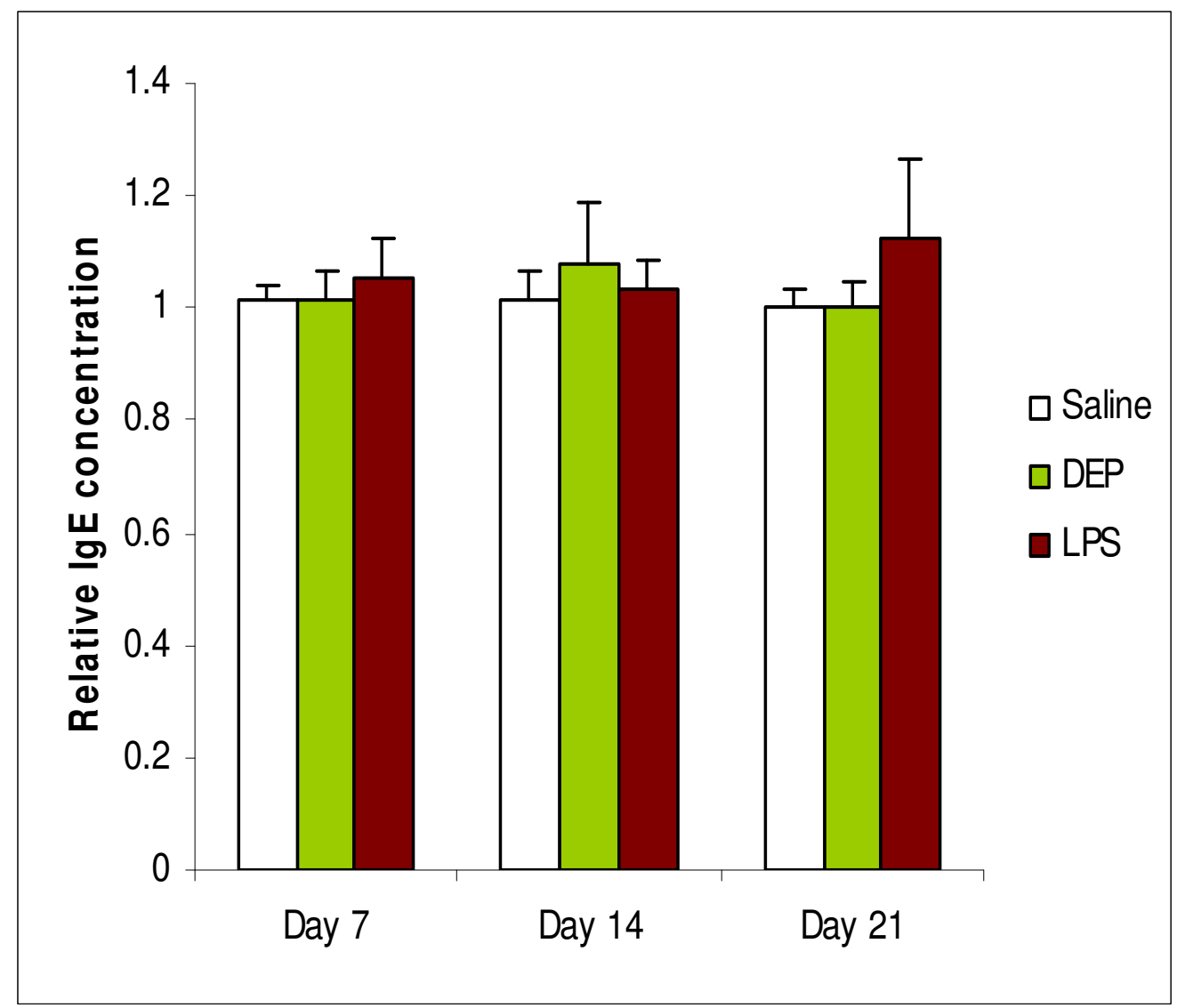

Figure 21. Relative concentrations of OVA-specific IgE in B cells isolated from spleens of saline, DEP and LPS treated rats. Values are expressed as the means $\pm \operatorname{SE}(n=4)$. 


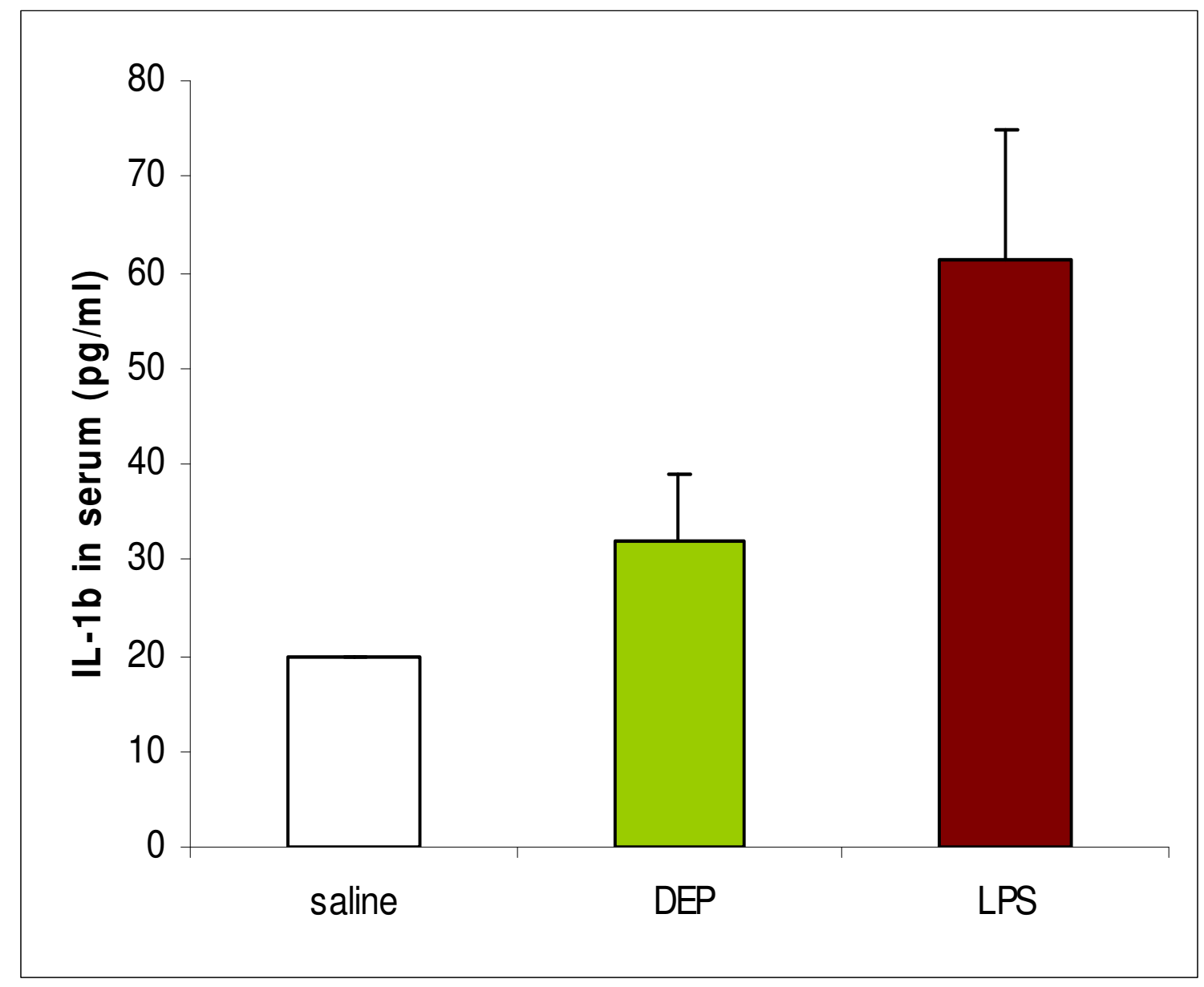

Figure 22. Production of IL-1 $\beta$ in serum in different exposure groups. BN rats were exposed to saline, DEP by i.t. and LPS by i.p.. Values are expressed as the means \pm SE (n $=4)$. 


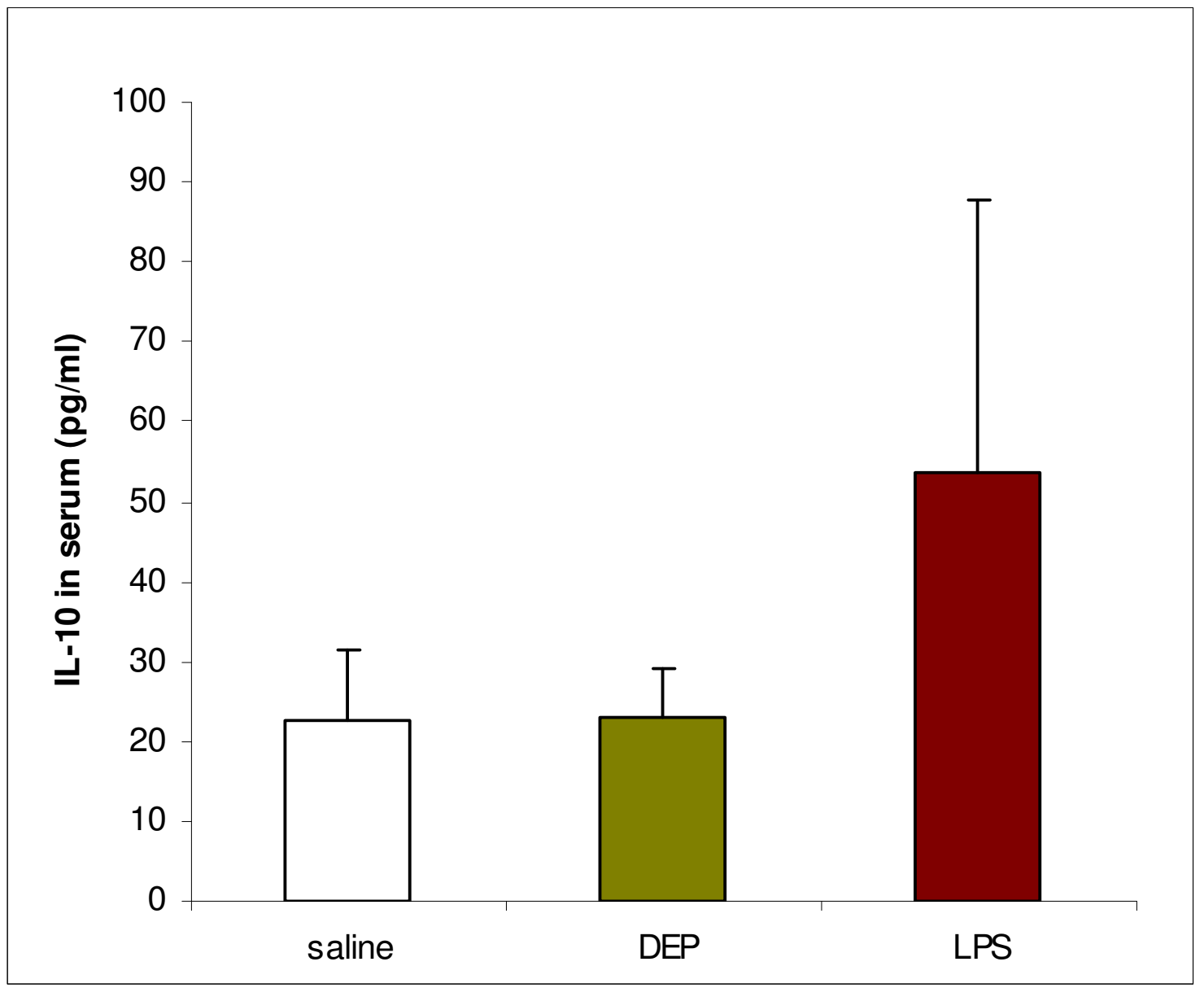

Figure 23. Production of IL-10 in serum in different exposure groups. BN rats were exposed to saline, DEP by i.t. and LPS by i.p.. Values are expressed as the means \pm SE (n $=4)$. 


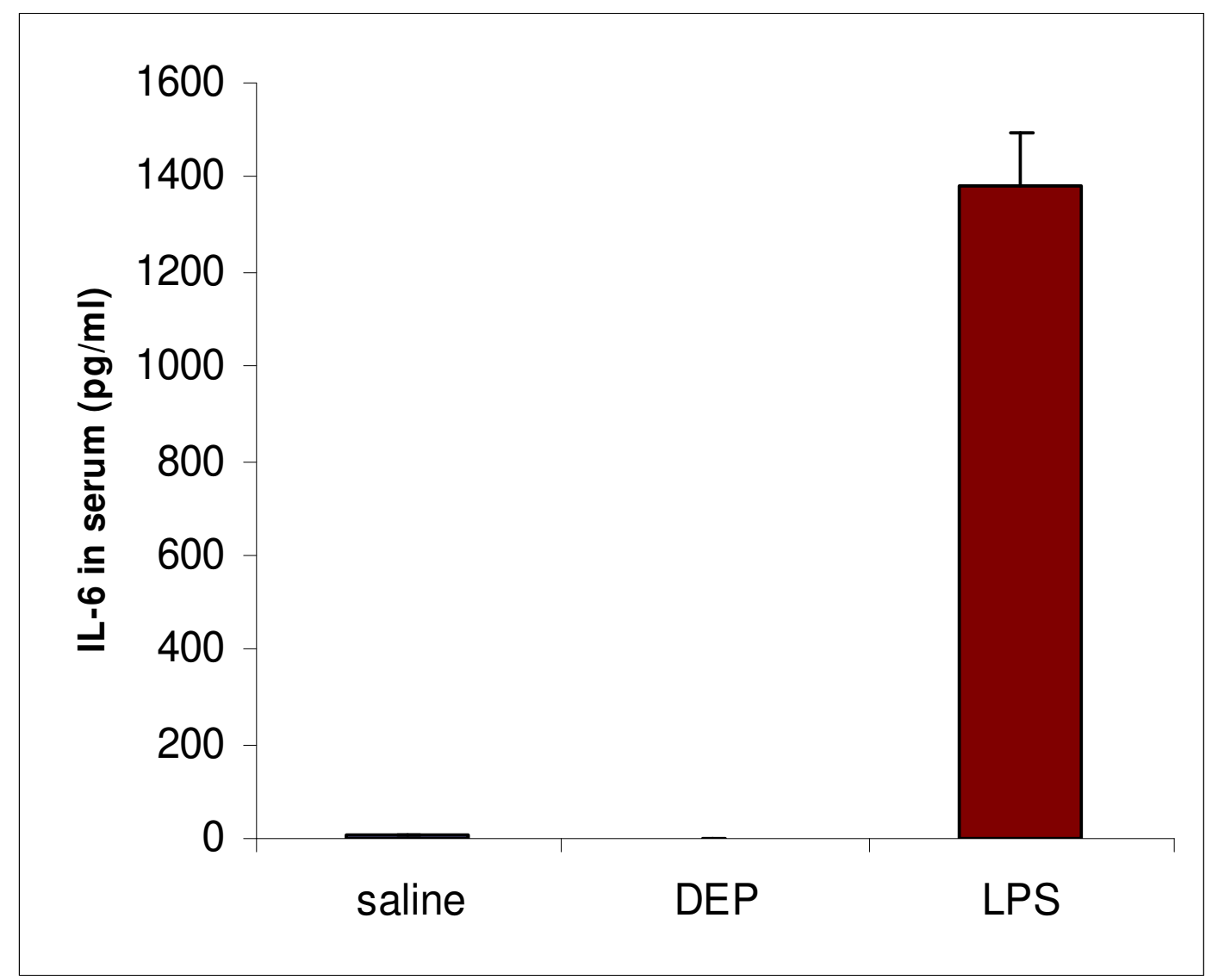

Figure 24. Production of IL-6 in serum in different exposure groups. BN rats were exposed to saline, DEP by i.t. and LPS by i.p.. Values are expressed as the means \pm SE ( $n$ =4). ${ }^{*}$ Significantly different from saline group, $p<0.05$. 


\section{DISCUSSION}

Experimental models of asthma, as in BN rats, require a sensitization period for the animal to develop the allergic response. Diesel exhaust particle exposure, on the other hand, is known to induce acute inflammatory responses through particle stimulation but anti-inflammatory responses through the organic component of DEP (Yin et al., 2004b; Ma and Ma, 2002). Hence, the effects of DEP on allergic responses may vary depending on the sensitization process and the timing of DEP exposure. In practical settings, subjects may be sensitized or nonsensitized to an allergen and may encounter DEP and allergen exposure at different time points, thus making the timing of DEP exposure an important factor for assessment of allergic responses. The present study was designed to characterize the effect of short-term DEP exposure on OVA-mediated airway responses and mechanism of DEP exposure on altering OVA induced airway inflammation and antigen-specific IgE and IgG production under two exposure protocols using an OVAallergic rat model. The dose for DEP exposure $\left(22.7 \pm 2.5 \mathrm{mg} / \mathrm{m}^{3}\right)$ appears to be high in comparison to the reported environmental and occupational concentrations, but in fact it results in a lung deposition ( $402 \pm 58 \mu \mathrm{g} / \mathrm{rat})$ that is relevant to both non-occupational and occupational exposure settings as discussed previously (Yin et al., 2002, 2004a). The results showed that in both protocols, the inhaled DEP enhanced the sensitization of rats to OVA in antigen-specific antibody production. This result, together with that from previous studies, suggests that frequent exposure to DEP may alter allergy-related responses in both previously sensitized and nonsensitized individuals, thus contributing 
to the manifestations and increased prevalence of asthma (Lovik et al., 1997; DiazSanchez et al., 1994, 1997; Takano et al., 1997).

DEP are carbon-based particles containing various organic compounds adsorbed onto the carbonaceous core. The organic component-mediated reactive oxygen species (ROS) generation plays an important role in cell-mediated immune responses (Yin et al., 2004b; Ma and Ma, 2002; Whitekus et al., 2002). The imbalance between cellular antioxidants and ROS levels can lead to oxidative stress and a depletion of intracellular thiol levels. Increasing clinical, epidemiological, and experimental evidence indicates that excess production of ROS and defective endogenous antioxidant defense mechanisms are associated with asthma (Henricks and Nijkamp, 2001). Glutathione-S-transferases (GSTs), for example, have been shown to be key regulators of the adjuvant effects of DEP on allergic responses. Compared with patients with a functional genotype, individuals with GSTM1 null or the GSTP1 I105 wild type genotypes showed enhanced nasal allergic responses in the presence of DEP, including increased production of antigen-specific IgE (Gilliland et al., 2004). As an important immune modulator, intracellular GSH has a regulatory role in antigen presenting cells, including AM, dendritic cells, and B cells, which is critical for the development of T cell-mediated immunity and the predominance of cellular production of Th1 or Th2 cytokines (Peterson et al., 1998; Ma and Ma, 2002; Murata et al., 2002). Our studies in protocol A showed that DEP exposure alone markedly reduced the levels of GSH in lymphocytes and, to a lesser extend, in AM at 9 and 30 days post DEP exposure, and that the combined DEP and OVA exposure resulted in a synergistic depletion of GSH in both cell types. However, the OVA-induced $\mathrm{CD}^{+}{ }^{+} \mathrm{T}$ cells and AM secretion of IL-10 and IL-12 were 
significantly decreased by DEP, while two other cytokines (IL-4 and IFN- $\gamma$ ) were not successfully detected. The fact that DEP aggravate intracellular GSH depletion in AM and lymphocytes suggests that the organic component of DEP, which induces intracellular ROS (Yin et al., 2004b), may play a role in the elevation of antigen-specific IgE and IgG. Although a clear switch of T-cell immunity toward Th2 response in terms of cytokine profile cannot be concluded from this study, elevated levels of OVA-specific IgE and IgG in the DEP plus OVA group strongly suggest the occurrence of this switch in vivo.

In protocol A we also showed that DEP exposure prior to OVA sensitization inhibited allergen-induced airway inflammation measured at 4 weeks post exposure. In agreement with this finding, we have previously shown that preexposure to DEP significantly decreased the number of inflammatory cells (AM and neutrophiles) in the lung and $\mathrm{T}$ cells and their $\mathrm{CD} 4^{+}$and $\mathrm{CD} 8^{+}$subsets in $\mathrm{LDLN}$ recovered from Listeria monocytogenes- infected BN rats (Yin et al., 2004a). Inhibition of OVA-induced airway inflammation by DEP as shown by the BAL cell differentials in this study, albeit not an unexpected effect, contrasted with that reported previously (Takano et al., 1998;

Miyabara et al., 1998a; Sagai et al., 1996). This discrepancy suggests that DEP may have multiple effects on allergic responses, depending on the status of the lung inflammation induced by both allergens and particles. On one hand, DEP exhibit time-dependent effects on allergen-induced airway inflammatory responses by increasing allergic inflammation in already-sensitized individuals or during the sensitization process, but attenuating these responses induced by delayed sensitization in previously nonsensitized individuals. On the other hand, local inflammation induced by DEP (or other particles), 
which is significant or not, depending on the doses and timing for exposure, is another important factor for DEP to affect allergen-related inflammation. In concurrent exposure studies, the aggravation of allergen-induced inflammatory responses by DEP, such as those reported by Takano et al. $(1997,1998)$, is expected, since the acute pulmonary responses to DEP exposure alone also involve inflammatory cell infiltration, airway inflammation, and altered lymphocyte function (Miyabara et al., 1998a; Sagai et al., 1996; Takano et al., 1998). In protocol A, no significant acute inflammatory response or lung injury was expected, while we did not examine the acute pulmonary response of rats to DEP exposure. According to the same exposure dose and protocol, DEP alone did not induce significant acute inflammatory responses and lung injury in $\mathrm{BN}$ rats as shown by the previous results (Yin et al., 2004a).

The mechanism through which inhaled DEP inhibit the allergen-induced airway inflammation in protocol A is complex but may involve a number of factors including NO, ROS, and their effects on cellular cytokine production. Studies in rats and mice have shown that NO production from lung cells (epithelial cells, macrophages, and Th1 cells) may down-regulate Th1 cell-derived IFN- $\gamma$ production and concomitantly up-regulate local expression of Th2 cell-derived IL-4 and IL-5 (Barnes and Liew, 1995), thus promoting the development of pulmonary eosinophilia and airway hyperreactivity (Liu et al., 1997; Feder et al., 1997). Although immunohistochemical analysis of lung tissues failed to detect alterations in iNOS expression in AM, the current study in protocol A showed that inhaled DEP significantly inhibit OVA-induced NO production in AMconditioned media and BAL fluid, and this corresponds to an attenuation of OVA induced eosinophilia. It has been known that DEP, through the organic compounds, 
induce cellular expression of antioxidative enzymes that contribute to the antiinflammatory responses. One such enzyme is heme oxygenase-1 (HO-1). We have shown previously that DEP up-regulated expression of HO-1 in AM through a mechanism that involves the organic component-induced CYP1A1 and ROS generation (Rengasamy et al., 2003; Yin et al., 2004b). Studies have shown that HO-1 may act through carbon monoxide, a major catalytic byproduct of HO-1-mediated heme degradation, which, interestingly, has also been shown to reduce allergen induced airway hyperresponsiveness and eosinophilia (Chapman et al., 2001). Additionally, studies in animal models of allergic asthma showed that CD8-deficent mice or those with depleted $\mathrm{CD} 4^{+} \mathrm{T}$ cells developed significantly lowered airway hyperresponsiveness and eosinophilic inflammation, indicating an important role of these T-cell subsets in airway eosinophilia (Miyahara et al., 2004b; Gavett et al., 1994; Komai et al., 2003). The inhibition of OVA-induced $\mathrm{CD}^{+}$and $\mathrm{CD} 8^{+} \mathrm{T}$ lymphocytes by DEP exposure, as demonstrated in our study, thus may also contribute to its attenuation of allergic airway inflammation.

AM play a pivotal role in controlling and directing immune responses by secreting a variety of mediators including both pro-inflammatory and anti-inflammatory cytokines. We and others have shown previously that in vivo or in vitro exposure to DEP suppressed AM phagocytotic capacity and their secretion of pro-inflammatory cytokines, such as IL$1 \beta$, IL-12, and TNF- $\alpha$, in response to bacterial infection or LPS stimulation (Amakawa et al., 2003; Saito et al., 2002; Yin et al., 2002). These studies indicated that DEP exposure dampened AM function and responses to external stimuli and that DEP may play a role in reducing inflammation. Indeed, DEP, at low dose were shown to exert an anti- 
inflammatory effect on bacteria-induced lung inflammation in rats (Yin et al., 2004a). Consistent with these results, the current study in protocol A showed that DEP significantly suppressed AM secretion of NO, IL-10, and IL-12 in response to OVA stimulation. In view of the decreased lung inflammation in the combined DEP- and OVA-exposed rats, the observed reduction in OVA-induced IL-10 by DEP seems puzzling, since lines of evidence have led to the hypothesis that IL-10 may act as one of the anti-inflammatory cytokines that regulate ongoing inflammatory responses (de Vries, 1995). In fact, the regulatory role of endogenous IL-10 in asthma remains unclear.

Previous studies have reported that IL-10 production in response to LPS was impaired in the monocyte/macrophage cell lineage of asthmatics (Borish et al., 1996; John et al., 1998), whereas other studies have reported an increase of IL-10-producing T cells and macrophages in asthmatic airways and a further increase of those cells after an allergen challenge (Colavita et al., 2000; Magnan et al., 1998; Robinson et al., 1996).

Furthermore, experimental asthma studies using IL-10 knockout mice have provided controversial results in which increased or decreased airway inflammatory responses to allergen challenge were found (Justice et al., 2001; Makela et al., 2000; Yang et al., 2000). Interestingly, the IL-10 knockout mice showed increased or no changeable Th2 responses including allergen-specific IgE production (Justice et al., 2001; Yang et al., 2000). These results, together with that obtained from the current study, show that the role of IL-10 in regulating allergen-related airway inflammatory responses may be very complex and need to be further studied. On the other hand, one would speculate on a decreased IgE production in the DEP-plus-OVA exposure group because AM antigen presenting function may be also dampened. Since AM are poor antigen-presenting cells 
compared to dendritic cells (Nicod et al., 2000), inhibition of AM function by DEP may not significantly affect the antigen presenting in the lung and subsequent antibody production. Inhibition of AM function by DEP may be, at least in part, responsible for the decreased production of both Th1 and Th2 cytokines as examined in the DEP plus OVA exposed rats.

In protocol B, exposure of non-sensitized rats to DEP resulted in only a moderate increase in neutrophils in the lung, and there was a clear absence of eosinophilic inflammation, antibody responses, or AHR. However, in OVA-sensitized rats, preexposure to DEP markedly enhanced OVA-induced AHR, eosinophils infiltration, and serum OVA-specific IgE and IgG production. Although alterations in the lung cytokine profile were unknown, the results show that DEP pre-exposure strongly enhances the OVA-induced Th2 responses in antibody production as well as eosinophil-mediated airway inflammation. To our knowledge, this is the first demonstration of a DEP enhanced allergic AHR in rats. These results are consistent with, and complement those obtained using various mouse models where DEP exposure was co-administered with antigen challenge (Ichinose et al., 1997, 2002; Miyabara et al., 1998b; Takano et al., 1997, 1998). It is interesting to point out that we demonstrated that DEP exposure prior to the sensitization enhanced the sensitization in antibody production but inhibited airway inflammation induced by OVA challenge using the same rat model (protocol A). Thus, the action of DEP exposure on allergic asthma is such that it affects both the sensitization and the asthmatic response of animals to the allergen. 
The mechanisms through which DEP alter the allergic reactions remain unclear in part because of the complex, time-dependent effects of DEP on allergen-induced immune responses. One of the cellular actions of DEP is the induction of intracellular ROS through the organic component-mediated activation of cytochrome P450 1A1 and other metabolic enzymes (Ma and Ma, 2002; Whitekus et al., 2002; Yin et al., 2004b). The imbalance of cellular antioxidative responses to ROS generation induced by DEP leads to oxidative stress and a reduction of total intracellular GSH in AM and lymphocytes (AlHumadi et al., 2002c). In protocol B we show that ROS generation in AM and ATII cells is an important feature of the combined DEP and OVA exposure. As shown by CL measurements, a marked increase in oxidant activity, which corresponds to a lowered total GSH concentration in AM and lymphocytes, is associated with the combined DEP and OVA exposure, which is greater than either DEP or OVA exposure alone. This suggests that DEP preexposure augments ROS production by cells from OVA sensitized rats. GSH, in addition to its role in protecting cells from oxidative injury, is critical to macrophages and dendritic cells that act as antigen-presenting cells for the development of T-cell-mediated immune responses. Depletion of GSH in these cells has been shown to skew the development of T cells from Th1 to Th2 type (Murata et al., 2002; Peterson et al., 1998), a manifestation of increased allergic asthmatic responses. That DEP augment OVA-specific antibody production is consistent with the fact that DEP facilitate depletion of GSH in AM and lymphocytes.

Nitric oxide has been considered an important marker in allergen-induced inflammatory responses. This reactive nitrogen intermediate can directly react with and deplete intracellular GSH (Folkes and Wardman, 2004) and may play a role in the 
development of eosinophilia and AHR in mouse and rat allergic models (Feder et al., 1997; Liu et al., 1997). It has been shown that NO derived from iNOS in epithelial cells promotes asthmatic inflammation by downregulating Th1 cells that secrete interferon- $\gamma$ and concomitantly upregulate Th2 cells that secrete IL-4 and IL-5 (Barnes and Liew, 1995). On the other hand, the constitutive NO-synthase (cNOS)-derived NO has been shown to exert bronchoprotective effects in asthma including airway smooth muscle relaxation and inhibition of smooth muscle proliferation (Ricciardolo et al., 2001, 2003). In fact, NO derived from cNOS and from iNOS may play different roles in the airways. The former seems to protect airways from excessive bronchoconstriction while the latter has a modulatory role in inflammatory disorders of the airways such as asthma. The effect of DEP pre-exposure, as shown in protocol B, is to increase iNOS expression in AM and ATII cells of OVA sensitized and challenged rats, suggesting that DEP interact directly with these lung cells. This interaction results in an acute response of increased production of NO that is known to mediate OVA-induced eosinophilic inflammation and AHR.

Our study shows an apparent linkage between the ROS and NO generation with increased responses of T lymphocytes. Both DEP and OVA exposure in protocol B enhanced the numbers of $\mathrm{T}$ cells and their $\mathrm{CD} 4^{+}$and $\mathrm{CD} 8^{+}$subsets recovered from the LDLN in the BN rat model. But it was the combined DEP and OVA exposure that yielded a substantial increase in $\mathrm{T}$ cell responses, which correlate with increased production of ROS and NO and decreased level of GSH. Clinical investigations have observed that $\mathrm{CD}^{+} \mathrm{T}$ lymphocytes and their secretion of $\mathrm{Th} 2$ cytokines played a central role in initiating and sustaining asthmatic responses in the asthmatic airway (Robinson, 
2000). Studies in animal models further showed that depletion of $\mathrm{CD} 4^{+} \mathrm{T}$ lymphocytes by administration of anti-CD4 antibody inhibited allergen-induced airway eosinophilia and AHR (Gavett et al., 1994; Komai et al., 2003). CD8 ${ }^{+} \mathrm{T}$ lymphocytes also play a role in allergic responses. Miyahara et al. (2004a, b) showed that CD8-deficient mice had a significantly lower AHR and eosinophilia in response to OVA sensitization and challenge comparing to the wild-type, but the allergic response was fully restored by adoptive transfer of antigen-primed effector $\mathrm{CD} 8^{+} \mathrm{T}$ cells.

Pulmonary type II cells are the principal cell type that expresses P450 and NOS enzymes in the lung. The allergic asthma is associated with increased protein nitration and airway inflammation due to the induction of iNOS in epithelial cells (Trifilieff et al, 2000; Iijima et al, 2001), suggesting that alteration of type II cell enzyme expression by DEP may be responsible for the adjuvant effect of DEP on airway inflammation in sensitized rats. To gain more insight, the effects of DEP and OVA on enzume expressions and cellular production of reactive oxygen and nitrogen species were determined in protocol B. Rats were sensitized with aerosolized OVA and exposed to DEP following protocol B, sacrificed on Day 31, and analyzed for type II cell expression of CYP enzymes and iNOS. Western blot analysis showed that OVA exposure alone induced iNOS expression and slightly down-regulated CYP2B1. DEP exposure alone induced CYP 1A1 but not iNOS expression. In combined exposure, however, DEP significantly augmented the induction of iNOS by OVA. Flow cytometric analysis further showed that DEP exposure alone increased the percentage of cells that produce superoxide but not NO comparing to the control, OVA exposure alone moderately enhanced the percentage of cells with increased NO and superoxide, but the combined exposure resulted in 
significant increase in the percentage of cells that produce NO, superoxide, and peroxynitrite over either OVA or DEP exposure alone. These results show a positive involvement of type II cells in the production of reactive oxygen and nitrogen species, and suggest that this cell type is a target by DEP and OVA in the induction of airway inflammation. 


\section{REFERENCES}

Adonis, M., Martinez, V., Riquelme, R., Ancic, P., Gonzalez, G., Tapia, R., Castro, M., Lucas, D., Berthou, F., Gil, L. (2003). Susceptibility and exposure biomarkers in people exposed to PAHs from diesel exhaust. Toxicol Lett. 144, 3-15.

Al-Humadi, N.H., Ma, J.K.H., Lewis, D.M., Ma, J.Y.C., Barger, M.W., Siegel, P.D. (2002a). Dose-dependent thiol and immune responses to ovalbumin challenge in Brown Norway rats. Toxicol Ind Health. 18, 343-52.

Al-Humadi, N.H., Siegel, P.D., Lewis, D.M., Barger, M.W., Ma, J. Y. C., Weissman, D.N., Ma, J.K.H. (2002b). The effect of diesel exhaust particles (DEP) and carbon black $(\mathrm{CB})$ on thiol changes in pulmonary ovalbumin allergic sensitized Brown Norway rats. Exp Lung Res. 28, 333-49.

Al-Humadi, N. H., Siegel, P. D., Lewis, D. M., Barger, M. W., Ma, J. Y. C., Weissman, D. N., and Ma, J. K. H. (2002c). Alteration of intracellular cysteine and glutathione levels in alveolar macrophages and lymphocytes by diesel exhaust particle exposure. Environ. Health Perspect. 110, 349-353.

Akerboom, T.P, Bilzer, M., Sies, H. (1982). The relationship of biliary glutathione disulfide efflux and intracellular glutathione disulfide content in perfused rat liver. $\mathrm{J}$ Biol Chem. 257, 4248-52.

Amakawa, K., Terashima, T., Matsuzaki, T., Matsumaru, A., Sagai, M., and Yamaguchi, K. (2003). Suppressive effects of diesel exhaust particles on cytokine release from human and murine alveolar macrophages. Exp. Lung Res. 29, 149-164.

Arlt, V.M., Bieler, C.A., Mier, W., Wiessler, M., Schmeiser, H.H. (2001). DNA adduct formation by the ubiquitous environmental contaminant 3-nitrobenzanthrone in rats determined by (32)P-postlabeling. Int J Cancer. 93, 450-4.

Aruoma, O.I., Halliwell, B., Dizdaroglu, M. (1989). Iron ion-dependent modification of bases in DNA by the superoxide radical-generating system hypoxanthine/xanthine oxidase. J Biol Chem. 264, 13024-8.

Attfield, M.D., Trabant, G.D., Wheeler, R.W. (1982). Exposure to diesel fumes and dust at six potash mines. Ann Occup Hyg. 26, 817-31.

Azzawi, M., Bradley, B., Jeffery, P. K. et al. (1990). Identification of activated T lymphocytes and eosinophils in bronchial biopsies in stable atopic asthma. Am. Rev. Respir. Dis. 142 , 1407-13. 
Baeza-Squiban, A., Bonvallot, V., Boland, S., Marano, F. (1999). Airborne particles evoke an inflammatory response in human airway epithelium. Activation of transcription factors. Cell Biol Toxicol. 15, 375-80

Barnes, P. J., and Liew, F. W. (1995). Nitric oxide and asthmatic inflammation. Immunol Today 128, 128-130.

Baulig, A., Garlatti, M., Bonvallot, V., Marchand, A., Barouki, R., Marano, F., BaezaSquiban, A. (2003). Involvement of reactive oxygen species in the metabolic pathways triggered by diesel exhaust particles in human airway epithelial cells. Am J Physiol Lung Cell Mol Physiol. 285, L671-9.

Bayram, H., Devalia, J.L., Sapsford, R.J., Ohtoshi, T., Miyabara, Y., Sagai, M., Davies, R.J. (1998a). The effect of diesel exhaust particles on cell function and release of inflammatory mediators from human bronchial epithelial cells in vitro. Am J Respir Cell Mol Biol. 18, 441-8.

Bayram, H., Devalia, J.L., Khair, O.A., Abdelaziz, M.M., Sapsford, R.J., Sagai, M., Davies, R.J. (1998b). Comparison of ciliary activity and inflammatory mediator release from bronchial epithelial cells of nonatopic nonasthmatic subjects and atopic asthmatic patients and the effect of diesel exhaust particles in vitro. J Allergy Clin Immunol. 102, 771-82.

Beck, S., Soukup, J.M., Gilmour. M.I., Devlin, R.B. (1996). Stimulation of human and rat alveolar macrophages by urban air particulates: effects on oxidant radical generation and cytokine production. Toxicol Appl Pharmacol. 141, 637-48.

Bergdahl, I.A., Toren, K., Eriksson, K., Hedlund, U., Nilsson, T., Flodin, R., Jarvholm, B. (2004). Increased mortality in COPD among construction workers exposed to inorganic dust. Eur Respir J. 23, 402-6.

Bhatia, R., Lopipero, P., Smith, A.H. (1998). Diesel exhaust exposure and lung cancer. Epidemiology. 9, 84-91.

Bigert, C., Gustavsson, P., Hallqvist, J. ( 2003). Myocardial infarction among professional drivers. Epidemiology. 14, 333-339.

Boland, S., Baeza-Squiban, A., Fournier, T., Houcine, O., Gendron, M.C., Chevrier, M., Jouvenot, G., Coste, A., Aubier, M., Marano, F. (1999). Diesel exhaust particles are taken up by human airway epithelial cells in vitro and alter cytokine production. Am $\mathrm{J}$ Physiol. 276, L604-13

Bond, J.A., Johnson, N.F., Snipes, M.B., Mauderly, J.L. (1990). DNA adduct formation in rat alveolar type II cells: cells potentially at risk for inhaled diesel exhaust. Environ Mol Mutagen. 16, 64-9.

Borm, P.J., Driscoll, K. (1996). Particles, inflammation and respiratory tract carcinogenesis. Toxicol Lett. 88, 109-13. 
Borish, L., Aarons, A., Rumbyrt, J., Cvietusa, P., Negri, J., and Wenzel, S. (1996). Interleukin-10 regulation in normal subjects and patients with asthma. J. Allergy Clin. Immunol. 97, 1288-1296.

Brauer, M., Hoek, G., Van Vliet, P., Meliefste, K., Fischer, P.H., Wijga, A., Koopman, L.P., Neijens, H.J., Gerritsen, J., Kerkhof, M., Heinrich, J., Bellander, T., Brunekreef, B. (2002). Air pollution from traffic and the development of respiratory infections and asthmatic and allergic symptoms in children. Am J Respir Crit Care Med.. 166, 1092-8.

Brown, D. M., Donaldson, K., Borm, P. J., Schins, R. P., Dehnhardt, M., Gilmour, P., Jimenez, L. A., and Stone, V. (2004). Calcium and ROSmediated activation of transcription factors and TNF-a cytokine gene expression in macrophages exposed to ultrafine particles. Am. J. Physiol. Lung Cell. Mol. Physiol. 286, L344-L353.

Bruske-Hohlfeld, I., Mohner, M., Ahrens, W., Pohlabeln, H., Heinrich, J., Kreuzer, M., Jockel, K.H., Wichmann, H.E. (1999). Lung cancer risk in male workers occupationally exposed to diesel motor emissions in Germany. Am J Ind Med. 36, 405-14.

Bruske-Hohlfeld, I., Mohner, M., Pohlabeln, H. (2000). Occupational lung cancer risk for men in Germany: results from a pooled case-control study. Am J Epidemiol.151, 38495.

Bunn, W.B. 3rd, Hesterberg, T.W., Valberg, P.A., Slavin, T.J., Hart, G., Lapin, C.A. (2004). A reevaluation of the literature regarding the health assessment of diesel engine exhaust. Inhal Toxicol. 16, 889-900.

Bunn, W.B. 3rd, Valberg. P.A., Slavin, T.J., Lapin, C.A. (2002). What is new in diesel. Int Arch Occup Environ Health. 75 Suppl, S122-32.

Busse, W.W., Lemanske, R.F. Jr. (2001). Asthma. N Engl J Med. 344, 350-62.

California EPA (1997). "'Public and Scientific Review Draft. Health RiskAssessment for Diesel Exhaust.' Office of Environmental Health Hazard Assessment, California Environmental Protection Agency, Berkeley, March 1997.

Chapman, J. T., Otterbein, L. E., Elias, J. A., and Choi, A. M. (2001). Carbon monoxide attenuates aeroallergen-induced inflammation in mice. Am. J. Physiol. Lung Cell. Mol. Physiol. 281, L209-L216.

Colavita, A. M., Hastie, A. T., Musani, A. I., Pascual, R. M., Reinach, A. J., Lustine, H. T., Galati, S. A., Zangrilli, J. G., Fish, J. E., and Peters, S. P. (2000). Kinetics of IL-10 production after egmental antigen challenge of atopic asthmatic subjects. J. Allergy Clin. Immunol. 106, 880-886.

D'Amato, G. (1999). Outdoor air pollution in urban areas and allergic respiratory diseases. Monaldi Arch Chest Dis 54, 470-474. 
D'Amato, G., Liccardi, G., D'Amato, M. (1998). Environment and development of respiratory allergy: I. Outdoors. Monaldi Arch Chest Dis, 49, 406-411.

DeLeve, L.D., Kaplowitz, N. (1990). Importance and regulation of hepatic glutathione. Semin Liver Dis. 10, 251-66.

Devalia, J.L., Bayram, H., Rusznak, C., Calderon, M., Sapsford, R.J., Abdelaziz, M.A., Wang, J., Davies, R.J. (1997). Mechanisms of pollution-induced airway disease: in vitro studies in the upper and lower airways. Allergy. 52(38 Suppl), 45-51.

de Vries, J. E. (1995). Immunosuppressive and anti-inflammatory properties of interleukin-10. Ann. Med. 27, 537-541.

Diaz-Sanchez, D., Dotson, A. R., Takenaka, H., and Saxon, A. (1994). Diesel exhaust particles induce local IgE production in vivo and alter the pattern of IgE messenger RNA isoforms. J. Clin. Invest. 94, 1417-1425.

Diaz-Sanchez, D., Garcia, M.P., Wang, M., Jyrala, M., Saxon, A. (1999). Nasal challenge with diesel exhaust particles can induce sensitization to a neoallergen in the human mucosa. J Allergy Clin Immunol. 104, 1183-8.

Diaz-Sanchez, D., Tsien, A., Fleming, J., and Saxon, A. (1997). Combined diesel exhaust particles and ragweed allergen challenge markedly enhances in vivo nasal ragweedspecific IgE and skew cytokine production to a T helper cell 2-type pattern. J. Immunol. $158,2406-2413$.

Diaz-Sanchez, D. (1997). The role of diesel exhaust particles and their associated polyaromatic hydrocarbons in the induction of allergic airway disease. Allergy. 52, 5256.

Diaz-Sanchez, D., Dotson, A.R., Takenaka, H., Saxon, A. (1994). Diesel exhaust particles induce local IgE production in vivo and alter the pattern of $\operatorname{IgE}$ messenger RNA isoforms. J Clin Invest. 94, 1417-25.

Diaz-Sanchez ,D., Garcia, M.P., Wang, M., Jyrala, M., Saxon, A. (1999). Nasal challenge with diesel exhaust particles can induce sensitization to a neoallergen in the human mucosa. J Allergy Clin Immunol. 104, 1183-8.

Diaz-Sanchez, D., Tsien, A., Casillas, A., Dotson, A.R., Saxon, A.( 1996). Enhanced nasal cytokine production in human beings after in vivo challenge with diesel exhaust particles. J Allergy Clin Immunol. 98, 114-23.

Diaz-Sanchez, D., Tsien, A., Fleming, J., Saxon, A. (1997). Combined diesel exhaust particulate and ragweed allergen challenge markedly enhances human in vivo nasal ragweed-specific IgE and skews cytokine production to a T helper cell 2-type pattern. J Immunol. 158, 2406-13. 
Dick, C. A. J., Brown, D. M., Donaldson, K., and Stone, V. (2003). The role of free radicals in the toxic and inflammatory effects of four different ultrafine particle types. Inhal. Toxicol. 15, 39-52.

Dockery, D.W., Pope, C.A. (1994). Acute respiratory effects of particulate air pollution. Ann Rev Publ Health.15, 107-132.

Don Porto Carero, A., Hoet, P.H., Verschaeve, L., Schoeters, G., Nemery, B. (2001). Genotoxic effects of carbon black particles, diesel exhaust particles, and urban air particulates and their extracts on a human alveolar epithelial cell line (A549) and a human monocytic cell line (THP-1). Environ Mol Mutagen. 37, 155-63.

Draper, W. M. (1986). Quantitation of nitro and dinitropolycyclic aromatic hydrocarbons in diesel exhaust particulate matter. Chemosphere 15, 437-447.

Duhme, H., Weiland, S.k., Leil, U., Lraemer, B., Schmid, M., Stender, M., Chambless, L. (1996). The association between self-reported symptoms of asthma and allergic rhinitis and self-reported traffic density on street of residence in adolescents. Epidemiology. 7, 578-582.

Durham, S. R., Lee, T. H., Cromwell, O., Shaw, R. J., Merrett, T. G., Merrett, J., Cooper, P., and Kay, A. B. (1984). Immunologic studies in allergen-induced late-phase asthmatic reactions. J. Allergy Clin. Immunol. 47, 49-60.

Dybing, E., Lovdal, T., Hetland, R. B., Lovik, M., and Schwarze, P. E. (2004). Respiratory allergy adjuvant and inflammatory effects of urban ambient particles. Toxicology 198, 307-314.

Feder, L. S., Stelts, D., Chapman, R. W., Manfra, D., Crawley, Y., Jones, H., Minnicozzi, M., Fernandez, X., Paster, T., Egan, R.W., et al. (1997). Role of nitric oxide on eosinophilic lung inflammation in allergic mice. Am. J. Respir. Cell Mol. Biol. 17, 436442.

Finkelstein, M.M., Verma, D.K., Sahai, D., Stefov, E. (2004). Ischemic heart disease mortality among heavy equipment operators. Am J Ind Med.,46, 16-22.

Fleming, D.M., Charlton, J.R. (2001). The prevalence of asthma and heart disease in transport workers: a practice-based study. Br J Gen Pract. 51, 638-43.

Folkes, L. K., and Wardman, P. (2004). Kinetics of the reaction between nitric oxide and glutathione: implications for thiol depletion in cells. Free Radic. Biol. Med. 37, 549556.

Foreman, R.C., Mercer, P.F., Kroegel, C., Warner, J.A. (1999). Role of the eosinophil in protein oxidation in asthma: possible effects on proteinase/antiproteinase balance. Int Arch Allergy Immunol. 118, 183-6. 
Foster, P.S., Hogan, S.P., Matthaei, K.I., Young, I.G. (1997). Interleukin-4 and interleukin-5 as targets for the inhibition of eosinophilic inflammation and allergic airways hyperreactivity. Mem Inst Oswaldo Cruz. 92 Suppl 2:55-61.

Gamble, J.F., Jones, W.G. (1983a). Respiratory effects of diesel exhaust in salt miners. Am Rev Respir Dis. 128, 389-94.

Gamble, J., Jones, W., Hudak, J. (1983b). An epidemiological study of salt miners in diesel and nondiesel mines. Am J Ind Med. 4, 435-58.

Gamble, J., Jones, W., Minshall, S. (1987a). Epidemiological-environmental study of diesel bus garage workers: chronic effects of diesel exhaust on the respiratory system. Environ Res. 44, 6-17.

Gamble, J., Jones, W., Minshall, S. (1987b). Epidemiological-environmental study of diesel bus garage workers: acute effects of $\mathrm{NO} 2$ and respirable particulate on the respiratory system. Environ Res. 42, 201-14.

Garshick, E., Laden, F., Hart, J.E., Rosner, B., Smith, T.J., Dockery, D.W., Speizer, F.E. (2004). Lung cancer in railroad workers exposed to diesel exhaust. Environ Health Perspect.112, 1539-43.

Garshick, E., Laden, F., Hart, J.E., Smith, T.J., Rosner, B. (2006). Smoking imputation and lung cancer in railroad workers exposed to diesel exhaust. Am J Ind Med. 49,709-18.

Garshick, E., Schenker, M.B., Munoz, A., Segal, M., Smith, T.J., Woskie, S.R., Hammond, S.K., Speizer, F.E. (1987). A case-control study of lung cancer and diesel exhaust exposure in railroad workers. Am Rev Respir Dis.135, 1242-8.

Garshick, E., Schenker, M.B., Munoz, A., Segal, M., Smith, T.J., Woskie, S.R., Hammond, S.K., Speizer, F.E. (1988). A retrospective cohort study of lung cancer and diesel exhaust exposure in railroad workers. Am Rev Respir Dis. 137, 820-5.

Gavett, S. H., Chen, X., Finkelman, F., andWills-Karp, M. (1994). Depletion of murine CD4p T lymphocytes prevents antigen-induced airway hyperreactivity and pulmonary eosinophilia. Am. J. Respir. Cell Mol. Biol. 10, 587-593.

Gielen, M.H., van der Zee, S.C., van Wijnen, J.H., van Steen, C.J., Brunekreef, B. (1997). Acute effects of summer air pollution on respiratory health of asthmatic children.

Am J Respir Crit Care Med. 155, 2105-8.

Gilliland, F. D., Li, Y. F., Saxon, A., and Diaz-Sanchez, D. (2004). Effect of glutathioneS-transferase M1 and P1 genotypes on xenobiotic enhancement of allergic responses: Randomised, placebo-controlled crossover study. Lancet 363, 119-125. 
Graham, L. M. (2004). All I need is the air that I breath: Outdoor air quality and asthma. Paediatr. Respir. Rev. 5(Suppl. A), S59-S64.

Granum, B., Gaarder, P. I., Groeng, E. C., Leikvold, R. B., Namork, E., and Lovik, M. (2001). Fine particles of widely different composition have an adjuvant effect on the production of allergen-specific antibodies. Toxicol. Lett. 115, 171-181.

Gustavsson, P., Plato, N., Hallqvist, J. (2001). A population-based case-referent study of myocardial infarction and occupational exposure to motor exhaust, other combustion products, organic solvents, lead, and dynamite. Epidemiology. 12, 222-228.

Hamada, K., Goldsmith, C. A., Goldman, A., and Kobzik, L. (2000). Resistance of very young mice to inhaled allergen sensitization is overcome by coexposure to an airpollutant aerosol. Am. J. Respir. Crit. Care Med. 161, 1285-1293.

Hart, J.E., Laden, F., Schenker, M.B., Garshick, E. (2006). Chronic obstructive pulmonary disease mortality in diesel-exposed railroad workers. Environ Health Perspect. 114, 1013-7.

Hashimoto, S. , Gon, Y., Takeshita, I., Matsumoto, K., Jibiki, I., Takizawa, H., Kudoh, S., Horie, T. (2000). Diesel exhaust particles activate p38 MAP kinase to produce interleukin 8 and RANTES by human bronchial epithelial cells and $\mathrm{N}$-acetylcysteine attenuates p38 M. Am J Respir Crit Care Med. 161, 280-5.

Heinrich, J., Hoelscher, B., Wjst, M., Ritz, B., Cyrys, J., Wichmann, H. (1999). Respiratory diseases and allergies in two polluted areas in East Germany. Environ Health Perspect, 107, 1-17.

Hiltermann, T.J., Peters, E.A., Alberts, B., Kwikkers, K., Borggreven, P.A., Hiemstra. P.S., Dijkman, J.H., van Bree, L.A., Stolk, J. (1998). Ozone-induced airway hyperresponsiveness in patients with asthma: role of neutrophil-derived serine proteinases. Free Radic Biol Med. 24, 952-8.

Hirano, S., Furuyama, A., Koike, E., Kobayashi, T. (2003). Oxidative-stress potency of organic extracts of diesel exhaust and urban fine particles in rat heart microvessel endothelial cells. Toxicology.,187(2-3):161-70.

Hnizdo, E., Vallyathan, V. (2003). Chronic obstructive pulmonary disease due to occupational exposure to silica dust: a review of epidemiological and pathological evidence. Occup Environ Med. 60, 237-43.

Hoek, G., Brunekreef, B., Goldbohm, S., Fischer, P., van den Brandt, P.A. (2002). Association between mortality and indicators of traffic-related air pollution in the Netherlands: a cohort study. Lancet. 360, 1203-1209.

Holgate, S.T., Sandstrom, T., Frew, A.J., Stenfors, N., Nordenhall, C., Salvi, S., Blomberg, A., Helleday, R., Soderberg, M.. (2003). Health effects of acute exposure to 
air pollution. Part I: Healthy and asthmatic subjects exposed to diesel exhaust. Res Rep Health Eff Inst.. 112,1-30; discussion 51-67.

Hulsmann, A.R., Raatgeep, H.R., den Hollander, J.C., Stijnen, T., Saxena, P.R., Kerrebijn, K.F., de Jongste, J.C. (1994). Am. J. Respir. Crit. Care Med. 149, 519-525.

IARC, (1989). Diesel engine exhaust. IARC Monogr Eval Carcinog Risks Hum. 46, p41.

Ichinose, T., Takano, H., Miyabara, Y., Sadakano, K., Sagai, M., and Shibamoto, T. (2002). Enhancement of antigen-induced eosinophilic inflammation in the airways of mast-cell deficient mice by diesel exhaust particles. Toxicology 180, 293-301.

Ichinose, T., Takano, H., Miyabara, Y., Yanagisawa, R., and Sagai, M. (1997). Murine strain differences in allergic airway inflammation and immunoglobulin production by a combination of antigen and diesel exhaust particles. Toxicology 122, 183-192.

Ichinose, T., Yajima, Y., Nagashima, M., Takenoshita, S., Nagamachi, Y., Sagai, M. (1997). Lung carcinogenesis and formation of 8-hydroxy-deoxyguanosine in mice by diesel exhaust particles. Carcinogenesis. 18, 185-92.

Iijima, H., Duguet, A., Eum, S.Y., Hamid, Q., Eidelman, D.H. (2001). Nitric oxide and protein nitration are eosinophil dependent in allergen-challenged mice. Am J Respir Crit Care Med. 163, 1233-40.

Ishizaki, T., Koizumi, K., Ikemori, R., Ishiyama, Y., Kushibiki, E. (1987). Studies of prevalence of Japanese cedar pollinosis among the residents in a densely cultivated area. Ann Allergy. 58, 265-70.

Iwai, K., Adachi, S., Takahashi, M., Moller, L., Udagawa, T., Mizuno. S., Sugawara, I. (2000). Early oxidative DNA damages and late development of lung cancer in diesel exhaust-exposed rats. Environ Res. 84, 255-64.

Jany, B., Betz, R., Schreck, R. (1995). Activation of the transcription factor NF-kappa B in human tracheobronchial epithelial cells by inflammatory stimuli. Eur Respir J. 8, 387-91.

Jarvholm B, Silverman D. (2003). Lung cancer in heavy equipment operators and truck drivers with diesel exhaust exposure in the construction industry. Occup Environ Med. 60, 516-20.

John, M., Lim, S., Seybold, J., Jose, P., Robichaud, A., O'Connor, B., Barnes, P. J., and Chung, K. F. (1998). Inhaled corticosteroids increase interleukin-10 but reduce macrophage inflammatory protein-1alpha, granulocyte-macrophage colony-stimulating factor, and interferon-gamma release from alveolar macrophages in asthma. Am. J.

Respir. Crit. Care Med. 157, 256-262. 
Justice, J. P., Shibata, Y., Sur, S., Mustafa, J., Fan, M., and Van Scott, M. R. (2001). IL10 gene knockout attenuates allergen-induced airway hyperresponsiveness in C57BL/6 mice. Am. J. Physiol. Lung Cell. Mol. Physiol. 280, L363-L368.

Kasai, H., Crain, P.F., Kuchino, Y., Nishimura, S., Ootsuyama, A., Tanooka, H. (1986). Formation of 8-hydroxyguanine moiety in cellular DNA by agents producing oxygen radicals and evidence for its repair. Carcinogenesis. 7, 1849-51.

Kehrer, J.P. (2000). The Haber-Weiss reaction and mechanisms of toxicity. Toxicology. 149, 43-50.

Knudsen, L.E., Gaskell, M., Martin, E.A., Poole, J., Scheepers, P.T., Jensen, A., Autrup, H., Farmer, P.B. (2005). Genotoxic damage in mine workers exposed to diesel exhaust, and the effects of glutathione transferase genotypes. Mutat Res. 583, 120-32.

Komai, M., Tanaka, H., Masuda, T., Nagao, K., Ishizaki, M., Sawada, M., and Nagai, H. (2003). Role of Th2 responses in the development of allergeninduced airway remodeling in a murine model of allergic asthma. Br. J. Pharmacol. 138, 912-920.

Koren, H. S. (1995). Associations between criteria air pollutants and asthma. Environ. Health Perspect. 103(Suppl. 6), 235-242.

Krishna, M.T., Madden, J., Teran. L.M., Biscione, G.L., Lau, L.C., Withers, N.J., Sandstrom, T., Mudway, I., Kelly, F.J., Walls, A., Frew, A.J., Holgate, S.T. (1998). Effects of $0.2 \mathrm{ppm}$ ozone on biomarkers of inflammation in bronchoalveolar lavage fluid and bronchial mucosa of healthy subjects. Eur Respir J. 11, 1294-300.

Kuusimaki, L., Peltonen, Y., Mutanen, P., Peltonen, K., Savela, K. (2004). Urinary hydroxy-metabolites of naphthalene, phenanthrene and pyrene as markers of exposure to diesel exhaust. Int Arch Occup Environ Health. 77, 23-30.

Kyriakis, J.M., Banerjee, P., Nikolakaki, E., Dai, T., Rubie, E.A., Ahmad, M.F., Avruch, J., Woodgett, J.R. (1994). The stress-activated protein kinase subfamily of c-Jun kinases. Nature. 369, 156-60.

Laden, F., Hart, J.E., Eschenroeder, A., Smith, T.J., Garshick, E. (2006). Historical estimation of diesel exhaust exposure in a cohort study of U.S. railroad workers and lung cancer. Cancer Causes Control. 17, 911-9.

Lambert, A. L., Dong,W., Winsett, D. W., Selgrade, M. K., and Gilmour, M. I. (1999). Residual oil fly ash exposure enhances allergic sensitization to house dust mite. Toxicol. Appl. Pharmacol. 158, 269-277.

Langen, R.C., Korn, S.H., Wouters, E.F. (2003). ROS in the local and systemic pathogenesis of COPD. Free Radic Biol Med. 35, 226-35. 
Larkin, E.K., Smith, T.J., Stayner, L., Rosner, B., Speizer, F.E., Garshick, E. (2000). Diesel exhaust exposure and lung cancer: adjustment for the effect of smoking in a retrospective cohort study. Am J Ind Med. 38. 399-409.

Le Tertre. A., Medina, S., Samoli, E., Forsberg, B., Michelozzi, P., Boumghar, A., Vonk, J.M., Bellini, A., Atkinson, R., Ayres, J.G., Sunyer, J., Schwartz, J., Katsouyanni. K. (2002). Short-term effects of particulate air pollution on cardiovascular diseases in eight European cities.J Epidemiol Community Health. 56, 773-9.

Lezcano-Meza, D, Teran, L.M. (1999). Occupational asthma and interleukin-8. Clin Exp Allergy. 29, 1301-3.

Liccardi, G., D'Amato, M., D'Amato, G. (1998). Asthma in pregnant patients: pathophysiology and management. Monaldi Arch Chest Dis. 53, 151-9.

Li, N., Kim, S., Wang, M., Froines, J., Sioutas, C., Nel, A. (2002). Use of a stratified oxidative stress model to study the biological effects of ambient concentrated and diesel exhaust particulate matter. Inhal Toxicol. 14, 459-86.

Lipsett, M., Campleman, S. (1999). Occupational exposure to diesel exhaust and lung cancer: a meta-analysis. Am J Public Health. 89, 1009-17.

Lipsett, M., Hurley, S., Ostro, B. (1997). Air pollution and emergency room visits for asthma in Santa Clara County, California. Environ Health Perspect. 105, 216-222.

Liu, S. F., Haddad, E. B., Adcock, I., Salmon, M., Koto, H., Gilbey, T., Barnes, P. J., and Chung, K. F. (1997). Inducible nitric oxide synthase after sensitization and allergen challenge of Brown Norway rat lung. Br. J. Pharmacol. 121, 1241-1246.

Lovik, M., Hogseth, A. K., Gaarder, P. I., Hagemannn, R., and Eide, I. (1997). Diesel exhaust particles and carbon black have adjuvant activity on the local lymph node response and systemic IgE production to ovalbumin. Toxicology 121, 165-178.

Ma, J. Y. C., and Ma, J. K. H. (2002). The dual effect of the particulate and organic components of diesel exhaust particles on the alteration of pulmonary immune/inflammatory responses and metabolic enzymes. Environ. Carcinog. Ecotox. Rev. C 20, 117-147. .

Magnan, A., van Pee, D., Bongrand, P., and Vervloet, D. (1998). Alveolar macrophage interleukin (IL)-10 and IL-12 production in atopic asthma. Allergy 53, 1092-1095.

Makela, M. J., Kanehiro, A., Borish, L., Dakhama, A., Loader, J., Joetham, A., Xing, Z., Jordana, M., Larsen, G. L., and Gelfand, E. W. (2000). IL-10 is necessary for the expression of airway hyperresponsiveness but not pulmonary inflammation after allergic sensitization. Proc. Natl. Acad. Sci. U.S.A. 97, 6007-6012. 
Mamessier, E., Nieves, A., Vervloet, D., Magnan, A. (2006). Diesel exhaust particles enhance T-cell activation in severe asthmatics. Allergy. 61,581-8.

Marano, F., Boland, S., Bonvallot, V., Baulig, A., Baeza-Squiban, A. (2002). Human airway epithelial cells in culture for studying the molecular mechanisms of the inflammatory response triggered by diesel exhaust particles. Cell Biol Toxicol. 18, 31520 .

Martin, L.D., Krunkosky, T.M., Dye, J.A., Fischer, B.M., Jiang, N.F., Rochelle, L.G., Akley, N.J., Dreher, K.L., Adler, K.B. (1997). The role of reactive oxygen and nitrogen species in the response of airway epithelium to particulates. Environ Health Perspect. $105,1301-7$.

Mastrangelo, G., Clonfero, E., Pavanello, S., Fedeli, U., Fadda, E., Turato, A., Piccinni, S., Montagnani, R., Marcer, G. (2003). Exposure to diesel exhaust enhances total IgE in non-atopic dockers. Int Arch Occup Environ Health. 76, 63-8.

Mauderly, J.L.( 1997). Relevance of particle-induced rat lung tumors for assessing lung carcinogenic hazard and human lung cancer risk. Environ Health Perspect. 105 Suppl 5, 1337-46.

Mauderly, J.L., Banas, D.A., Griffith, W.C., Hahn, F.F., Henderson, R.F., McClellan, R.O. (1996). Diesel exhaust is not a pulmonary carcinogen in CD-1 mice exposed under conditions carcinogenic to F344 rats. Fundam Appl Toxicol. 30, 233-42.

Mauderly, J.L., Jones, R.K., Griffith, W.C., Henderson, R.F., McClellan, R.O. (1987). Diesel exhaust is a pulmonary carcinogen in rats exposed chronically by inhalation. Fundam Appl Toxicol. 9, 208-21.

Mills, N.L., Tornqvist, H., Robinson, S.D., Gonzalez, M., Darnley, K., MacNee, W., Boon, N.A., Donaldson, K., Blomberg, A., Sandstrom, T., Newby, D.E. (2005). Diesel exhaust inhalation causes vascular dysfunction and impaired endogenous fibrinolysis. Circulation. 112,3930-6.

Miyabara, Y., Ichinose, T., Takano, H., Lim, H. B., and Sagai, M. (1998a). Effects of diesel exhaust on allergic airway inflammation in mice. J. Allergy Clin. Immunol. 102, 805-812.

Miyabara, Y., Takano, H., Ichinose, T., Lim, H. B., and Sagai, M. (1998b). Diesel exhaust enhances allergic airway inflammation and hyperresponsiveness in mice. Am. J. Respir. Crit. Care Med. 157, 1138-1144.

Miyahara, N., Swanson, B. J., Takeda, K., Taube, C., Miyahara, S., Kodama, T., Dakhama, A., Ott, V. L., and Gelfand, E. W. (2004a). Effector CD8 ${ }^{+}$T cells mediate inflammation and airway hyperresponsiveness. Nat. Med. 10, 865-869. 
Miyahara, N., Takeda, K., Kodama, T., Joetham, A., Taube, C., Park, J. W., Miyahara, S., Balhorn, A., Dakhama, A., and Gelfand, E. W. (2004b). Contribution of antigen-primed $\mathrm{CD}^{+} \mathrm{T}$ cells to the development of airway hyperresponsiveness and inflammation is associated with IL-13. J. Immunol. 172, 2549-2558.

Monks, T.J., Hanzlik, R.P., Cohen, G.M., Ross, D., Graham, D.G. (1992). Quinone chemistry and toxicity. Toxicol Appl Pharmacol. 112, 2-16.

Morrow, P.E., Haseman, J.K., Hobbs, C.H., Driscoll, K.E., Vu, V., Oberdorster, G. (1996). The maximum tolerated dose for inhalation bioassays: toxicity vs overload. Fundam Appl Toxicol. 29, 155-67.

Murata, Y., Shimamura, T., and Hamuro, J. (2002). The polarization of T(h)1/T(h)2 balance is dependent on the intracellular thiol redox status of macrophages due to the distinctive cytokine production. Int. Immunol. 14, 201-212.

Muzyka, V., Bogovski, S., Scheepers, P., Volf, J., Kusova, J. (2003). Effects of occupational exposure to diesel exhaust on porphyrin metabolism in lymphocytes of workers employed at black coal and oil-shale mines. Am J Ind Med. 44, 70-4.

Muzyka, V., Bogovski, S., Viitak, A., Veidebaum, T. (2002). Alterations of heme metabolism in lymphocytes and metal content in blood plasma as markers of diesel fuels effects on human organism. Sci Total Environ. 286, 73-81.

Muzyka, V., Scheepers, P.T., Bogovski, S., Lang, I., Schmidt, N., Ryazanov, V., Veidebaum, T. (2004). Porphyrin metabolism in lymphocytes of miners exposed to diesel exhaust at oil shale mine. Sci Total Environ. 322, 41-50.

Nel, A. E., Diaz-Sanchez, D., Ng, D., Hiura T., and Saxon, A. (1998). Enhancement of allergic inflammation by the interaction between diesel exhaust particles and the immune system. J. Allergy Clin. Immunol. 102, 539-54.

Ng, D., Kokot, N., Hiura, T., Faris, M., Saxon, A., Nel, A. (1998). Macrophage activation by polycyclic aromatic hydrocarbons: evidence for the involvement of stress-activated protein kinases, activator protein-1, and antioxidant response elements. J Immunol. 161, 942-51.

Nicod, L. P., Cochand, L., and Dreher, D. (2000). Antigen presentation in the lung: Dendritic cells and macrophages. Sarcoidosis Vasc. Diffuse Lung Dis. 17, 246-255.

Nikula, K.J., Snipes, M.B., Barr, E.B., Griffith, W.C., Henderson, R.F., Mauderly, J.L. (1995). Comparative pulmonary toxicities and carcinogenicities of chronically inhaled diesel exhaust and carbon black in F344 rats. Fundam Appl Toxicol. 25, 80-94.

Nightingale, J.A., Maggs, R., Cullinan, P., Donnelly, L.E., Rogers, D.F., Kinnersley, R., Chung, K.F., Barnes, P.J., Ashmore, M., Newman-Taylor, A. (2000). Airway 
inflammation after controlled exposure to diesel exhaust particulates. Am J Respir Crit Care Med. 162, 161-6.

NIOSH (1988). Current Intelligence Bulletin No. 50. Carcinogenic Effects of Exposure to Diesel Exhaust. Publication No. 88-116. National Institute of Occupational Safety and Health, U.S. Department of Health and Human Services.

Nordenhall, C., Pourazar, J., Blomberg, A., Levin, J.O., Sandstrom, T., Adelroth, E. (2000). Airway inflammation following exposure to diesel exhaust: a study of time kinetics using induced sputum. Eur Respir J. 15, 1046-51.

Nordenhall, C., Pourazar, J., Ledin, M.C., Levin, J.O., Sandstrom, T., Adelroth, E. (2001). Diesel exhaust enhances airway responsiveness in asthmatic subjects. Eur Respir J. 17, 909-15.

Norris, G., YoungPong, S.N., Koenig, J.Q., Larson, T.V., Sheppard, L., Stout, J.W. (1999). An association between fine particles and asthma emergency department visits for children in Seattle. Environ Health Perspect. 107, 489-493

Oberdorster, G. (1995). Lung particle overload: implications for occupational exposures to particles. Regul Toxicol Pharmacol. 21, 123-35.

Oberdorster, G. (1997). Pulmonary carcinogenicity of inhaled particles and the maximum tolerated dose. Environ Health Perspect. 105 Suppl 5, 1347-55.

Ohta, K., Yamashita, N., Tajima, M., Miyasaka, T., Nakano, J., Nakajima, M., Ishii, A., Horiuchi, T., Mano, K., Miyamoto, T. (1999). Diesel exhaust particulate induces airway hyperresponsiveness in a murine model: essential role of GM-CSF. J Allergy Clin Immunol. 104, 1024-30.

Oliver LC, Miracle-McMahill H, Littman AB, Oakes JM, Gaita RR Jr. (2001). Respiratory symptoms and lung function in workers in heavy and highway construction: a cross-sectional study. Am J Ind Med. 40, 73-86.

Ordonez, C.L., Shaughnessy, T.E., Matthay, M.A., Fahy, J.V. (2000). Increased neutrophil numbers and IL-8 levels in airway secretions in acute severe asthma: Clinical and biologic significance. Am J Respir Crit Care Med. 161, 1185-90.

Ormstad, H., Gaarder, P. I., Johansen, B. V., and Lovik, M. (1998). Airborne house dust elicits a local lymph node reaction and has an adjuvant effect on specific IgE production in the mouse. Toxicology 129, 227-236.

Owen, S., Pearson, D., Suarez-Mendez, V., O'Driscoll, R., Woodcock ,A. (1991). Evidence of free-radical activity in asthma. N Engl J Med. 325, 586-7. 
Pandya, R.J., Solomon, G., Kinner, A., Balmes, J.R. (2002). Diesel exhaust and asthma: hypotheses and molecular mechanisms of action. Environ Health Perspect. 110 Suppl 1, 103-12.

Parent, M.E., Rousseau, M.C., Boffetta, P., Cohen, A., Siemiatycki, J. (2006). Exposure to diesel and gasoline engine emissions and the risk of lung cancer. Am J Epidemiol. [Epub ahead of print]

Pekkanen, J., Peters, A., Hoek, G., Tiittanen, P., Brunekreef, B., de Hartog, J., Heinrich, J., Ibald-Mulli, A., Kreyling, W.G., Lanki, T., Timonen, K.L., Vanninen, E. (2002).

Particulate air pollution and risk of ST-segment depression during repeated submaximal exercise tests among subjects with coronary heart disease: the Exposure and Risk Assessment for Fine and Ultrafine Particles in Ambient Air (ULTRA) study. Circulation. 106, 933-8.

Penning, T.M., Burczynski, M.E., Hung, C.F., McCoull, K.D., Palackal, N.T., Tsuruda, L.S. (1999). Dihydrodiol dehydrogenases and polycyclic aromatic hydrocarbon activation: generation of reactive and redox active o-quinones. Chem Res Toxicol. 12, $1-18$.

Peters, A., Dockery, D.W., Muller, J.E., Mittleman, M.A. (2001) Increased particulate air pollution and the triggering of myocardial infarction. Circulation. 103, 2810-5.

Peters, A., Perz, S., Doring, A., Stieber, J., Koenig, W., Wichmann, H.E. (1999). Increases in heart rate during an air pollution episode. Am J Epidemiol. 150, 1094-8.

Peters, A., Doring, A., Wichmann, H.E., Koenig, W. (1997). Increased plasma viscosity during an air pollution episode: a link to mortality? Lancet. 349, 1582-7.

Peters, A., Pope, C.A. III. (2002). Cardiopulmonary mortality and air pollution. Lancet.360, 1184-1185.

Peters, A., von Klot, S., Heier, M., Trentinaglia, I., Hormann, A., Wichmann, H.E., Lowel, H. (2004). Cooperative Health Research in the Region of Augsburg Study Group. Exposure to traffic and the onset of myocardial infarction. N Engl J Med.351, 1721-30.

Peterson, J. D., Herzenberg, L. A., Vasquez, K., and Waltenbaugh, C. (1998). Glutathione levels in antigen-presenting cells modulate Th1 versus Th2 response patterns. Proc. Natl. Acad. Sci. U.S.A. 95, 3071-3076.

Pinkus, R., Weiner, L.M., Daniel, V. (1996). Role of oxidants and antioxidants in the induction of AP-1, NF-kappaB, and glutathione S-transferase gene expression. J Biol Chem. 271, 13422-9.

Pohjola, S.K., Lappi, M., Honkanen, M., Rantanen, L., Savela, K. (2003). DNA binding of polycyclic aromatic hydrocarbons in a human bronchial epithelial cell line treated 
with diesel and gasoline particulate extracts and benzo[a]pyrene. Mutagenesis. 18, 42938 .

Rahman, I. (2005). The role of oxidative stress in the pathogenesis of COPD: implications for therapy. Treat Respir Med. 4, 175-200.

Reger, R., Hancock, J., Hankinson, J., Hearl, F., Merchant, J. (1982). Coal miners exposed to diesel exhaust emissions. Ann Occup Hyg. 26, 799-815.

Rengasamy, A., Barger, M.W., Kane, E., Ma, J. K. H., Castranova, V., and Ma, J. Y. C. (2003). Diesel exhaust particles-induced alterations of pulmonary phase I and phase II enzymes of rats. J. Toxicol. Environ. Health 66, 153-167.

Ricci, M., Matucci, A., Rossi, O. (1994). T cells, cytokines, IgE and allergic airways inflammation. J Investig Allergol Clin Immunol. 4, 214-20.

Ricciardolo, F. (2003). Multiple roles of nitric oxide in the airways. Thorax 58, 75-182.

Ricciardolo, F. L., Timmers, M. C., Geppetti, P., van Schadewijk, A., Brahim, J. J., Sont, J. K., de Gouw, H. W., Hiemstra, P. S., van Krieken, J. H., and Sterk, P. J. (2001). Allergen-induced impairment of bronchoprotective nitric oxide synthesis in asthma. J. Allergy Clin. Immunol. 108, 198-204.

Robinson, D., Hamid, Q., Bentley, A., Ying, S., Kay, A.B, Durham, S.R.. (1993). Activation of CD4+ T cells, increased TH2-type cytokine mRNA expression, and eosinophils recruitment in bronchoalveolar lavage after allergen inhalation challenge in patients with atopic asthma. J. Allergy Clin. Immunol. 92, 313-24.

Robertson, A., Dodgson, J., Collings, P., Seaton, A. (1984). Exposure to oxides of nitrogen: respiratory symptoms and lung function in British coalminers. Br J Ind Med. 41, 214-9.

Robinson, D. S. (2000). The Th1 and Th2 concept in atopic allergic disease. Chem. Immunol. 78, 50-61.

Robinson, D. S., Tsicopoulos, A., Meng, Q., Durham, S., Kay, A. B., and Hamid, Q. (1996). Increased interleukin-10 messenger RNA expression in atopic allergy and asthma. Am. J. Respir. Cell Mol. Biol. 14, 113-117.

Sadeghi-Hashjin, G., Folkerts, G., Henricks, P.A., Verheyen, A.K., van der Linde, H.J., van Ark, I., Coene, A., Nijkamp, F.P. (1996). Peroxynitrite induces airway hyperresponsiveness in guinea pigs in vitro and in vivo. Am J Respir Crit Care Med. $153,1697-701$. 
Sagai, M., Furuyama, A., and Ichinose, T. (1996). Biological effects of diesel exhaust particles (DEP), III: Pathogenesis of asthma-like symptoms in mice. Free Radic. Biol. Med. 21, 199-209.

Saito, Y., Azuma, A., Kudo, S., Takizawa, H., and Sugawara, I. (2002). Effects of diesel exhaust on murine alveolar macrophages and a macrophage cell line. Exp. Lung Res. $28,201-217$.

Salvi, S., Blomberg, A., Rudell, B., Kelly, F., Sandstrom, T., Holgate, S.T., Frew, A. (1999). Acute inflammatory responses in the airways and peripheral blood after shortterm exposure to diesel exhaust in healthy human volunteers. Am J Respir Crit Care Med. 159, 702-9.

Salvi, S.S., Nordenhall, C., Blomberg, A., Rudell, B., Pourazar, J., Kelly, F.J., Wilson, S., Sandstrom, T., Holgate, S.T., Frew, A.J. (2000). Acute exposure to diesel exhaust increases IL-8 and GRO-alpha production in healthy human Am J Respir Crit Care Med. 161, 550-7.

Samet, J.M., Dominici, F., Curriero, F.C., Coursac, I., Zeger, S.L. (2000). Fine particulate air pollution and mortality in 20 U.S. cities, 1987-1994. N Engl J Med. 343, 1742-9.

Sanders, S.P., Zweier, J.L., Harrison, S.J., Trush, M.A., Rembish, S.J., Liu, M.C. (1995). Spontaneous oxygen radical production at sites of antigen challenge in allergic subjects. Am J Respir Crit Care Med. 151, 1725-33.

Saverin, R., Braunlich, A., Dahmann, D., Enderlein, G., Heuchert, G. (1999). Diesel exhaust and lung cancer mortality in potash mining. Am J Ind Med. 36, 415-22.

Sato, H., Sone, H., Sagai, M., Suzuki, K.T., Aoki, Y. (2000). Increase in mutation frequency in lung of Big Blue rat by exposure to diesel exhaust. Carcinogenesis. 21, 653-61.

Schauer, U., Leinhaas, C., Jager, R., Rieger, C.H. (1991). Enhanced superoxide generation by eosinophils from asthmatic children. Int Arch Allergy Appl Immunol. 96, 317-21.

Scheepers, P.T., Bos, R.P. (1992). Combustion of diesel fuel from a toxicological perspective. I. Origin of incomplete combustion products. Int Arch Occup Environ Health, 64, 149-161.

Scheepers, P.T., Coggon, D., Knudsen, L.E., Anzion, R., Autrup, H., Bogovski, S., Bos, R.P., Dahmann, D., Farmer, P., Martin, E.A., Micka, V., Muzyka, V., Neumann, H.G., Poole, J., Schmidt-Ott, A., Seiler, F., Volf, J., Zwirner-Baier, I. (2002). BIOMarkers for occupational diesel exhaust exposure monitoring (BIOMODEM)- a study in underground mining. Toxicol Lett. 1343, 305-17. 
Scheepers, P.T., Micka, V., Muzyka, V., Anzion, R., Dahmann, D., Poole, J., Bos, R.P. (2003). Exposure to dust and particle-associated 1-nitropyrene of drivers of dieselpowered equipment in underground mining. Ann Occup Hyg. 47, 379-88.

Schikowski, T., Sugiri, D., Ranft, U., Gehring, U., Heinrich, J., Wichmann, H.E., Kramer, U. (2005). Long-term air pollution exposure and living close to busy roads are associated with COPD in women. Respir Res. 6, 152.

Schins, R.P., Borm, P.J. (1999). Mechanisms and mediators in coal dust induced toxicity: a review. Ann Occup Hyg. 43, 7-33.

Schins, R.P., Schilderman, P.A., Borm, P.J. (1995). Oxidative DNA damage in peripheral blood lymphocytes of coal workers,. Int Arch Occup Environ Health. 67, 153-7.

Schraufstatter, I., Hyslop, P.A., Jackson, J.H., Cochrane, C.G. (1988). Oxidant-induced DNA damage of target cells. J Clin Invest. 82, 1040-50.

Schuetzle, D. (1983). Sampling of vehicle emissions for chemical analysis and biological testing. Environ Health Perspect. 47, 65-80.

Schwartz, J. (1994). Air pollution and daily mortality: a review and meta analysis. Environ Res. 64, 36-52.

Seaton, A., MacNee, W., Donaldson, K., Godden, D. (1995). Particulate air pollution and acute health effects. Lancet. 345, 176-8.

Seaton, A., Soutar, A., Crawford, V., Elton, R., McNerlan, S., Cherrie, J., Watt, M., Agius, R., Stout, R. (1999). Particulate air pollution and the blood. Thorax. 54, 1027 32.

Sedgwick, J.B., Geiger, K.M., Busse, W.W. (1990). Superoxide generation by hypodense eosinophils from patients with asthma. Am Rev Respir Dis. 142, 120-5.

Seltzer J, Bigby BG, Stulbarg M, Holtzman MJ, Nadel JA, Ueki IF, Leikauf GD, Goetzl EJ, Boushey HA. (1986). O3-induced change in bronchial reactivity to methacholine and airway inflammation in humans. J Appl Physiol., 60(4):1321-6.

Sjögren, B. (1998a). Mortality of Dutch coal miners in relation to pneumoconiosis, chronic obstructive pulmonary disease, and lung function. Occup Environment Med. 55, 503-503.

Sjögren, B. (1998b). A possible connection between furnace dust exposure, plasma fibrinogen levels and cardiovascular disease. Scand J Work Environ Health. 24, 236237.

Stayner, L., Dankovic, D., Smith, R., Steenland, K. (1998). Predicted lung cancer risk among miners exposed to diesel exhaust particles. Am J Ind Med. 34, 207-19. 
Stearns, R.C., Lawrence, J., Murthy, G.G., Diaz, E., Koutrakis, P., Suh, H., Tsuda, A., Godleski, J.J. (2002). Lung inflammation induced by concentrated ambient air particles is related to particle composition. Am J Respir Crit Care Med. 165, 1610-7.

Steenland, K., Deddens, J., Stayner, L. (1998). Diesel exhaust and lung cancer in the trucking industry: exposure-response analyses and risk assessment. Am J Ind Med. 34, 220-8.

Steenland, N.K., Silverman, D.T., Hornung, R.W. (1990). Case-control study of lung cancer and truck driving in the Teamsters Union. Am J Public Health. 80, 670-4.

Steerenberg, P. A., Dormans, J. A., van Doorn, C. C., Middendorp, S., Vos, J. G., and van Loveren, H. (1999). A pollen model in the rat for testing adjuvant activity of air pollution components. Inhal. Toxicol. 11, 1109-1122.

Steerenberg, P. A., Withagen, C. E., Dormans, J. A., van Dalen, W. J., van Loveren, H., and Casee, F. R. (2003). Adjuvant activity of various diesel exhaust and ambient particles in two allergic models. Toxicol. Environ. Health A 66, 1421-1439.

Stenfors, N., Nordenhall, C., Salvi, S.S., Mudway, I., Soderberg, M., Blomberg, A., Helleday, R., Levin, J.O., Holgate, S.T., Kelly, F.J., Frew, A.J., Sandstrom, T. (2004). Different airway inflammatory responses in asthmatic and healthy humans exposed to diesel. Eur Respir J. 23, 82-6.

Svartengren, M., Strand, V., Bylin, G., Jarup, L., Pershagen, G. (2000). Short-term exposure to air pollution in a road tunnel enhances the asthmatic response to allergen. Eur Respir J. 15, 716-24.

Sydbom, A., Blomberg, A., Parnia, S., Stenfors, N., Sandstrom, T., Dahlen, S.E. (2001). Health effects of diesel exhaust emissions. Eur Respir J. 17,733-46.

Takano, H., Ichinose, T., Miyabara, Y., Shibuya, T., Lim, H. B., Yoshikawa, T., and Sagai, M. (1998). Inhalation of diesel exhaust enhances allergen-related eosinophil recruitment and airway hyperresponsiveness in mice. Toxicol. Appl. Pharmacol. 150, $328-337$.

Takano, H.,Yoshikawa, T., Ichinose, T., Miyabara,Y., Imaoka, K., and Sagai, M. (1997). Diesel exhaust particles enhance antigen-induced airway inflammation and local cytokine expression in mice. Am. J. Respir. Crit. Care Med. 156, 36-42.

Takafuji, S., Suzuki, S., Koizumi, K., Tadokoro, K., Miyamoto, T., Ikemori, R., Muranaka, M. (1987). Diesel-exhaust particulates inoculated by the intranasal route have an adjuvant activity for IgE production in mice. J Allergy Clin Immunol. 79, 639645 . 
Takenaka, H., Zhang, K., Diaz-Sanchez, D., Tsien, A., Saxon, A. (1995). Enhanced human IgE production results from exposure to the aromatic hydrocarbons from diesel exhaust: direct effects on B-cell IgE production. J Allergy Clin Immunol. 95, 103-15.

Takizawa, H., Abe, S., Okazaki, H., Kohyama, T., Sugawara, I., Saito, Y., Ohtoshi, T., Kawasaki, S., Desaki, M., Nakahara, K., Yamamoto, K., Matsushima, K., Tanaka, M., Sagai, M., Kudoh, S. (2003). Diesel exhaust particles upregulate eotaxin gene expression in human bronchial epithelial cells via nuclear factor-kappa B-dependent pathway. Am J Physiol Lung Cell Mol Physiol. 284, L1055-62.

Takizawa, H., Ohtoshi, T., Kawasaki, S., Kohyama, T., Desaki, M., Kasama, T., Kobayashi, K., Nakahara, K., Yamamoto, K., Matsushima, K., Kudoh, S. (1999). Diesel exhaust particles induce NF-kappa B activation in human bronchial epithelial cells in vitro: importance in cytokine transcription. J Immunol. 162, 4705-11.

Tao, F., Gonzalez-Flecha, B., Kobzik, L. (2003). Reactive oxygen species in pulmonary inflammation by ambient particulates. Free Radic Biol Med. 35, 327-40.

Takano, H., Ichinose, T., Miyabara, Y., Shibuya, T., Lim, H. B., Yoshikawa, T., and Sagai, M. (1998). Inhalation of diesel exhaust enhances allergen-related eosinophil recruitment and airway hyperresponsiveness in mice. Toxicol. Appl. Pharmacol. 150, $328-337$.

Takano, H., Yoshikawa, T., Ichinose, T., Miyabara, Y., Imaoka, K., Sagai, M. (1997). Diesel exhaust particles enhance antigen-induced airway inflammation and local cytokine expression in mice. Am J Respir Crit Care Med. 156, 36-42.

Terada, N., Maesako, K., Hiruma, K., Hamano, N., Houki, G., Konno, A., Ikeda, T., Sai, M. (1997). Diesel exhaust particulates enhance eosinophil adhesion to nasal epithelial cells and cause degranulation. Int Arch Allergy Immunol. 114, 167-74.

Teramoto, S., Shu, C.Y., Ouchi, Y., Fukuchi, Y. (1996). Increased spontaneous production and generation of superoxide anion by blood neutrophils in patients with asthma. J Asthma. 33, 149-55.

Tokiwa, H., Sera, N., Nakanishi, Y., Sagai, M. (1999). 8-Hydroxyguanosine formed in human lung tissues and the association with diesel exhaust particles. Free Radic Biol Med. 27, 1251-8.

Trifilieff, A., Fujitani, Y., Mentz, F., Dugas, B., Fuentes, M., Bertrand, C. (2000). Inducible nitric oxide synthase inhibitors suppress airway inflammation in mice through down-regulation of chemokine expression. J Immunol. 165, 1526-33.

Trush, M.A., Kensler, T.W. (1991). An overview of the relationship between oxidative stress and chemical carcinogenesis. Free Radic Biol Med. 10, 201-9.

Tsien, A., Diaz-Sanchez, D., Ma, J., Saxon, A. (1997). The organic component of diesel exhaust particles and phenanthrene, a major polyaromatic hydrocarbon constituent, 
enhances IgE production by IgE-secreting EBV-transformed human B cells in vitro. Toxicol Appl Pharmacol. 142, 256-63.

Tsurudome, Y., Hirano, T., Yamato, H., Tanaka, I., Sagai, M., Hirano, H., Nagata, N., Itoh, H., Kasai, H. (1999). Changes in levels of 8-hydroxyguanine in DNA, its repair and OGG1 mRNA in rat lungs after intratracheal administration of diesel exhaust particles. Carcinogenesis. 20, 1573-6.

Ulvestad, B., Bakke, B., Melbostad, E., Fuglerud, P., Kongerud, J., Lund, M.B. (2000). Increased risk of obstructive pulmonary disease in tunnel workers. Thorax. 55, 277-82.

U.S. Department of Labor, Mine Safety, and Health Administration. (1998). Diesel particulate matter exposure of underground metal and nonmetal mines, 30 CFR 57. Fed Reg 63, 58104-58148.

U.S.Envionmental Protection Agency. (2002). Health assessment document for diesel exhaust. Washington, DC, U.S.EPA.

Van Zijverden, M., and Granum, B. (2000). Adjuvant activity of particulate pollutants in different mouse models. Toxicology 152, 69-77.

Vouk, V.B., Piver, W.T. (1983). Metallic elements in fossil fuel combustion products: amounts and form of emissions and evaluation of carcinogenicity and mutagenicity. Environ Health Perspect. 47, 201-25.

Wade, J.F., Newman, L.S. (1993). Diesel asthma: reactive airways disease following overexposure to locomotive exhaust. J Occup Med. 35, 149-154.

Whitekus, M.J., Li, N., Zhang, M., Wang, M., Horwitz, M.A., Nelson, S.K., Horwitz, L.D., Brechun, N., Diaz-Sanchez, D., Nel, A.E. (2002). Thiol antioxidants inhibit the adjuvant effects of aerosolized diesel exhaust particles in a murine model for ovalbumin sensitization. J Immunol. 168, 2560-7.

Wood, L.G., Fitzgerald, D.A., Gibson, P.G., Cooper, D.M., Garg, M.L. (2000). Lipid peroxidation as determined by plasma isoprostanes is related to disease severity in mild asthma. Lipids. 35, 967-74.

Yang, H. M., Barger, M. W., Castranova, V., Ma, J. K. H., Yang, J. J., and Ma, J. Y. C. (1999). Effects of diesel exhaust particles (DEP), carbon black, and silica on macrophage responses to lipopolysaccharide: Evidence of DEP suppression of macrophage activity. J. Toxicol. Environ. Health 58, 261-278.

Yang, X., Wang, S., Fan, Y., and Han, X. (2000). IL-10 deficiency prevents IL-5 overproduction and eosinophilic inflammation in a murine model of asthmalike reaction. Eur. J. Immunol. 30, 382-391. 
Yin, X. J., Dong, C. C., Ma, J. Y. C., Antonini, J. M., Roberts, J. R., Stanley, C. F., Schafer, R., and Ma, J. K. H. (2004a). Suppression of cell-mediated immune responses to Listeria infection by repeated exposure to diesel exhaust particles in Brown Norway rats. Toxicol. Sci. 77, 263-271.

Yin, X.J., Dong, C.C., Ma, J.Y., Roberts, J.R., Antonini, J.M., and Ma, J.K.H. (2006). Suppression of phagocytotic and bactericidal functions of rat alveolar macrophages by the organic components of diesel exhaust particles. J Toxicol Environ Health A, in press.

Yin, X. J., Ma, J. Y. C., Antonini, J. M., Castranova, V., and Ma, J. K. H. (2004b). Roles of reactive oxygen species and heme oxygenase-1 in modulation of alveolar macrophage-mediated pulmonary immune responses to Listeria monocytogenes by diesel exhaust particles. Toxicol. Sci. 82, 143-153.

Yin, X. J., Schafer, R., Ma, J. Y. C., Antonini, J. M., Weissman, D. N., Siegel, P. D., Barger, M. W., Roberts, J. R., and Ma, J. K. H. (2002). Alteration of pulmonary immunity to Listeria monocytogenes by diesel exhaust particles (DEP). I. Effects of DEP on early pulmonary responses. Environ. Health Perspect. 110, 1105-1111.

Yin, X.J., Schafer, R., Ma, J.Y.C., Antonini, J.M., Roberts, J.R., Weissman, D.N., Siegel, P.D., and Ma, J.K.H. (2003). Alteration of pulmonary immunity to Listeria monocytogenes by diesel exhaust particles (DEP). II. Effects of DEP on T-cellmediated immune responses in rats. Environ Health Perspect. 111,524-30.

Yoneda. K., Rokutan, K., Nakamura, Y., Yanagawa, H., Kondo-Teshima, S., Sone, S. (2004). Stimulation of human bronchial epithelial cells by IgE-dependent histaminereleasing factor. Am J Physiol Lung Cell Mol Physiol. 286, L174-81.

Zandi, E., Rothwarf, D.M., Delhase, M., Hayakawa, M., Karin, M. (1997). The IkappaB kinase complex (IKK) contains two kinase subunits, IKKalpha and IKKbeta, necessary for IkappaB phosphorylation and NF-kappaB activation. Cell. 91, 243-52.

Zanobetti, A., Schwartz, J. (2005). The effect of particulate air pollution on emergency admissions for myocardial infarction: a multicity case-crossover analysis. Environ Health Perspect. 113, 978-82. 